\title{
True and masked three-coordinate T-shaped platinum(II) intermediates
}

\author{
Manuel A. Ortuño ${ }^{1}$, Salvador Conejero ${ }^{* 2}$ and Agustí Lledós ${ }^{* 1}$
}

\section{Review}

\section{Address:}

${ }^{1}$ Departament de Química, Universitat Autònoma de Barcelona, 08193 Cerdanyola del Vallès, Spain and ${ }^{2}$ Instituto de Investigaciones Químicas (IIQ), Departamento de Química Inorgánica, CSIC and Universidad de Sevilla, Avda. Américo Vespucio 49, 41092 Sevilla, Spain

\section{Email:}

Salvador Conejero* - sconejero@iiq.csic.es; Agustí Lledós * agusti@klingon.uab.es

* Corresponding author

Keywords:

$\mathrm{C}-\mathrm{H}$ bond activation; intermediate; platinum(II); reactive

intermediates; three-coordinate; T-shaped
Beilstein J. Org. Chem. 2013, 9, 1352-1382.

doi:10.3762/bjoc. 9.153

Received: 05 April 2013

Accepted: 10 June 2013

Published: 09 July 2013

This article is part of the Thematic Series "New reactive intermediates in organic chemistry".

Guest Editor: G. Bucher

(C) 2013 Ortuño et al; licensee Beilstein-Institut.

License and terms: see end of document.

\begin{abstract}
Although four-coordinate square-planar geometries, with a formally 16-electron counting, are absolutely dominant in isolated Pt(II) complexes, three-coordinate, 14-electron Pt(II) complexes are believed to be key intermediates in a number of platinum-mediated organometallic transformations. Although very few authenticated three-coordinate Pt(II) complexes have been characterized, a much larger number of complexes can be described as operationally three-coordinate in a kinetic sense. In these compounds, which we have called masked T-shaped complexes, the fourth position is occupied by a very weak ligand (agostic bond, solvent molecule or counteranion), which can be easily displaced. This review summarizes the structural features of the true and masked T-shaped $\mathrm{Pt}(\mathrm{II})$ complexes reported so far and describes synthetic strategies employed for their formation. Moreover, recent experimental and theoretical reports are analyzed, which suggest the involvement of such intermediates in reaction mechanisms, particularly $\mathrm{C}-\mathrm{H}$ bond-activation processes.
\end{abstract}

\section{Review}

\section{Scope of this review}

Reaction intermediates are transient species able to undergo transformations along chemical processes. Electron deficient transition-metal complexes with vacant coordination sites are well-suited to play such a role. Coordinatively and electronically unsaturated species have often been invoked as crucial intermediates in reactions involving late transition-metal

complexes. Ligand dissociation, forming intermediates with open coordination sites, has been proposed as the initial step in many reactions involving square-planar $\mathrm{d}^{8}$ organometallic complexes [1]. Four-coordinate square-planar structures, with a formally 16-electron counting, are absolutely dominant in isolated $\mathrm{Pt}(\mathrm{II})$ complexes. However, three-coordinate, 14-elec- 
tron $\mathrm{Pt}(\mathrm{II})$ complexes are believed to be key intermediates in a number of reactions, e.g., $\beta$-hydrogen elimination, thermal decomposition of dialkyls, insertion of olefins into $\mathrm{M}-\mathrm{H}$ bonds, electrophilic attack at $\mathrm{Pt}-\mathrm{C}$ bonds, and ligand cycloplatination [2]. Likewise, related $\mathrm{Pd}(\mathrm{II})$ complexes $[3,4]$ are relevant in cross-coupling reactions and $\mathrm{C}-\mathrm{H}$ bond-activation processes. The accessibility of three-coordinate Pd(II) species have been recently discussed [5].

Three-coordinate $\mathrm{Pt}(\mathrm{II})$ intermediates are the focus of this review. Despite the kinetic perception of the intermediacy of these coordinatively unsaturated species in important organometallic processes, direct proofs of 14-electron Pt(II) complexes have been difficult to find. The strong readiness to alleviate the unsaturation makes them very reactive species but hampers their isolation. Low-coordinate Pt(II) complexes have been generated in gas-phase experiments $[6,7]$ but have remained elusive in solution. With a few exceptions the fourth coordination site is occupied by a weak ligand, e.g., an agostic interaction, a counteranion or a solvent molecule. However, if this additional interaction is weak and labile enough, the threecoordinate species is very accessible and the complex can be considered as "operationally unsaturated" in a kinetic sense [8]. We will name these compounds "masked" three-coordinate complexes to distinguish them from the true low-coordinate complexes. In this review, we will summarize recent advances in true and masked three-coordinate Pt(II) complexes, highlighting both their structural features and their possible participation as reaction intermediates. Computational studies have become an invaluable tool for the investigation of short-lived elusive intermediates and will be quoted throughout the article. The review is organized as follows. First, a general picture of the electronic and geometrical structure of three-coordinate $\mathrm{Pt}(\mathrm{II})$ complexes will be presented. Then, the structural features of the main families of these compounds will be summarized. The next sections will be devoted to the spectroscopic tools for their detection and the synthetic strategies employed to their formation. Afterwards, the rearrangement processes exhibited by the low-coordinate complexes in solution will be discussed. Finally, participation of three-coordinate Pt(II) intermediates in reactions, mainly $\mathrm{C}-\mathrm{H}$ bond-activation processes and ligand exchanges, will be analyzed. A thorough review on the bonding and stereochemistry of three-coordinate transition-metal compounds was published several years ago [9].

\section{Electronic and geometrical structure}

As we will discuss later on, three-coordinate, 14-electron Pt(II) $\mathrm{d}^{8}$ complexes display a T-shaped structure, i.e., a structure with two ligands mutually trans and the third ligand trans to the vacant position. A qualitative molecular orbital scheme of the $\mathrm{d}$ block of a T-shaped $\mathrm{d}^{8}$ metal complex can be easily derived from that of a square-planar complex by removing one of the ligands (Figure 1) $[10,11]$. The three nonbonding orbitals in square-planar complexes $\left(\mathrm{d}_{\mathrm{xz}}, \mathrm{d}_{\mathrm{xy}}\right.$ and $\left.\mathrm{d}_{\mathrm{yz}}\right)$ are not affected by the removal of a ligand. The $d_{z}{ }^{2}$ orbital is slightly stabilized due to the disappearance of a small antibonding interaction. However, the most striking difference is observed in the lowest unoccupied $\mathrm{d}_{\mathrm{x}}{ }^{2}-\mathrm{y}{ }^{2}$ orbital; its energy strongly decreases by removing an antibonding interaction with one ligand and its shape changes by mixing with the $p_{y}$ orbital. This hybridization takes place so that the orbital is directed away from the three ligands toward the empty coordination site, making this position suitable for the approach of an incoming ligand. This simple picture has been corroborated by DFT calculations on T-shaped [Pt(alkyl) $\left.\left(\mathrm{PMe}_{3}\right)_{2}\right]^{+}$complexes [2].

The splitting of the d-block orbitals favors a singlet ground state for T-shaped $\mathrm{d}^{8}$ complexes and these species usually exhibit a low-spin reactivity. Recent DFT calculations on the 14-electron $\left[\mathrm{Pt}\left({ }^{\mathrm{F}} \mathrm{PNP}\right)\right]^{+}$complex $\left({ }^{\mathrm{F}} \mathrm{PNP}=\left(4-\mathrm{F}-2-\left(\mathrm{iPr}_{2} \mathrm{P}\right) \mathrm{C}_{6} \mathrm{H}_{3}\right)_{2} \mathrm{~N}\right)$ predict a relatively small $\left(10-12 \mathrm{kcal} \mathrm{mol}^{-1}\right)$ separation between the singlet and the triplet states of this intermediate [12]. It is worth pointing out that a d $\mathrm{d}^{8} \mathrm{C}_{2 v} \mathrm{ML}_{3}$ fragment is isolobal with $\mathrm{CH}_{2}$, although the ordering of the two valence orbitals $a_{1}$ and $b_{2}$ differs. For a singlet 14-electron $\mathrm{T}$-shaped $\mathrm{ML}_{3}$, the two electrons fill the $\mathrm{b}_{2}$ level $\left(\mathrm{d}_{\mathrm{yz}}\right)$, while for a singlet $\mathrm{CH}_{2}$ fragment they occupy the $\mathrm{a}_{1}$ orbital (empty $\mathrm{d}_{\mathrm{x}}{ }^{2}-\mathrm{y}$ in $\mathrm{ML}_{3}$, Figure 1) [13].

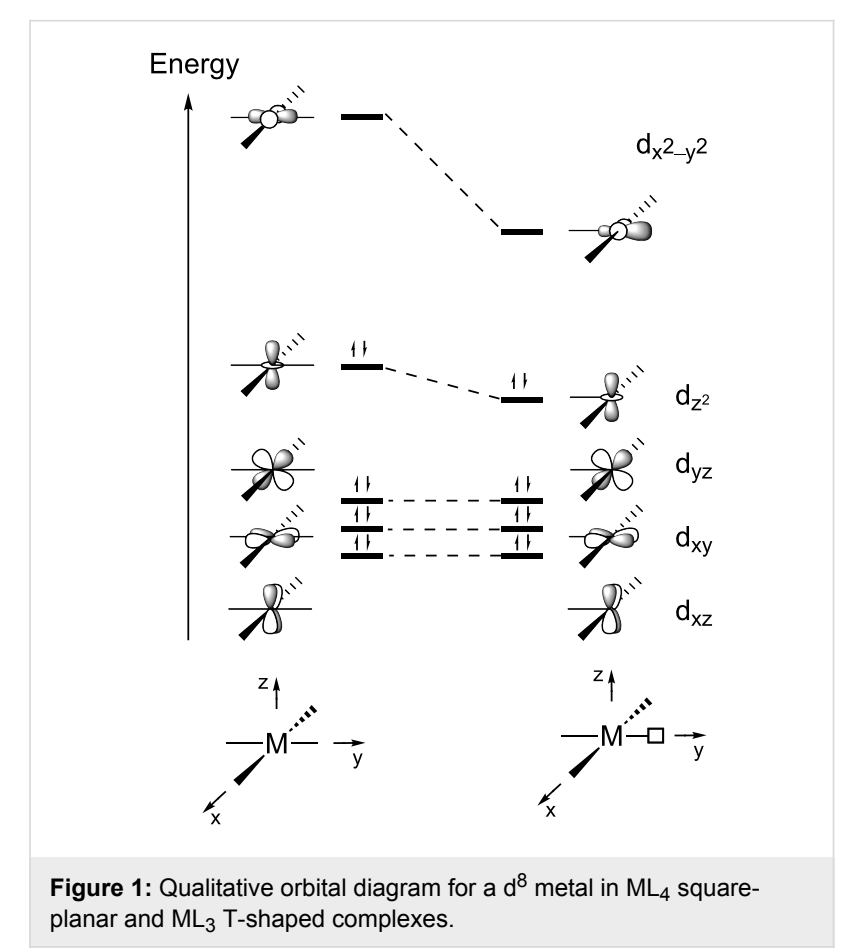

Steric reasons should favor trigonal-planar $D_{3} h^{\text {-like structures }}$ for three-coordinate $\mathrm{Pt}(\mathrm{II})$ complexes instead of the sterically 
unfavorable T-shaped structure. The preference of these $\mathrm{Pt}(\mathrm{II})$ compounds (with a low spin $\mathrm{d}^{8}$ configuration) for T-shaped structures is due to electronic effects and can be understood from the Walsh diagram shown in Figure 2. The Walsh diagram describes the variation of the $\mathrm{L}-\mathrm{M}-\mathrm{L}$ angle from a T-shaped structure through $D_{3 h}$ to a Y-shaped structure. A d ${ }^{8}$, 14-electron $\mathrm{ML}_{3}$ complex would have the lowest four levels filled in Figure 2. In a $D_{3 h}$ geometry, the degeneracy of e' orbitals will promote a Jahn-Teller distortion towards $\mathrm{T}$ or $\mathrm{Y}$ geometries $[10,14]$.

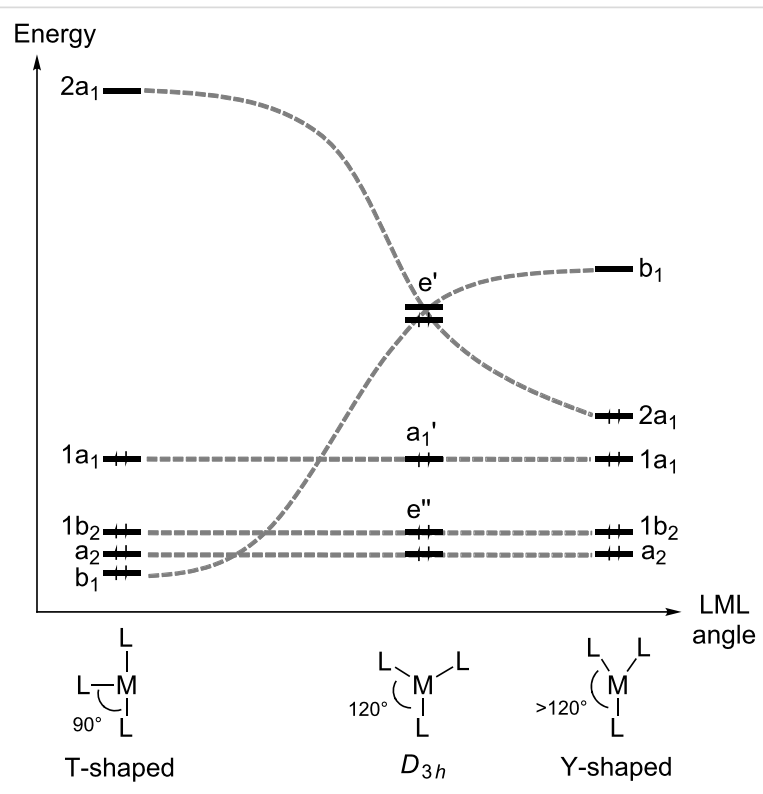

Figure 2: Walsh diagram for the $d$-block of $a d^{8} \mathrm{ML}_{3}$ complex upon bending of one $\mathrm{L}-\mathrm{M}-\mathrm{L}$ angle.

DFT calculations on asymmetric cis-[Pt(alkyl) $\left.\left(\mathrm{PMe}_{3}\right)_{2}\right]^{+}$show that, in spite of the reduced symmetry, the bending energy profile maintains the same basic features: the T-shaped configurations of the 14-electron species are energy minima, and their cis-like to trans-like interconversion occurs via transition states with Y-shaped configurations [2].

The X-ray structure of the recently reported three-coordinate platinum complex $\left[\mathrm{Pt}\left(\mathrm{SiMe}_{2} \mathrm{Ph}\right)_{2}(\mathrm{IPr})\right](\mathrm{IPr}=1,3$-bis(2,6-diisopropylphenyl)imidazol-2-ylidene) shows a unique $\mathrm{Y}$-shaped geometry in which the $\mathrm{Si}-\mathrm{Pt}-\mathrm{Si}$ angle is very acute $\left(80.9^{\circ}\right)$ and far from the ideal values for both trigonal-planar and T-shaped structures (Y1, Figure 3) [15]. Computations on non-sterically demanding models $\left[\mathrm{Pt}(\mathrm{R})_{2}(\mathrm{Im})\right]\left(\mathrm{R}=\mathrm{SiMe}_{3}, \mathrm{Me} ; \mathrm{Im}=\right.$ imidazol-2-ylidene) appealed to the trans influence of both NHC and silyl ligands to explain the structure. However, a recent DFT investigation concluded that $\mathbf{Y} 1$ is better described as a $\operatorname{Pt}(0) \sigma$-disilane complex [16] than as a $\mathrm{Pt}(\mathrm{II})$ disilyl species. Thorough geometrical and electronic analyses support a
$\operatorname{Pt}(0) \cdots$ disilane coordination via donation and back-donation interactions. This suggestion also explains the experimentally observed ${ }^{195} \mathrm{Pt}$ NMR chemical shift, which is closer to the $\operatorname{Pt}(0)$ rather than the $\mathrm{Pt}(\mathrm{II})$ species.

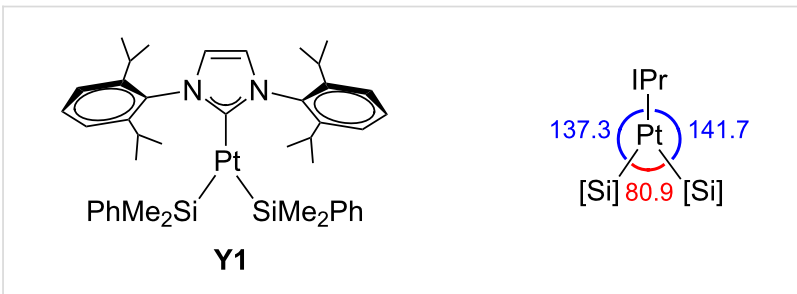

Figure 3: Neutral Y-shaped Pt complex Y1 [15]. Angles are given in degrees.

The nonequivalence of axial and equatorial positions in $\mathrm{ML}_{3}$ complexes raises the question of which positions are preferred by the ligands in such compounds. Although in most of the experimentally characterized systems the steric demands dictate the disposition of the ligands, electronic effects are also at work, and they were analyzed for simple model systems with theoretical methods. An early study based on perturbation theory concluded that in $\mathrm{T}$-shaped $\mathrm{ML}_{3} \mathrm{~d}^{8}$ complexes both axial and equatorial bonds should have similar strength and that the most electronegative atoms will substitute axially [17]. DFT calculations on $\left[\mathrm{PtXY}\left(\mathrm{PH}_{3}\right)\right]\left(\mathrm{X}, \mathrm{Y}=\mathrm{Cl}, \mathrm{CH}_{3}, \mathrm{SiH}_{3}, \mathrm{Si}(\mathrm{OH})_{3}\right)$ demonstrated the importance of the trans influence in governing the stability of T-shaped isomers. In the most stable isomer, the ligand with the smaller trans influence is located trans to the $\mathrm{PH}_{3}$ ligand [18].

\section{Structurally characterized compounds}

The T-shaped structure is easily recognized by the absence of one ligand in a square-planar disposition. Nevertheless, the number of well-characterized three-coordinate Pt(II) complexes is very low. To achieve a true T-shaped structure, the vacancy at the metal center must be blocked to avoid intra- and intermolecular interactions, such as agostic bonds and counteranion or solvent coordination. These interactions mask the T-shaped structure, but due to their potential labile nature, the three-coordinate species are still accessible.

In this section we will describe the main families of T-shaped Pt(II) complexes, which are structurally characterized (Figure 4). First, true T-shaped structures with no stabilization at the vacant site are compiled. Then, complexes involving agostic, counteranion and solvent interactions will be summarized. From now on, true T-shaped complexes are labeled as $\mathbf{T}$ complexes, while agostic, counteranion and solvent-stabilized complexes are designated as $\mathbf{A}, \mathbf{C}$ and $\mathbf{S}$ complexes, respectively. 


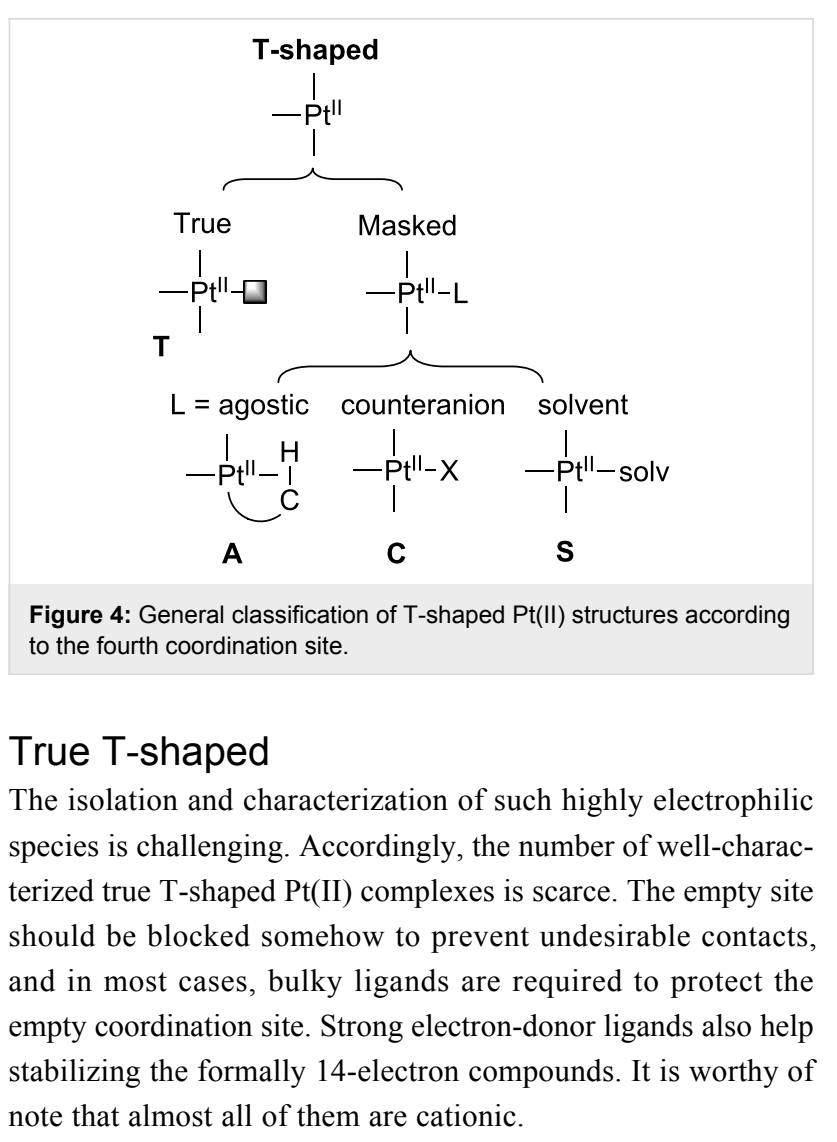

The first true T-shaped complexes were prepared by using phosphine ligands (Figure 5). In the 80 s, Goel et al. proposed, from nuclear magnetic resonance (NMR) data, a T-shaped structure for the cationic hydride trans $-\left[\left(t-\mathrm{Bu}_{3} \mathrm{P}\right)_{2} \mathrm{Pt}(\mathrm{H})\right]^{+} \mathbf{T 1}$ containing bulky phosphine ligands [19]. However, it was not until 2005 when Braunschweig et al. successfully characterized a true 14-electron T-shaped Pt(II) boryl complex T2a by means of X-ray studies [20]. By halide abstraction, the cationic trans-

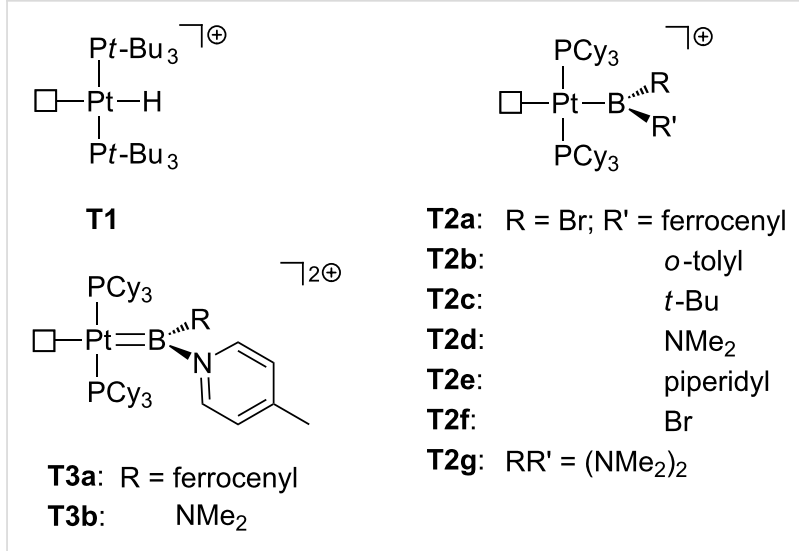

Figure 5: Hydride, boryl and borylene true T-shaped $\mathrm{Pt}(\mathrm{II})$ complexes.

$\left[\mathrm{Pt}(\mathrm{B}(\mathrm{Fc}) \mathrm{Br})\left(\mathrm{PCy}_{3}\right)_{2}\right]^{+} \mathbf{T 2 a}(\mathrm{Fc}=$ ferrocenyl; $\mathrm{Cy}=$ cyclohexyl $)$ could be obtained, in which the boryl ligand is located trans to the empty site. No agostic interactions were detected, the shortest $\mathrm{Pt}-\mathrm{H}$ and $\mathrm{Pt}-\mathrm{C}$ distances being $2.542 \AA$ and $3.117 \AA$, respectively. Inspired by this chemical template, the synthesis of Pt-boryl derivatives of the type trans-[Pt(BRR') $\left.\left(\mathrm{PCy}_{3}\right)_{2}\right]^{+}$ has been extended [21]. Even at extreme electronic conditions in dicationic trans- $\left[\mathrm{Pt}(\mathrm{BR}(4-\text { picoline }))\left(\mathrm{PCy}_{3}\right)_{2}\right]^{2+} \mathbf{T} 3$, the complex remains truly $\mathrm{T}$-shaped, although small Lewis donors such as $\mathrm{CO}$ and acetonitrile can coordinate to the open coordination site of T3 [22]. DFT-based electron localization function (ELF) analyses [20] and geometry optimizations [22] supported the lack of agostic interactions in these complexes. This absence has been attributed to the strong trans influence exerted by the ligand in trans position with respect to the vacant site $[23,24]$.

Moreover, in the past few years the synthesis of 14-electron $\mathrm{Pt}(\mathrm{II})$ complexes was extended by using N-heterocyclic carbene (NHC) ligands (Figure 6), which have been proven to be useful

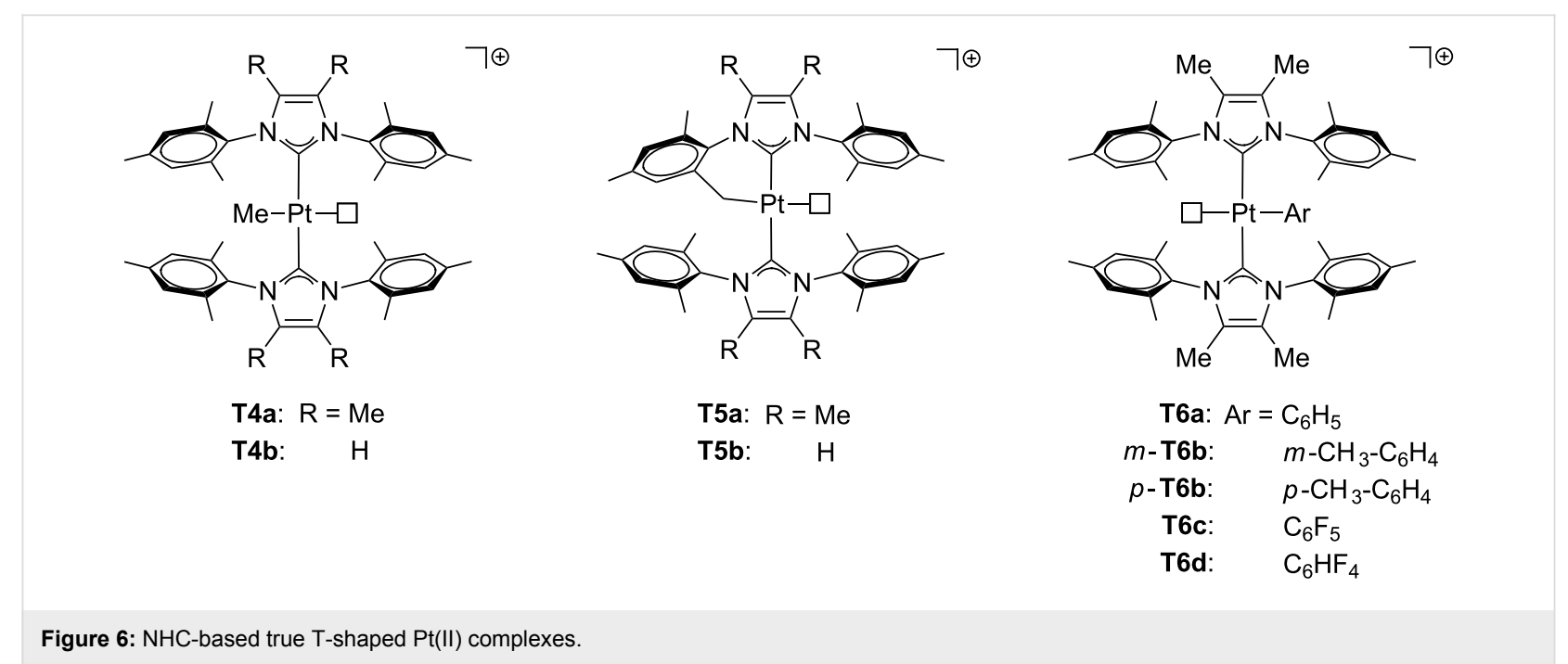


stabilizing electron-deficient transition-metal species [25-27]. In this regard, recent studies state that the use of IMes* $(4,5-$ dimethyl-1,3-bis(2,4,6-trimethylphenyl)imidazol-2-ylidene) and IMes (1,3-bis(2,4,6-trimethylphenyl)imidazol-2-ylidene) ligands in $\left[\mathrm{Pt}(\mathrm{Me})(\mathrm{NHC})_{2}\right]^{+} \mathbf{T} 4$ and $\left[\mathrm{Pt}\left(\mathrm{NHC}^{\prime}\right)(\mathrm{NHC})\right]^{+} \mathbf{T 5}$ $\left(\mathrm{NHC}=\mathrm{IMes}^{*}\right.$, IMes; $\mathrm{NHC}^{\prime}=$ cyclometalated ligand $)$ provides pure T-shaped species with no agostic stabilization [28]. Additionally, the resulting $\left[\mathrm{Pt}(\mathrm{Ar})\left(\mathrm{IMes}{ }^{*}\right)_{2}\right]^{+} \mathbf{T 6}$ formed after $\mathrm{C}-\mathrm{H}$ bond activation has also proven to be a three-coordinate species with no agostic interactions according to the X-ray structure of the derivative T6d, in which the closest $\mathrm{Pt}-\mathrm{H}$ contact is located at $3.117 \AA$. The absence of agostic interactions has been attributed to geometrical constraints, the limited flexibility of the mesityl groups in IMes* and IMes hampering the approach of the $\mathrm{CH}$ bond to the metal center. Once again, Lewis acids as acetonitrile can access the empty site, which means that a potential reactant molecule can coordinate to the metal for further reactions.

\section{Masked T-shaped via agostic interaction}

The agostic interaction [29,30] is usually explained as an intramolecular 3-center-2-electron interaction between a metal $\mathrm{M}$ and a $\mathrm{C}-\mathrm{H}$ bond. This type of contact is a recurrent event in unsaturated transition-metal complexes [31] and it can be characterized by structural and spectroscopic techniques $[29,30]$ together with computational tools $[32,33]$. The agostic interaction shows different behaviors. It can be a transient species prior to the $\mathrm{C}-\mathrm{H}$ bond breaking or stabilize low electron count situations. In this section we will focus on the latter aspect. Since this intramolecular interaction is difficult to avoid, even in the presence of bulky ligands, it is the most common motif for the stabilization of three-coordinate complexes.

Early works on T-shaped Pt(II) species are related to complexes stabilized with phosphine ligands (Figure 7). Pioneering studies on alkyl complexes from Orpen's and Spencer's research groups reported the synthesis of cationic $[\mathrm{Pt}(\text { norbornyl })(\mathrm{P}-\mathrm{P})]^{+}$ complexes A1a-e (P-P = bidentate phosphine ligand) [34,35]. Further studies involved other alkyl ligands such as ethyl (A2b-c), 3,3-dimethylbutyl (A3b-c) and 2,3,3-trimethylbutyl (A4) [36-38]. NMR spectroscopic data and X-ray structures of A1a [34] and A2b [36] demonstrate that these compounds display a $\beta$-agostic interaction filling the fourth coordination site. This interaction is strong enough to cleave the $\mathrm{C}-\mathrm{H}$ bond, creating a chemical equilibrium with the corresponding hydrido-alkene derivatives. Indeed, the detected ground state of the compounds in brackets (A2a, A2d, A2e and A3a in Figure 7) is the hydrido-alkene isomer instead of the agostic-alkyl one. Later, Baratta et al. succeeded in the isolation of 14-electron Pt(II) complexes bearing bulky phosphine

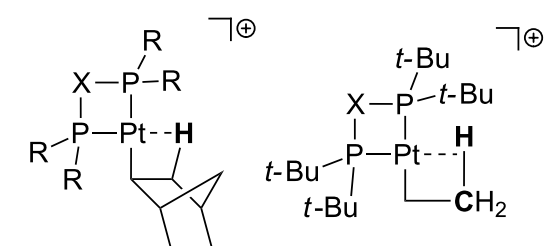

norbornyl ethyl

A1a: $\quad$ (A2a): $\mathrm{R}=t$-Bu; $\mathrm{X}=\left(\mathrm{CH}_{2}\right)_{2}$

A1b: A2b:

A1c: A2c:

A1d:

A1e:

(A2d):
(A2e)

$\left(\mathrm{CH}_{2}\right)_{3}$

O- $\mathrm{C}_{6} \mathrm{H}_{4}\left(\mathrm{CH}_{2}\right)_{2}$

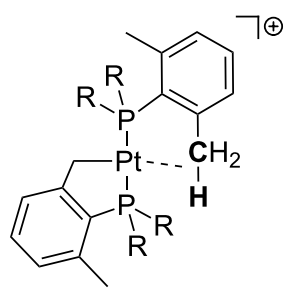

A5a: $\mathrm{R}=\mathrm{Ph}$

A5b: Cy

A5c: $\quad \mathrm{iPr}$<smiles>[X][P]1(C(C)(C)C)[C@H](C(C)(C)C)C[PH]1([Z])C(C)(C)C</smiles>

(A3a): $\mathrm{X}=\left(\mathrm{CH}_{2}\right)_{2}$

A3b: $\quad\left(\mathrm{CH}_{2}\right)_{3}$

A3c: $\quad 0-\mathrm{C}_{6} \mathrm{H}_{4}\left(\mathrm{CH}_{2}\right)_{2}$<smiles>CC(C)(C)C1(C(C)(C)C)CC(C)(C)P12(C(C)(C)C)CCCP2(C(C)(C)C)(C(C)(C)C)C(C)(C)C</smiles>

A4<smiles>CC1CCP(C)(C(C)C)([PH](C(C)C)(C(C)C)C(C)(C)C)C1C</smiles>

A7

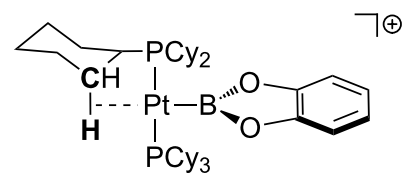

A8 
ligands [39]. The usage of trans-[Pt( $\left.\mathrm{Me}) \mathrm{Cl}\left(\mathrm{PR}_{3}\right)_{2}\right]$ as a starting material, followed by halide removal and the release of methane by intramolecular $\mathrm{C}-\mathrm{H}$ bond activation provided the cationic T-shaped cyclometalated complexes A5a-b. The X-ray structure of $\mathbf{A 5 b}$ shows that the platinum atom exhibits a $\delta$-agostic interaction with one hydrogen atom of the methyl group of the non-cyclometalated phosphine ligand. Subsequent hydrogenation generates the corresponding hydride complexes A6a-b. On the basis of NMR studies $\left({ }^{1} J_{\mathrm{Pt}, \mathrm{H}}\right.$ values of ca. $2000 \mathrm{~Hz}$, see next section), a weak interaction trans to the hydride ligand, typically an agostic contact, is supposed to exist. Carmona and co-workers also prepared quite similar complexes, A5c and A6c, where R labels represent isopropyl groups [40]. Weller and co-workers reported the formation of complex trans$\left[\mathrm{Pt}(\mathrm{Me})\left(\mathrm{PiPr}_{3}\right)_{2}\right]^{+} \mathbf{A} 7$ in which a $\gamma$-agostic interaction is located in the fourth coordination site [41]. The addition of tetrahydrofuran (THF) rapidly forms the corresponding adduct. Braunschweig et al. obtained the agostic structure $\mathbf{A 8}$ by employing $\mathrm{BCat}$ as a ligand $(\mathrm{BCat}=$ catecholatoboryl $)$ in three-coordinate $\mathrm{Pt}(\mathrm{II})$ complexes [21]. Unlike the previous pure T-shaped boryl complexes T2 (Figure 5), the weaker trans influence of the BCat ligand allows the formation of an agostic contact. Treatment of $\mathbf{A 8}$ with Lewis bases also removes the agostic interaction, generating the adduct complex.
Natural Bond Orbital (NBO) and Atoms In Molecules (AIM) calculations on complexes A1, A2b, A5b and A7 classified the $\mathrm{Pt} \cdots \mathrm{H}-\mathrm{C}$ contacts as agostic interactions for all the species with the only exception being $\mathbf{A} 7$, in which a $\mathrm{H}$-bond character can also be ascribed [42].

Concerning other types of ligands (Figure 8), the phenylpyridyl complex A9 reported by Rourke and co-workers exhibits a bifurcated $\delta$-agostic interaction that has been determined by $\mathrm{X}$-ray studies [43]. This is one of the rare neutral T-shaped Pt(II) complexes. Referring to NHC ligands, RivadaWheelaghan et al. isolated the three-coordinate methyl $\left[\mathrm{Pt}(\mathrm{Me})(\mathrm{IPr})_{2}\right]^{+}(\mathbf{A 1 0})$ and cyclometalated $\left[\mathrm{Pt}\left(\mathrm{NHC}^{\prime}\right) \mathrm{NHC}\right]^{+}$ complexes $(\mathrm{NHC}=\operatorname{IPr} \mathbf{A 1 1 a}, \mathrm{I} t$-Bu (1,3-bis(tertbutyl)imidazol-2-ylidene) A11b; $\mathrm{NHC}^{\prime}=$ cyclometalated ligand) [44]. In sharp contrast with the analogous $\mathbf{T 5}$ and T6 (Figure 6) [28], $\delta$ - and $\zeta$-agostic interactions at the fourth coordination site were detected by X-ray and NMR studies for complexes containing $\operatorname{IPr}(\mathbf{A 1 1 a})$ and $\mathrm{I} t$-Bu (A11b), respectively.

Selected $\mathrm{Pt} \cdots \mathrm{H}-\mathrm{C}$ parameters from the X-ray structures of agostic compounds are collected in Table 1. As it can be expected, short $\mathrm{Pt}-\mathrm{H}$ and $\mathrm{Pt}-\mathrm{C}$ distances are observed for the

\begin{tabular}{|c|c|c|c|c|c|}
\hline Complex & Agostic length & $\mathrm{Pt}-\mathrm{H}$ distance/Å & Pt-C distance/Å & $\begin{array}{l}\mathrm{Pt}-\mathrm{H}-\mathrm{C} \\
\text { angle/degrees }\end{array}$ & Reference \\
\hline A1a & $\beta$ & 1.895 & 2.309 & 91.2 & [34] \\
\hline$A 2 b$ & $\beta$ & $-^{a}$ & 2.282 & $-^{a}$ & [37] \\
\hline A5b & $\delta$ & 2.057 & 2.432 & 102.5 & [39] \\
\hline A7 & Y & 2.244 & 2.855 & 124.2 & {$[41]$} \\
\hline A8 & $\mathrm{y}$ & 2.322 & 2.923 & 118.2 & [21] \\
\hline A9 & $\delta$ & $2.151,2.138^{b}$ & 2.472 & $96.5,94.6^{b}$ & [42] \\
\hline A11a & $\zeta$ & 2.017 & 2.876 & 145.1 & [44] \\
\hline
\end{tabular}

aNot available. ${ }^{\mathrm{b} B i f u r c a t e d}$ agostic interaction.

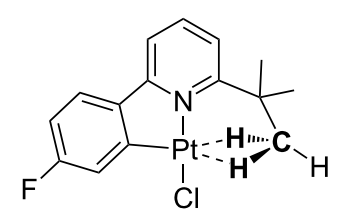

A9

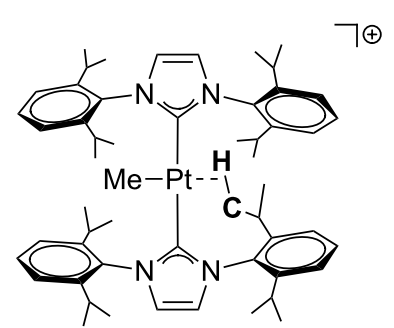

A10

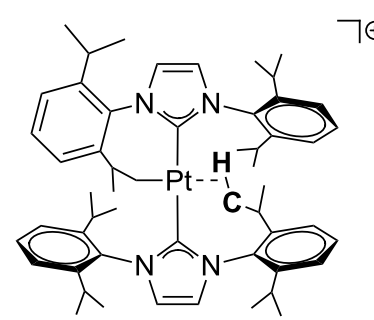

A11a

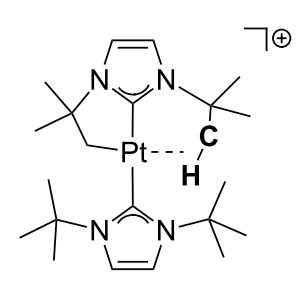

A11b 
$\beta$-agostic interactions in A1a and $\mathbf{A 2 b}$. In addition, $\mathrm{Pt}-\mathrm{H}-\mathrm{C}$ angles larger than $100^{\circ}$ correlate with large $\mathrm{Pt}-\mathrm{C}$ distances as shown in A7, A8 and A11a. Although a remote contact is described in A11a, the largest distances correspond with the $\gamma$-agostic A8. In other words, the strength of the agostic interaction is not only governed by geometrical constraints and the surroundings of the $\mathrm{CH}$ group, but also by the trans influence of the ligand in trans position with respect to the agostic interaction [23,24]. In this case, the boryl ligand in $\mathbf{A 8}$ exhibits a higher trans influence than the alkyl group in A11a [45,46], and therefore the agostic interaction in the former is weaker.

\section{Masked T-shaped via counteranion inter- action}

Most of the T-shaped Pt(II) complexes are cationic. Thus, there is the possibility of stabilizing the unsaturated structure by nonbulky, weakly coordinating counteranions. Triflate (OTf $=$ $\mathrm{SO}_{3} \mathrm{CF}_{3}$ ) and tetrafluoroborate are the best candidates to play such a role (Figure 9). All the well-characterized compounds bear a coordinated triflate anion. In the $80 \mathrm{~s}$, Whitesides et al. described the synthesis of trans-[Pt(Np)(OTf $\left.)\left(\mathrm{PMe}_{3}\right)_{2}\right](\mathrm{Np}=$ neopentyl) C1a. This compound reacts with benzene forming trans $-\left[\mathrm{Pt}(\mathrm{Ph})(\mathrm{OTf})\left(\mathrm{PMe}_{3}\right)_{2}\right] \mathbf{C 1 b}$ through a mechanism that involves trans- $\left[\mathrm{Pt}(\mathrm{Np})\left(\mathrm{PMe}_{3}\right)_{2}\right]^{+}$as a reactive intermediate [47]. The labile character of the coordinated triflate has been alleged to justify the significant difference between the ${ }^{1} J_{\mathrm{Pt}, \mathrm{P}}$ found for $[\mathrm{Pt}(\mathrm{Me})(\mathrm{OTf})(\mathrm{dmpe})] \mathbf{C 2}(\mathrm{dmpe}=1,2-$ bis(dimethylphosphino)ethane) in $\mathrm{CD}_{2} \mathrm{Cl}_{2}(4572 \mathrm{~Hz})$ and in acetone $(4305 \mathrm{~Hz})$. In the latter media one solvent molecule is proposed to displace the triflate ligand, forming $[\mathrm{Pt}(\mathrm{Me})($ acetone)(dmpe)][OTf] [48]. The complex $[\mathrm{Pt}(\mathrm{Me})(\mathrm{OTf})(\mathrm{dbbipy})] \mathbf{C 3}$ (dbbipy = 4,4'-di-tert-butyl-2,2'- bipyridine) was prepared by treatment of $[\mathrm{PtCl}(\mathrm{Me})(\mathrm{dbbipy})]$ with AgOTf [49]. Regarding tridentate ligands, the X-ray structure of the triflate complex [Pt(3,3'-iPr 2 -BQA)(OTf)] C4b (BQA $=$ bis(8-quinolinyl)amine) shows a coordinated OTf ligand $(\mathrm{Pt}-\mathrm{O}=2.097 \AA)$ in trans position to the amido $\mathrm{N}$-donor of the pincer-like amido ligand. In solution, the labile triflate ligand can be displaced, allowing a reaction with benzene [50]. Milstein and co-workers have reported a series of pincer-type $\mathrm{Pt}(\mathrm{II})$ complexes C5-8 containing an XCX ligand core $(\mathrm{X}=\mathrm{N}$, $\mathrm{P})$, incorporating the anions $\mathrm{OTf}^{-}$and $\mathrm{BF}_{4}{ }^{-}$[51-53]. The structure of $\mathbf{C 5} \mathbf{b}$ was determined by X-ray crystallography [51]. The $\mathrm{Pt}-\mathrm{O}$ bond distance in this compound, in which the triflate anion is coordinated to platinum in trans position with respect to the aromatic ring, is considerably longer than in $\mathbf{C 4 b}(\mathbf{C} 4 \mathbf{b}$ : $2.097 \AA[50]$; C5b: $2.249 \AA$ [51]). The weakly coordinating character of triflate accounts for its sensitivity to the trans influence.

\section{Masked T-shaped via solvent coordination}

In solution, a solvent molecule can occupy the vacant position of a T-shaped three-coordinate Pt(II) compound via $\sigma$-interaction. A number of phosphine-based complexes with different solvent molecules coordinated to the T-shaped frame have been characterized (Figure 10). In this regard, Kubas and co-workers prepared a set of hydride trans $-\left[\mathrm{PtH}\left(\mathrm{PiPr}_{3}\right)_{2} \text { (solv) }\right]^{+}$compounds where "solv" stands for $\eta^{1}-\mathrm{ClCH}_{2} \mathrm{Cl}(\mathrm{S1a}), \mathrm{OEt}_{2}$ (S1b) and THF (S1c) solvent molecules [54]. Interestingly, the closely related species T1 (Figure 5) does not include any solvent molecule filling the vacancy [19]. Moreover, the structures of S1a and S1c were fully confirmed by X-ray studies. The similar dichloromethane adduct S1d was later detected by NMR spectroscopy [55]. This work was extended to methyl complexes

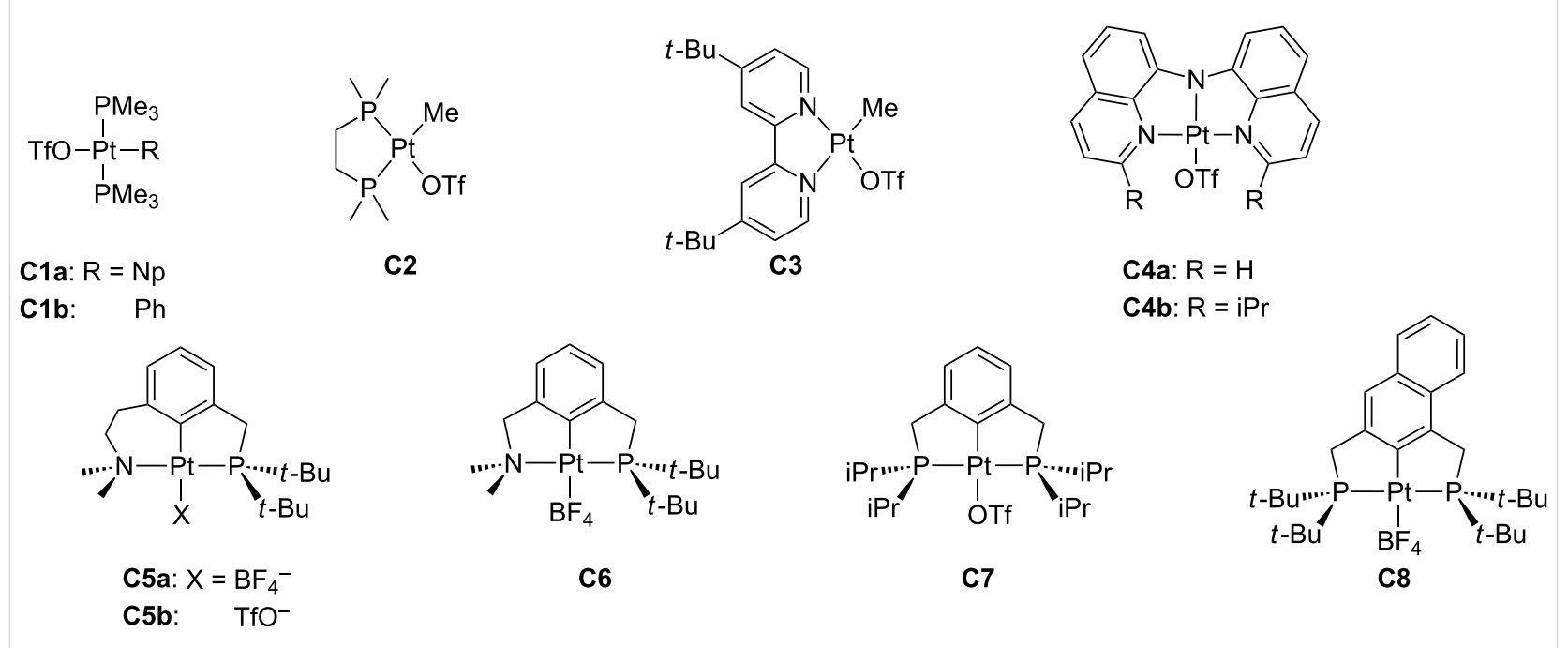




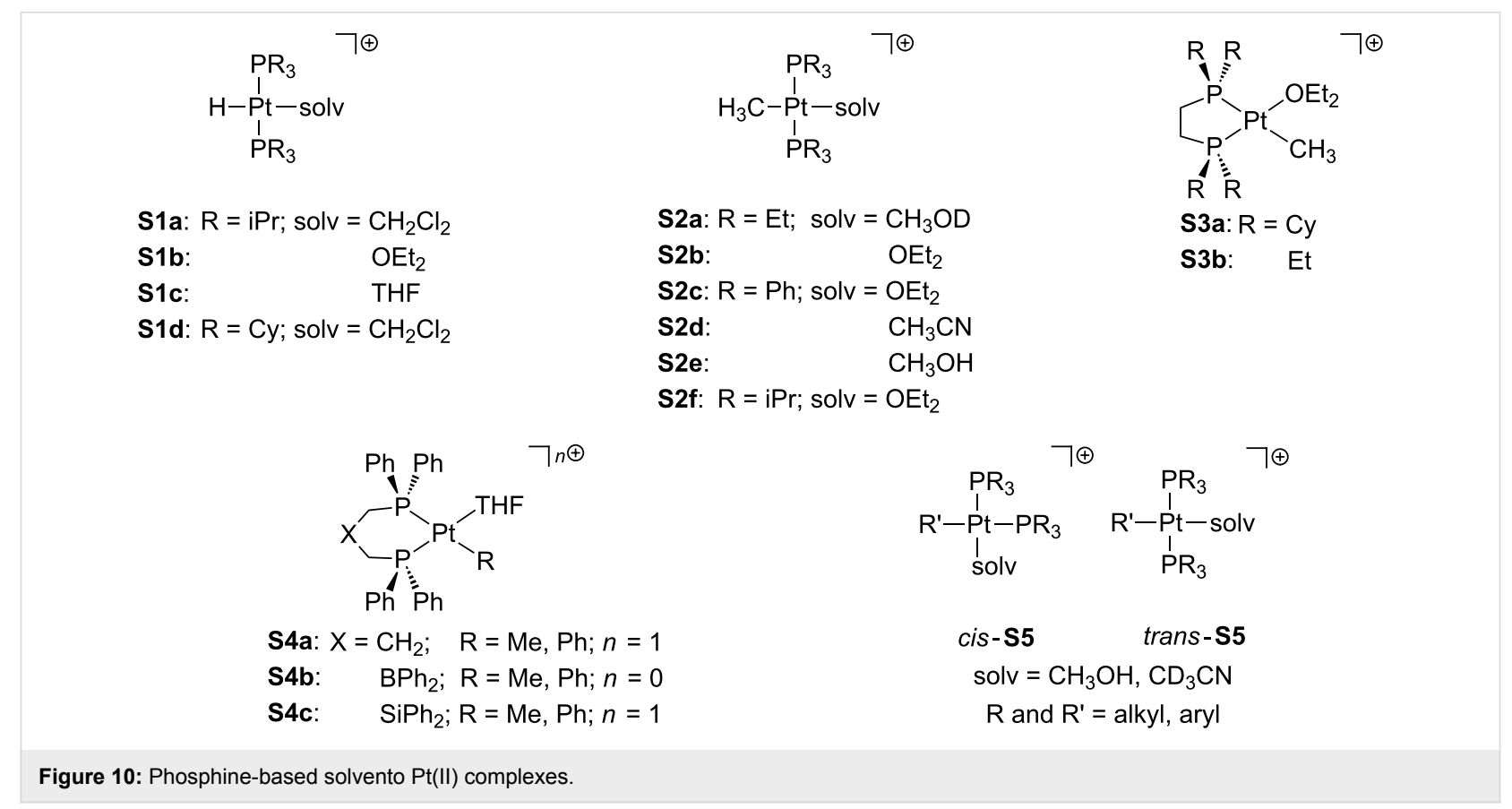

with the formula trans-[Pt(Me)( $\left(\mathrm{PR}_{3}\right)_{2}$ (solv)] (S2) [56,57]. Similar structures have been obtained by the use of chelating phosphine ligands in diethylether (S3) [58]. In this line, Peters and co-workers developed several bidentate phosphine ligands to yield complexes $\mathbf{S} \mathbf{4}$ in which one THF molecule is coordinated to the metal center $[59,60]$. Romeo's group was actively working on solvento Pt(II) complexes S5. For instance, they employed an extended series of phosphine ligands to obtain cis and trans-solvento complexes containing methanol [61]. The formation of acetonitrile- $d_{3}$ adducts with triethylphosphine ligands was also reported $[2,62]$.

Several examples involving chelating nitrogen-based ligands have also been reported (Figure 11). Bercaw and co-workers developed cationic solvento Pt(II) complexes S6 bearing tetramethylethylenediamine (tmeda) [63]. X-ray crystallography of S6a. BAr ${ }^{\mathrm{F}}$ and $\mathbf{S 6 c} \cdot \mathrm{BAr}^{\mathrm{F}}$ verified the solvent coordination [64]. Diimine analogues, valuable in $\mathrm{C}-\mathrm{H}$ bond-activation processes, have been extensively reported elsewhere (S7) [6572]. Later, Tilset's group prepared and characterized a set of solvento tolyl complexes of the type $\left[\mathrm{Pt}(\mathrm{Tol})(\mathrm{N}-\mathrm{N})\left(\mathrm{CH}_{3} \mathrm{CN}\right)\right]$ S8 by means of ${ }^{1} \mathrm{H}$ and ${ }^{19} \mathrm{~F}$ NMR [73]. The formation of $p$-xylene derivates $\mathbf{S 9}$ containing a molecule of the weakly coordinating 2,2,2-trifluoroethanol (TFE) has also been reported $[69,74]$. Unsaturated bipyridyl compounds $\mathbf{S 1 0}$ have been isolated in which the presence of solvent molecules has been detected $[75,76]$. The stabilizing role of the solvent molecule is quite relevant. For instance, the removal of the THF molecule in S10b provokes the decomposition of the complex [75]. The facile displacement of the solvent ligand allows the use of these

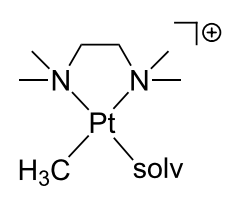

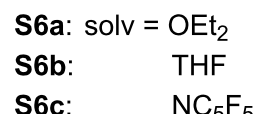<smiles></smiles>

S7

$$
\mathrm{R}=\mathrm{CH}_{3}, \mathrm{C}_{6} \mathrm{H}_{5}
$$$$
\mathrm{R}^{\prime}=\mathrm{H}, \mathrm{CH}_{3}
$$$$
\mathrm{Ar}=\text { aryl }
$$$$
\text { solv }=\mathrm{H}_{2} \mathrm{O}, \mathrm{TFE}, \mathrm{NCCH}_{3}
$$

TFE $=$ 2,2,2-trifluoroethanol<smiles>[R][P+]1([Se])N([Al])C(C)=C(C)N1[Al]</smiles>

S8: solv $=\mathrm{NCCH}_{3} ; \mathrm{R}=$ tolyl

s9: solv = TFE; $\quad R=x y l y l$

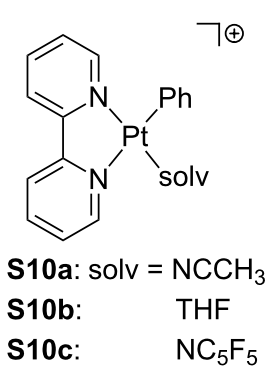


compounds as catalysts in hydrophenylation reactions [76]. Other related complexes have been prepared elsewhere [77-81].

Pincer ligands $[82,83]$ naturally define a three-coordinate environment and, in this way, they are well-suited as ligands in T-shaped compounds. Accordingly, a number of T-shaped $\mathrm{Pt}(\mathrm{II})$ pincer complexes with an additional solvent molecule as a fourth ligand have been reported (S11-19, Figure 12). Van Eldik and co-workers studied the aquo complexes $\mathbf{S 1 1}$ by using several tridentate nitrogen-based ligands (NNN) [84]. Peters and co-workers isolated $[\mathrm{Pt}(\mathrm{OTf})(\mathrm{NNN})]$ species, though NMR data were collected in acetonitrile- $d_{3}$ solution, in which the solvento adduct $\mathbf{S 1 2}$ is favored [50]. Extensive work carried out by van Koten and co-workers $[85,86]$ concerned NCN aquo compounds such as $\mathbf{S 1 3}$. Unsaturated complexes bearing NCP ligands were characterized by Milstein and co-workers, including water (S14a) [51] and acetone (S14b) [87] solvent molecules. Isolation of compound $\mathbf{S 1 5}$ in acetone/pyridine solution provided suitable crystals for X-ray studies, which showed that a pyridine molecule has been added [87]. Other investigations have been devoted to complexes with PCP ligands. For instance, Bullock and co-workers prepared a dihydrogen adduct of the type $\left[\mathrm{PtH}_{2}(\mathrm{PCP})\right]^{+}$in dichloromethane, but NMR data suggest a mixture of the former compound and the corresponding solvento complex S16a [88]. Milstein et al. proposed that the closely related complex $\mathbf{S 1 6 b}$ exists in THF solution, since an interaction with the $\mathrm{BF}_{4}{ }^{-}$counteranion is not observed, although the elemental analysis evidences the lack of the THF molecule in the solid state [89]. Contrarily, the naphthyl deriva- tive $\mathbf{S 1 7}$ was found together with the $\mathrm{BF}_{4}{ }^{-}$adduct $\mathbf{C 8}$ (Figure 9) [53]. For silicon-related ligands, Turculet and co-workers successfully crystallized $\mathbf{S 1 8}$ in a diethylether solution at low temperature, showing one diethylether molecule directly coordinated to the platinum center [90]. A set of dicationic complexes based on carbene groups have been developed by Limbach and co-workers, forming pyridine S19a and acetonitrile S19b,c adducts [91].

The relevance of solvent-stabilized T-shaped Pt(II) complexes extends beyond the organometallic field. Their presence in cisplatin-protein adducts has also been proposed concerning the bovine $\mathrm{Cu}, \mathrm{Zn}$ superoxide dismutase [92] and the hen egg white lysozyme [93]. The corresponding crystallographic structures show the platinum coordinated to a histidine residue of the protein and two ligands $\left(\mathrm{Cl}^{-}\right.$[92] or $\mathrm{NH}_{3}$ [93]). However, in both situations the fourth ligand was not fully detectable, so that the authors suggested the participation of a coordinating water molecule. Indeed, quantum mechanics/molecular mechanics (QM/MM) calculations on the cisplatin-hen egg white lysozyme adduct confirmed the facile inclusion of a solvent water molecule in the first coordination shell of the platinum complex (Figure 13) [94].

\section{NMR coupling constants to ${ }^{195} \mathrm{Pt}$ as sensi- tive probes for coordinatively unsaturated $\mathrm{Pt}(\mathrm{II})$ complexes}

NMR spectroscopy has provided additional evidence for the existence of low electron-count Pt(II) complexes not only<smiles>OP123CN1CN2CN3</smiles>

S11

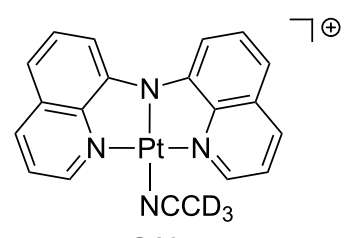

$\mathrm{S} 12$<smiles>CN1Cc2cccc3c2[P]1(O)N(C)C3</smiles>

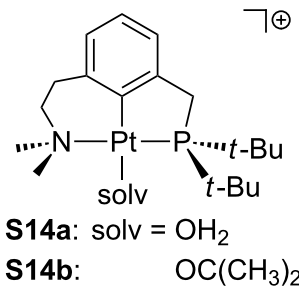

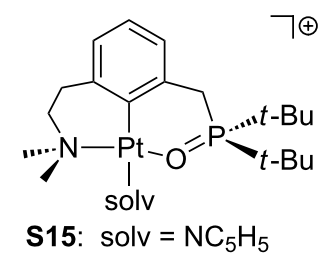

S15: solv $=\mathrm{NC}_{5} \mathrm{H}_{5}$

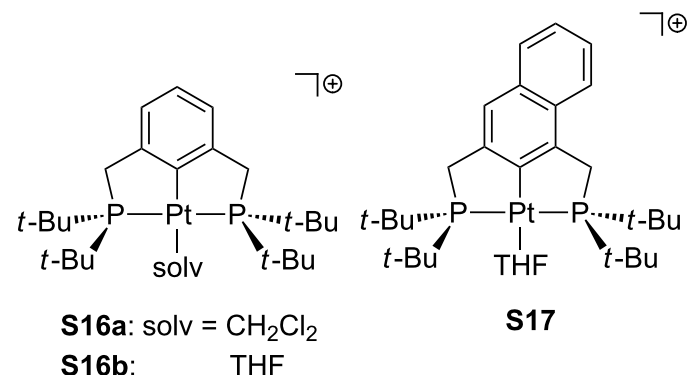<smiles>CCOP1(c2ccccc2)(c2ccccc2)P(c2ccccc2)c2ccccc2[Si]1(C)c1ccccc1</smiles>

S18

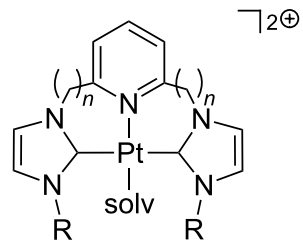

S19a: solv $=\mathrm{NC}_{5} \mathrm{H}_{5} ; n=1 ; \mathrm{R}=\mathrm{CH}_{3}$ S19b: solv $=\mathrm{NCCD}_{3} ; n=1 ; \mathrm{R}=n-\mathrm{Bu}$ S19c: S19d: $n=1 ; \mathrm{R}=$ Mes $n=0 ; \mathrm{R}=$ Mes 


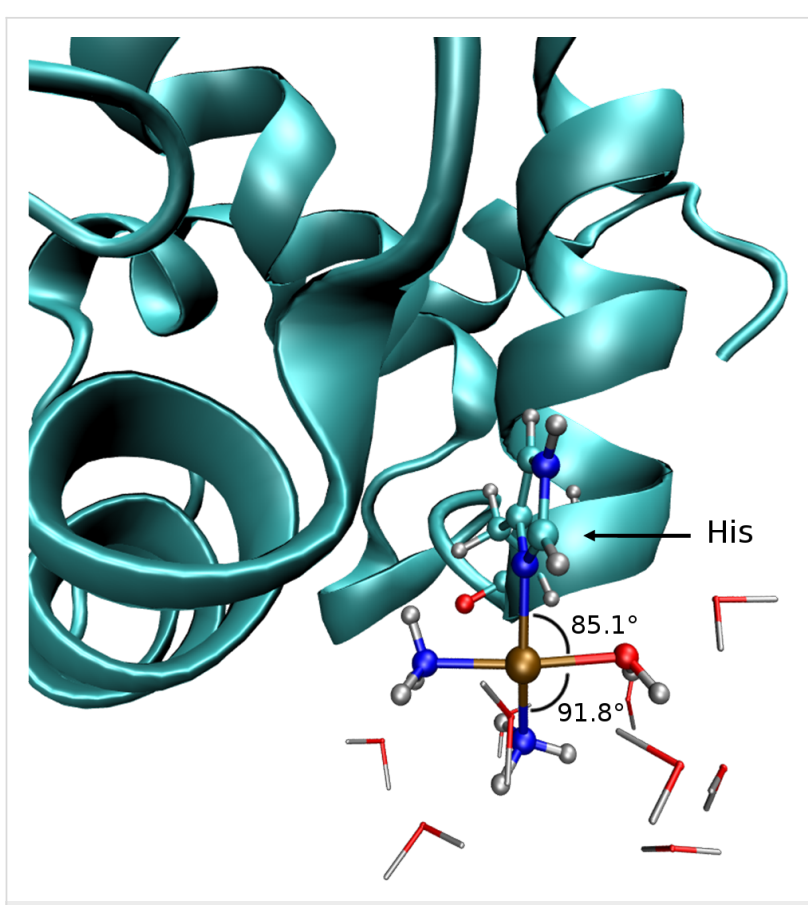

Figure 13: Structure of the QM/MM optimized cisplatin-protein adduct [94].

through the observation (in some cases) of NMR signals for the $\mathrm{C}-\mathrm{H}$ bonds involved in agostic interactions, but also by the magnitude of the coupling constant of some of the ligands around the metal center with the NMR active ${ }^{195} \mathrm{Pt}$ nuclei (33.7\% natural abundance). This is actually not the case with ${ }^{31} \mathrm{P}$ NMR, for which the $J_{\mathrm{Pt}, \mathrm{P}}$ values seem to be virtually insensitive to the nature of the complex. As an example, in the boryl derivatives reported by Braunschweig et al. [21] the $J_{\mathrm{Pt}, \mathrm{P}}$ coupling constant is almost the same both in the starting material, $\left[\mathrm{Pt}\left(\mathrm{BR}_{2}\right) \mathrm{Br}\left(\mathrm{PCy}_{3}\right)_{2}\right]$, and in the three-coordinate $\mathrm{Pt}(\mathrm{II})$ species, $\left[\mathrm{Pt}\left(\mathrm{BR}_{2}\right)\left(\mathrm{PCy}_{3}\right)_{2}\right]\left[\mathrm{BAr}^{\mathrm{F}}\right] \mathbf{T 2}$. On the other hand, the coupling constants of the proton and carbon atoms of alkyl and hydride ligands with ${ }^{195} \mathrm{Pt}$ are very sensitive to the presence of coordinating ligands trans to them (Figure 14).

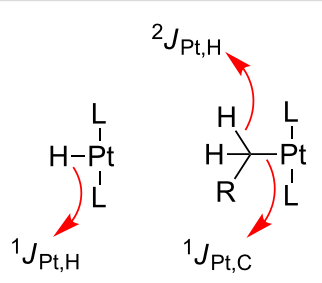

Figure 14: NMR coupling constants used for the characterization of three-coordinate $\mathrm{Pt}(\mathrm{II})$ species.

A nice example is illustrated in the hydride, T-shaped $\mathrm{Pt}(\mathrm{II})$ complex trans- $\left[\mathrm{PtH}\left(\mathrm{P} t-\mathrm{Bu}_{3}\right)_{2}\right][\mathrm{X}] \mathbf{T} \mathbf{1}\left(\mathrm{X}=\mathrm{PF}_{6}, \mathrm{BF}_{4}, \mathrm{ClO}_{4}\right.$, $\mathrm{SO}_{3} \mathrm{CF}_{3}$ ) reported by Goel and Srivastava [19]. The magnitude of the ${ }^{1} J_{\mathrm{Pt}, \mathrm{H}}$ coupling constant of the hydride ligand in its precursor trans- $\left[\mathrm{PtHCl}\left(\mathrm{Pt}-\mathrm{Bu}_{3}\right)_{2}\right]$ is $1070 \mathrm{~Hz}$, but in the 14-electron derivative trans $-\left[\mathrm{PtH}\left(\mathrm{P} t-\mathrm{Bu}_{3}\right)_{2}\right][\mathrm{X}] \mathbf{T} 1$ it increases to ca. $2600 \mathrm{~Hz}$, the largest ${ }^{1} J_{\mathrm{Pt}, \mathrm{H}}$ reported in the literature. A decrease of this coupling constant to $2050-2070 \mathrm{~Hz}$ was observed in the related hydride $\mathrm{Pt}(\mathrm{II})$ complexes trans-[PtH( $\mathrm{PR}_{2}(2,6-$ $\left.\left.\left.\mathrm{Me}_{2} \mathrm{C}_{6} \mathrm{H}_{3}\right)\right)_{2}\right]^{+}$(Figure 7, $\mathrm{R}=\mathrm{Ph}$ A6a, Cy A6b, iPr A6c), which are stabilized by agostic interactions involving the methyl groups of the aryl fragments. In the same vein, weakly coordinating ligands such as the solvent stabilized $\mathrm{Pt}(\mathrm{II})$ derivatives trans- $\left[\mathrm{PtH}\left(\mathrm{ClCH}_{2} \mathrm{Cl}\right)\left(\mathrm{PR}_{3}\right)_{2}\right]\left[\mathrm{BAr}^{\mathrm{F}}\right]($ Figure $10, \mathrm{R}=\mathrm{iPr} \mathbf{S 1 a}$, Cy S1d) exhibit a smaller $J_{\mathrm{Pt}, \mathrm{H}}$ of $1480(\mathrm{R}=\mathrm{Cy})$ or $1852 \mathrm{~Hz}(\mathrm{R}$ $=\mathrm{iPr}$ ) in agreement with the presence of a ligand trans to the hydride. With regard to $\mathrm{Pt}-\mathrm{H}$ two-bond and $\mathrm{Pt}-\mathrm{C}$ one-bond coupling constants in $\mathrm{Pt}-\mathrm{C}_{\mathrm{alkyl}}$ complexes (Figure 15 and Table 2), Weller et al. reported that the methyl group in the complex trans-[Pt(Me) $\left.\left(\mathrm{PiPr}_{3}\right)_{2}\right]^{+} \mathbf{A} 7$ exhibits a ${ }^{2} J_{\mathrm{Pt}, \mathrm{H}}$ value of $106 \mathrm{~Hz}$. This value is almost identical to those reported for the NHC derivatives trans- $\left[\mathrm{Pt}(\mathrm{Me})(\mathrm{NHC})_{2}\right]^{+}\left(\mathrm{NHC}=\mathrm{IMes}^{*} \mathbf{T 4 a}\right.$, IMes T4b; 110 and $103 \mathrm{~Hz}$, respectively). The ${ }^{1} J_{\mathrm{Pt}, \mathrm{C}}$ is also very large for these methyl derivatives, ranging from 755 to $780 \mathrm{~Hz}$ (Table 2). Cyclometalated phosphine [39,40] and NHC $[28,44] \mathrm{Pt}(\mathrm{II})$ compounds were also shown to have very large ${ }^{2} J_{\mathrm{Pt}, \mathrm{H}}$ coupling constants (slightly larger than those for the noncyclometalated versions) spanning from $107 \mathrm{~Hz}$ to ca. $135 \mathrm{~Hz}$ (average) and ${ }^{1} J_{\mathrm{Pt}, \mathrm{C}}$ values between 805 and $975 \mathrm{~Hz}$.

\begin{tabular}{|c|c|c|c|}
\hline Complex & ${ }^{2} J_{\mathrm{Pt}, \mathrm{H}} / \mathrm{Hz}$ & ${ }^{1} J_{\mathrm{Pt}, \mathrm{C}} / \mathrm{Hz}$ & Reference \\
\hline A7 & 106 & 755 & [41] \\
\hline T4a & 103 & $-^{a}$ & [28] \\
\hline $\mathrm{T} 4 \mathrm{~b}$ & 110 & $-^{a}$ & [28] \\
\hline A10 & $-^{a}$ & 780 & [44] \\
\hline A5a & 109 & 840 & [39] \\
\hline A5b & 107 & 806 & [39] \\
\hline$A 5 c$ & 107 & $-^{a}$ & {$[40]$} \\
\hline $\mathrm{T} 5 \mathrm{a}$ & 132 (av.) & $-^{a}$ & [28] \\
\hline T5b & 135 & $-^{a}$ & [28] \\
\hline A11a & 113 (av.) & 860 & {$[44]$} \\
\hline A11b & 120 & 975 & [44] \\
\hline
\end{tabular}

aNot available.

In those cases where solvent molecules (THF, acetonitrile) have been reported to coordinate to some of the complexes shown in Figure 15 , smaller values of both the ${ }^{2} J_{\mathrm{Pt}, \mathrm{H}}$ and the ${ }^{1} J_{\mathrm{Pt}, \mathrm{C}}$ coupling constant are observed. For example, the ${ }^{2} J_{\mathrm{Pt}, \mathrm{H}}$ of the methyl ligand decreases to $98 \mathrm{~Hz}$ in the THF adduct of derivative A7, whereas the acetonitrile adduct of complex A11b 
<smiles>CC1CCP(C)(C(C)(C)C)([PH](C(C)C)(C(C)C)C(C)(C)C)C1C</smiles>

A7

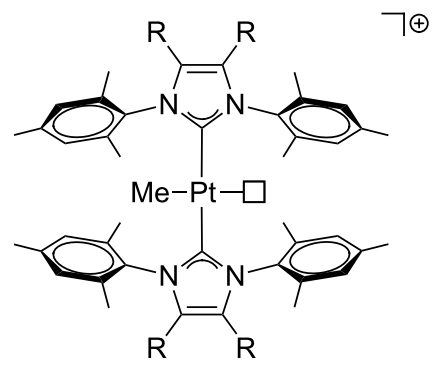

T4a: $R=M e$

T4b: $\quad H$

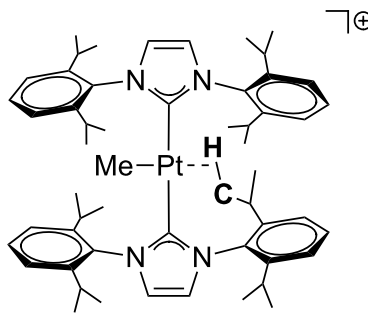

A10

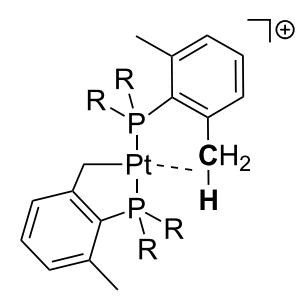

A5a: $R=P h$

A5b: $\quad$ Cy

A5c: $\quad i \mathrm{Pr}$

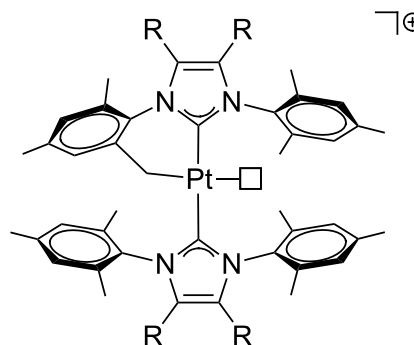

T5a: $R=M e$

T5b:

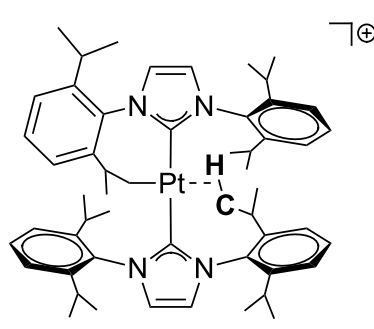

A11a<smiles></smiles>

A11b

Figure 15: The chemical formula of the complexes discussed in Table 2.

(A11b $\cdot \mathrm{NCMe}$ ) shows resonances for the $\mathrm{Pt}-\mathrm{CH}_{2}$ fragment with ${ }^{2} J_{\mathrm{Pt}, \mathrm{H}}$ and ${ }^{1} J_{\mathrm{Pt}, \mathrm{C}}$ values of 87 and $798 \mathrm{~Hz}$, respectively [28].

\section{Synthetic routes to stable, solvent-stabilized and transient 14-electron Pt(II) species} True and agostic T-shaped Pt(II) complexes

Several methods have been described to prepare coordinatively unsaturated Pt(II) complexes with a T-shaped geometry. Although the number of species that have been authenticated by crystallographic or spectroscopic methods is still very limited, the best and most general method for obtaining them is by removing a halogen ligand $(\mathrm{Cl}, \mathrm{Br}, \mathrm{I})$ from the platinum coordination center in $\mathbf{1}$ by using a halogen abstractor with a poor coordinating anion, such as tetrakis[3,5-(trifluoromethyl)phenyl]borate or hexafluoroantimonate (Scheme 1) [19$21,28,39,44]$.

This procedure has been successfully employed for the generation of complexes stabilized by two phosphine $\mathrm{PR}_{3}$ or two $\mathrm{NHC}$ ligands, in which the third coordination site is occupied by alkyl, hydride or boryl ligands. Therefore, high trans-influence ligands are present in all these cases, favoring the dissociation of the Pt-X bond. The generality of this method is so powerful that it has provided access to an intriguing dicationic borylene $\mathrm{Pt}(\mathrm{II})$ complex $\mathbf{T} 3$ which is not stabilized by agostic interactions (Scheme 2) [22].

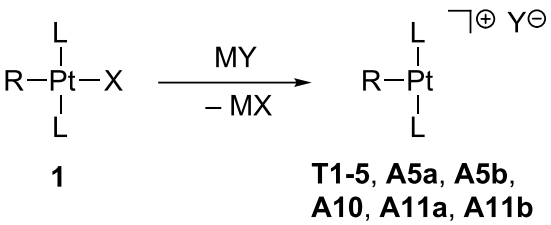

$$
\begin{aligned}
& \mathrm{MY}=\mathrm{NaBAr}^{\mathrm{F}}, \mathrm{AgSbF}_{6}, \mathrm{BF}_{4} \\
& \mathrm{~L}=\mathrm{PR}_{3}, \mathrm{NHC} \\
& \mathrm{R}=\text { alkyl, } \mathrm{H} \text {, boryl }
\end{aligned}
$$

Scheme 1: Halogen abstraction from 1.

[BArF]

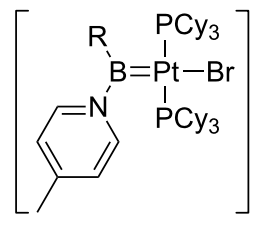

2

Scheme 2: Halogen abstraction from 2 forming the dicationic complex T3 [22]. 
A stable T-shaped structure trans- $\left[\mathrm{Pt}(\mathrm{Me})\left(\mathrm{PiPr}_{3}\right)_{2}\right]^{+}(\mathbf{A} 7)$ has also been generated [41] by methide abstraction from the neutral derivative cis-[Pt( $\left.\mathrm{Me})_{2}\left(\mathrm{PiPr}_{3}\right)_{2}\right]$ by using highly electrophilic Lewis acids such as $\mathrm{B}\left(\mathrm{C}_{6} \mathrm{~F}_{5}\right)_{3}$ or $\left[\mathrm{CPh}_{3}\right][1-\mathrm{H}-$ closo$\left.\mathrm{CB}_{11} \mathrm{Me}_{11}\right]$ (with the concomitant formation of $\mathrm{MeB}\left(\mathrm{C}_{6} \mathrm{~F}_{5}\right)_{3}{ }^{-}$or $\mathrm{MeCPh}_{3}$, respectively). This synthetic route uses the same procedure described by Goldberg et al. for the generation of a transient, neutral $\mathrm{Pt}(\mathrm{II})$ derivative $\left[\mathrm{Pt}(\mathrm{Me})\left(\kappa^{2}-\mathrm{Tp}^{\mathrm{Me} 2}\right)\right]$ from the anionic $\mathrm{Pt}(\mathrm{II})$ complex $\mathrm{K}\left[\mathrm{Pt}(\mathrm{Me})_{2}\left(\kappa^{2}-\mathrm{Tp}^{\mathrm{Me} 2}\right)\right]$ [95]. Alternatively, the cationic compound $\left[\mathrm{Pt}(\mathrm{Me})\left(\mathrm{PiPr}_{3}\right)_{2}\right]^{+}$was synthesized by homolytic cleavage of the $\mathrm{Pt}-\mathrm{Me}$ bond by using the neutral radical [1-H-closo- $\left.\mathrm{CB}_{11} \mathrm{Me}_{11}\right]^{\bullet}$ as a reagent.

$\mathrm{H}_{2}$ addition across $\mathrm{Pt}-\mathrm{C}_{\mathrm{alkyl}}$ bonds can also lead to electrondeficient $\mathrm{Pt}(\mathrm{II})$ species stabilized by agostic interactions. Baratta and co-workers studied the addition of $\mathrm{H}_{2}$ to preformed T-shaped Pt(II) complexes A5a,b to prepare Pt(II) hydrides A6a,b (Scheme 3) [39].<smiles>[R2][PH]1([R2])Cc2cccc(C)c2P1Cc1cccc(C)c1</smiles>

A5a: $\mathrm{R}=\mathrm{Ph}$

A5b: Cy

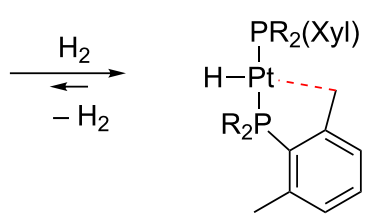

A6a: $R=P h$
Scheme 3: Hydrogenation of complexes A5a and A5b [39].

Alternatively, Carmona and co-workers have recently described that the hydrogenation of the 16-electron $\mathrm{Pt}(\mathrm{II})$ carbene 3 bearing a cyclometalated phosphine ligand (Scheme 4) resulted in the formation of the cyclometalated complex A5c, which can be further hydrogenated to give the Pt(II) hydride A6c [40], similar to those reported by Baratta [39].

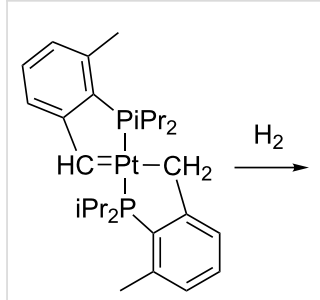

3<smiles>Cc1cccc(C)c1P(C)I</smiles><smiles>CCP1c2c(C)cccc2C[PH]1(CC)C(F)(F)F</smiles>

A5c

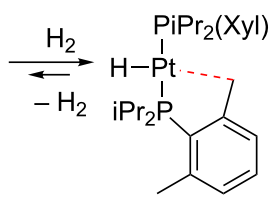

A6c
Scheme 4: Hydrogenation of complexes 3 and A5c [40].

Low electron-count species can also be prepared by $\mathrm{C}-\mathrm{H}$ bondactivation reactions from coordinatively unsaturated compounds in a way similar to the addition of $\mathrm{H}_{2}$ to $\mathrm{Pt}-\mathrm{C}_{\text {alkyl }}$ bonds mentioned above. The cyclometalated complex T5a shown in Scheme 5 reacts with aromatic compounds to yield the corresponding aryl complexes while keeping the unsaturated nature at the platinum atom. The complexes thus synthesized are not stabilized by agostic interactions according to spectroscopic (NMR), crystallographic and theoretical methods [28].

Spencer et al. reported that the formation of stable electron-deficient Pt(II) complexes stabilized by strong $\beta$-agostic interactions can be accessible by protonation of electron-rich alkene $\operatorname{Pt}(0)$ compounds 4 (Scheme 6) [35,36].

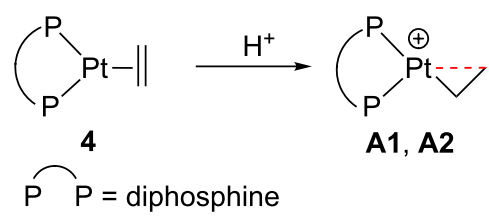

Scheme 6: Protonation of complexes $4[35,36]$.

Finally, Rourke et al. isolated a neutral Pt(II) derivative A9 by a direct and simple approach that involves a cyclometalation process of the 2-substituted bulky pyridine $\mathbf{5}$ when it is reacted with the platinum salt $\mathrm{K}_{2} \mathrm{PtCl}_{4}$ (Scheme 7) [43].
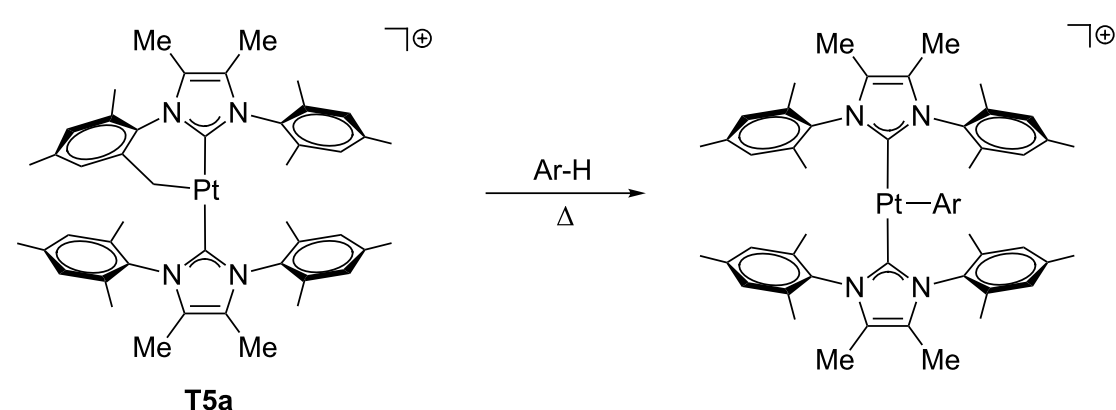
T6a: $\mathrm{Ar}=\mathrm{C}_{6} \mathrm{H}_{5}$
$m$-T6b: $\quad m-\mathrm{CH}_{3}-\mathrm{C}_{6} \mathrm{H}_{4}$
p-T6b: $\quad p-\mathrm{CH}_{3}-\mathrm{C}_{6} \mathrm{H}_{4}$
T6c: $\quad \mathrm{C}_{6} \mathrm{~F}_{5}$
T6d: $\quad p-\mathrm{C}_{6} \mathrm{HF}_{4}$


<smiles>CC(C)(C)c1cccc(-c2ccc(F)cc2)n1</smiles>

5

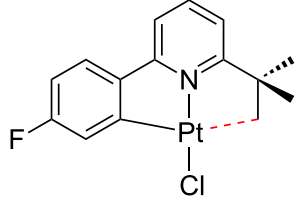

A9
Scheme 7: Cyclometalation of 5 [43].

\section{$\mathrm{Pt}(\mathrm{II})$ complexes stabilized by solvent molecules}

Although some of these compounds have been prepared by halogen [58] or methide [74] abstraction as described above, the vast majority of the $\mathrm{Pt}(\mathrm{II})$ derivatives stabilized by solvent molecules have been obtained by protonation of neutral alkyl, aryl or hydride $\mathrm{Pt}(\mathrm{II})$, as shown in Scheme 8 (see for example: [55,59,60,63,67,69,72,77-81]), or Pt(IV) complexes [96-98]. Nonetheless, this method has not yet been exploited for the preparation of true 14-electron species or agostic stabilized derivatives.

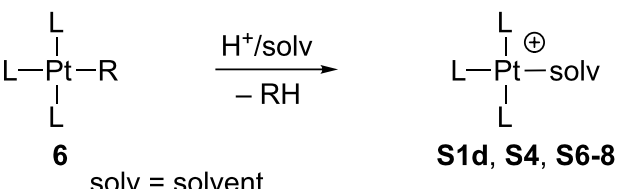

$$
\begin{aligned}
& \mathrm{R}=\text { alkyl, aryl, } \mathrm{H}
\end{aligned}
$$

Scheme 8: Protonation of 6

\section{Transient electron-deficient $\mathrm{Pt}(\mathrm{II})$ complexes from six- and five-coordinate Pt(IV) derivatives}

In some cases, transient, highly reactive 14-electron Pt(II) compounds have been generated by thermal decomposition of trimethyl, five-coordinate $\mathrm{Pt}(\mathrm{IV})$ complexes 7 . These latter compounds are in some cases sufficiently stable to be isolated and characterized by X-ray diffraction studies, but thermally unstable at moderate to high temperatures releasing ethane and a three-coordinate $\mathrm{Pt}(\mathrm{II})$ intermediate $\left[\mathrm{Pt}(\mathrm{Me}) \mathrm{L}_{2}\right]^{+}$(Scheme 9). The coordinatively unsaturated complexes $\left[\mathrm{Pt}(\mathrm{Me}) \mathrm{L}_{2}\right]^{+}$thus generated undergo subsequent reactivity with appropriate reagents [99-102].<smiles>C[Pb]1(C)NCCN1</smiles>

7

$$
\frac{\Delta}{-\mathrm{C}_{2} \mathrm{H}_{6}}
$$

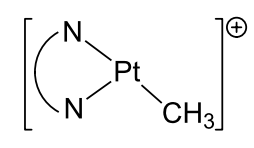

8
Scheme 9: Reductive elimination of ethane from 7.
Similarly, methane reductive elimination from $\mathrm{Pt}(\mathrm{IV})$ complexes $\left[\mathrm{PtH}(\mathrm{Me})(\mathrm{R})\left(\eta^{3}-\mathrm{N}_{3}\right)\right]^{n+} 9\left(\mathrm{R}=\mathrm{Me}, \mathrm{H} ; \mathrm{N}_{3}=\right.$ trispyridine[2.1.1]-(2,6)-pyridinophane or tris(pyrazolyl)borate; $n=$ $0,1)$ produces a transient three-coordinate $\mathrm{Pt}(\mathrm{II})$ complex $\left[\mathrm{Pt}(\mathrm{R})\left(\eta^{2}-\mathrm{N}_{3}\right)\right]^{n+} \mathbf{1 0}$ (Scheme 10$)$, which is able to activate $\mathrm{C}-\mathrm{H}$ bonds of hydrocarbons or form solvent adducts [103-105].

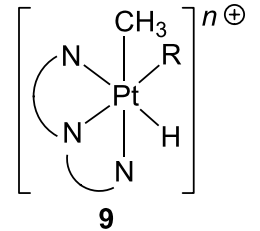

9

$$
\begin{gathered}
\underset{-\mathrm{CH}_{4}}{\stackrel{\Delta}{\longrightarrow}} \\
n=0,1
\end{gathered}
$$$$
\mathrm{R}=\mathrm{CH}_{3}, \mathrm{H}
$$<smiles>[R7]1CCN2CCN1CC2</smiles>

10
Scheme 10: Reductive elimination of methane from six-coordinate $\mathrm{Pt}(\mathrm{IV})$ complexes.

\section{Solution behavior}

In masked three-coordinate $\mathrm{d}^{8}$ complexes, the fourth coordination site is occupied by a weakly bound ligand, which can be easily displaced. In this way, in solution the ligands of these compounds are opened to conformational events that will be discussed in this section. The empty site can also be available for incoming substrates, allowing the participation of these complexes as reaction intermediates. This aspect will be discussed in the next section.

Most of the reports of fluxional processes correspond to agostic bonded complexes. The equivalence of ${ }^{1} \mathrm{H}$ and ${ }^{13} \mathrm{C}$ chemical shifts observed in solution for the $\gamma$-, $\delta$ - and remote-agostic contacts is a common feature of the complexes collected in Figure 15 and arises from the rapid intramolecular exchange of the $\mathrm{C}-\mathrm{H}$ bond involved in the agostic interaction. In several cases, such as A11a [44], the overlapping of the proton signals and signal averaging of the ligands avoid drawing a conclusion about the nature of the agostic interaction at work in solution. Recently, ab initio molecular dynamics (AIMD) simulations of some representative T-shaped $\mathrm{Pt}(\mathrm{II})$ complexes (T5b, A2b and A11a), performed in explicit dichloromethane solvent, have provided a detailed description of the mechanism by which the equivalence of signals takes place [106]. Simulations showed that the dynamics of the agostic interaction in solution strongly depends on the complex. Contingent upon the strength of the agostic interaction and the flexibility of the ligand, several events related with the occupation of the fourth coordination site by an agostic bond could happen: (i) the same $\mathrm{C}-\mathrm{H}$ bond maintains the agostic interaction with the platinum atom for the entire simulation (A2b); (ii) an agostic interaction is present throughout the simulation, though the $\mathrm{C}-\mathrm{H}$ bond changes by a rotation of alkyl groups (A11b); (iii) the agostic interaction moves on and off (A11a) [106]. 
There are indirect evidences that agostic bonds, solvent and weakly coordinating counteranions could easily exchange their role of stabilizing the unsaturated complex by placement at the vacant site. Although no kinetic studies on exchanges of these kinds of ligands have been reported, the detection of the agostic and solvent complexes for the same system and, for pincer complexes, of the counteranion and solvent forms, suggests that the exchange can take place. For instance, in trans$\left[\mathrm{Pt}(\mathrm{Me})\left(\mathrm{PiPr}_{3}\right)_{2}\right]^{+}(\mathbf{A} 7)$ a $\gamma$-agostic interaction can be displaced by addition of THF, forming the corresponding adduct [41]. NMR data in $\mathrm{CD}_{3} \mathrm{CN}$ of the triflate complex [Pt(BQA)(OTf)] (C4a) leads to its formulation as $\left[\mathrm{Pt}(\mathrm{BQA})\left(\mathrm{NCCD}_{3}\right)\right][\mathrm{OTf}]$ (S12) [50]. Similar behavior has been observed for other pincer complexes. The naphthyl-based PCP-Pt(II) complex was found in THF as a 1:2 mixture of the counteranion $\left(\mathrm{BF}_{4}{ }^{-}, \mathbf{C 8}\right)$ and solvent (S17) forms [53].

Energetically accessible T-shaped species can also be intermediates in the site exchange of bidentate ligands of squareplanar complexes. Fluxional motions of the 2,9-dimethyl-1,10phenanthroline ligand (dmphen) have been observed in cationic complexes as $[\mathrm{Pt}(\mathrm{Me})(\mathrm{NN})(\mathrm{L})]^{+}\left(\mathrm{NN}=\right.$ dmphen; $\mathrm{L}=\mathrm{SOR}\left(\mathrm{R}^{\prime}\right)$, $\mathrm{PR}_{3}$ ) [107-111]. The driving force of these flipping processes is the distortion of the dmphen ligand with respect to the coordination plane, which is caused by the methyl groups. Indeed, the fluxional motion is not detected when the unhindered 1,10phenanthroline ligand is used. Interestingly, the mechanism can be switchable between associative and dissociative [107-109]. For the latter scenario, 14-electron T-shaped species involving phosphine ligands can be envisaged as feasible intermediates. The dissociative pathway fully prevails when overcrowded $\mathrm{PR}_{3}$ ligands are employed, where R stands for $o$-methoxyphenyl 11 [110] and $o$-tolyl 12 [111]. The detailed mechanism (Scheme 11) is described as follows: (i) dissociative nitrogen decomplexation, (ii) isomerization between two nonequivalent exchanging sites, and (iii) nitrogen coordination recovering the initial chelating situation. The fluxional motion of dmphen is not affected by the counteranion, solvent, or the presence of weak nucleophiles deliberately added. In addition, for 11a and 12a both flipping of dmphen and phosphine rotation motions are synchronized, behaving as molecular gears. The calculated activation barriers are ca. 13.3 and $16.4 \mathrm{kcal} \mathrm{mol}^{-1}$ for the motions involving 11 and $\mathbf{1 2}$, respectively.

Concerning 14-electron intermediates $\mathbf{b}$ and $\mathbf{b}$ ', the assistance of methoxy groups in $\mathbf{1 1} \mathbf{b}, \mathbf{b}$ ' [110] as well as the presence of agostic interactions in $\mathbf{1 2 b}, \mathbf{b}$ ' [111] can be postulated (Figure 16). Indeed, 12a easily undergoes a cyclometalation process, probably assisted by an agostic contact via intermediate $\mathbf{1 2 b}$.<smiles></smiles>

$\mathrm{R}=$ o-methoxyphenyl<smiles>[R][Te]1(N)c2ccccc2[C]P1([R])([R])C</smiles>

$\mathrm{R}=\mathrm{o}$-tolyl
$\mathrm{NN}=$ dmphen

Figure 16: Feasible interactions for unsaturated intermediates 11b (left) and 12b (right) during fluxional motions [110,111].<smiles>[R][PH]([R])([Y10])[PH]1(C)N2CN[N+]21C</smiles><smiles>[C-]#CC=C</smiles>

(iii)<smiles>[R][PH]([R])([Y16])[Pb][NH2+]CN</smiles>

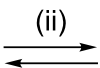

$1 c^{\prime}$<smiles>[R][PH]([R])([Z])P(C)[NH+]([NH-])C[NH3+]</smiles>
$11 b$ $12 b$<smiles>[R][PH]([R])([R])[Pb](C)NCC</smiles>

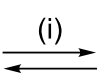

(i) N-dissociation

(ii) isomerization

(iii) N-coordination<smiles>[R][P+](C)(NC[NH3+])[PH]([R])([R])[Y10]</smiles>

(iii)<smiles>[R][PH]([R])([R])[PH]1(C)[N]CN1</smiles><smiles>Cc1ccc2ccc3ccc(C)nc3c2n1</smiles>

11: $R=o-$ methoxyphenyl

12: $R=o$-tolyl 


\section{Three-coordinate $\mathrm{Pt}(\mathrm{II})$ species as reaction intermediates}

Coordinatively unsaturated Pt(II) species are considered as intermediates in many organometallic processes. Early studies by Whitesides and co-workers dealing with the thermal decomposition of $\left[\mathrm{Pt}(\mathrm{R})_{2} \mathrm{~L}_{2}\right]$ complexes demonstrated that the dissociation of a phosphine ligand is a preliminary requisite for the reaction to occur [112]. Since then, T-shaped three-coordinate 14-electron intermediates have been proposed in a large number of reaction mechanisms. A review concerning dissociative pathways in $\mathrm{Pt}(\mathrm{II})$ complexes was published in 1990 [113].

Due to both the low electron count and the presence of a vacant site in the coordination sphere, T-shaped Pt(II) species are suitable intermediates in ligand-exchange and bond-breaking processes of unreactive bonds, such as $\mathrm{C}-\mathrm{H}$ bond activations. A selection of results from the past few years regarding these two issues are collected in this section to illustrate the growing importance of three-coordinate $\mathrm{Pt}(\mathrm{II})$ species as reaction intermediates.

\section{Intramolecular $\mathrm{C}-\mathrm{H}$ bond activation}

Intramolecular $\mathrm{C}-\mathrm{H}$ bond activation is a common reaction of unsaturated $\mathrm{Pt}(\mathrm{II})$ complexes. Cyclometalation processes, sometimes involving agostic situations [114], have been thoroughly reviewed recently [115].

According to Baratta and co-workers, the abstraction of $\mathrm{Cl}$ from 13a,b with $\mathrm{Na}\left[\mathrm{BAr}{ }^{\mathrm{F}}\right]$ directly generates the cyclometalated products A5a,b and methane (Scheme 12) [39]. Unsaturated intermediates such as $\left[\mathrm{Pt}(\mathrm{Me})\left(\mathrm{PR}_{3}\right)_{2}\right]^{+}$, probably stabilized by agostic contacts, might be considered.

Weller et al. reported some reactivity features of complex A7 [41]. Although it shows an agostic interaction, no cyclometalation via $\mathrm{C}-\mathrm{H}$ bond activation is observed in $\mathrm{CD}_{2} \mathrm{Cl}_{2}\left(40{ }^{\circ} \mathrm{C}\right.$, 7 days). However, the addition of THF rapidly traps the T-shaped complex forming the adduct 14 (Scheme 13). This species does undergo cyclometalation in the presence of trace

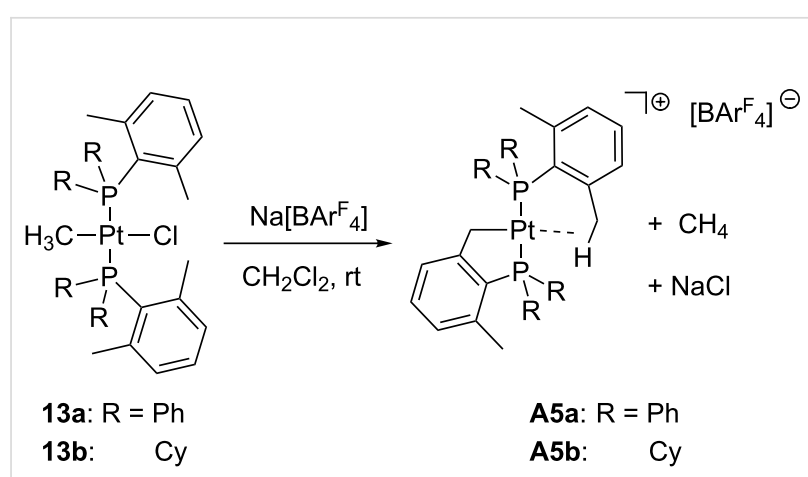

Scheme 12: Halogen abstraction from 13a,b and subsequent cyclometalation to yield complexes A5a,b [39].

amounts of acids to yield 16 [116]. The unsaturated agostic species $\mathbf{1 5}$ has been proposed as a reaction intermediate.

Goldberg and co-workers put forward the participation of T-shaped Pt(II) species in processes, implying the five-coordinate Pt(IV) complex 7a (Scheme 14) [102]. This compound undergoes reductive elimination in benzene- $d_{6}$ solvent with the concomitant formation of ethane. The resulting three-coordinate 8a is supposed to be stabilized by an agostic interaction or solvent coordination. Indeed, two possible scenarios related to these interactions are envisaged. Firstly, 8a evolves to 17 through a cyclometalation process ((i) in Scheme 14) which involves one $t$ - $\mathrm{Bu}$ group of the bidentate ligand. On the other hand, 8a can also activate the C-D bonds of benzene- $d_{6}$ molecules forming 18 ((ii) in Scheme 14). Since both 17 and 18 exhibit potential empty coordination sites, benzene activation from $\mathbf{1 7}$ and cyclometalation from $\mathbf{1 8}$ are plausible scenarios. Nevertheless, the three-coordinate intermediate $\mathbf{1 7}$ is not isolable and reacts further with a molecule of the starting material 7a leading to the dinuclear species 19. The inclusion of deuterium atoms in the $t$ - $\mathrm{Bu}$ groups of 19 suggests that both intra- and intermolecular $\mathrm{C}-\mathrm{H}$ bond activations are competitive pathways. The transient formation of derivative 17 was confirmed by trapping experiments with ethylene.

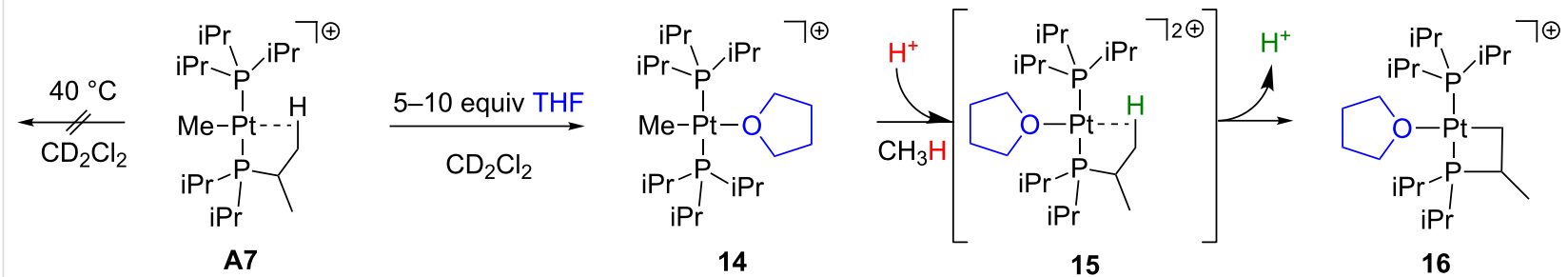




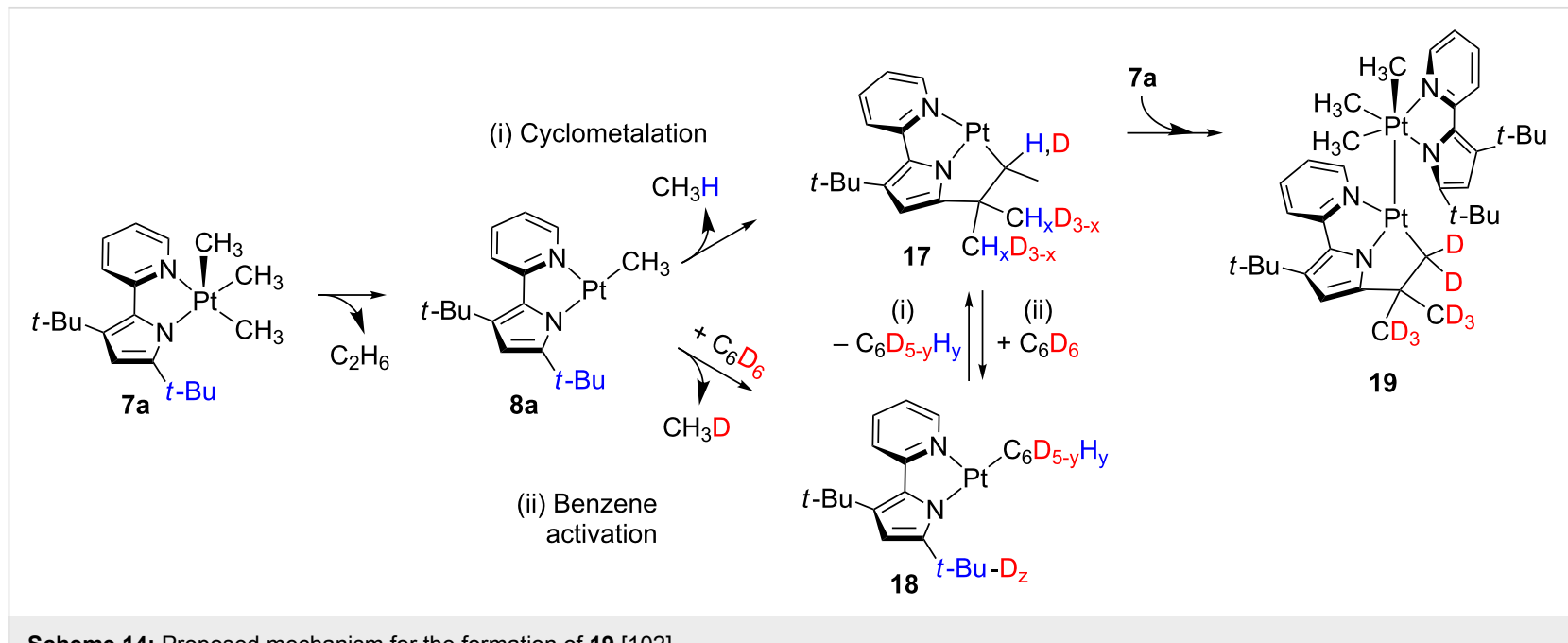

Scheme 14: Proposed mechanism for the formation of 19 [102].

Examples of cyclometalation processes preceded by ligand dissociation have been described by Romeo and co-workers $[111,117,118]$. For instance, $\left[\mathrm{Pt}_{2}(\mathrm{Hbph})_{4}\left(\mu-\mathrm{SEt}_{2}\right)_{2}\right] \mathbf{2 0}(\mathrm{Hbph}=$ $\eta^{1}$-biphenyl monoanion) undergoes cyclometalation to form $\left[\mathrm{Pt}_{2}(\mathrm{bph})_{2}\left(\mu-\mathrm{SEt}_{2}\right)_{2}\right] 22$ and biphenyl $\mathrm{H}_{2} \mathrm{bph}$ (Scheme 15) [117]. Intramolecular $\mathrm{C}-\mathrm{H}$ bond activation seems to be driven by thioether dissociation via $\mathbf{2 1}$, a process previously reported for the complex $\left[\mathrm{Pt}_{2}(\mathrm{Me})_{4}\left(\mu-\mathrm{SMe}_{2}\right)_{2}\right]$ [119].

Marrone et al. computed the cyclometalation process of $\left[\mathrm{Pt}(\mathrm{Me})_{2}\left(\mathrm{PR}_{3}\right)(\mathrm{DMSO})\right] 23$ to yield $\left[\mathrm{Pt}(\mathrm{Me})\left(\mathrm{PR}_{2} \mathrm{R}^{\prime}\right)(\mathrm{DMSO})\right]$ $28\left(\mathrm{R}=o\right.$-tolyl, $\mathrm{R}^{\prime}=$ cyclometalated group; $\mathrm{DMSO}=$ dimethylsulfoxide) [120] as experimentally reported in [118]. They demonstrated that the reaction involves coordinatively unsaturated 14-electron T-shaped complexes through (i) DMSO dissociation, (ii) $\mathrm{C}-\mathrm{H}$ bond activation, (iii) methane release, and (iv) DMSO association (Figure 17). Starting from 23, initial ligand dissociation generates the T-shaped intermediate $\mathbf{2 4}$, in which one $o$-tolyl group of the phosphine ligand establishes an agostic interaction with the platinum center. This agostic interaction weakens the $\mathrm{C}-\mathrm{H}$ bond inducing an oxidative-addition (OA) process. The resulting five-coordinate $\mathrm{Pt}(\mathrm{IV})$ hydride complex
25 , located at $26.0 \mathrm{kcal} \mathrm{mol}^{-1}$ above reactants, quickly undergoes reductive elimination (RE) providing the methane adduct 26. After methane releasing, the cyclometalated $T$-shaped structure 27 is obtained, once again stabilized by an agostic interaction. The corresponding transition states for $\mathrm{OA}$ and $\mathrm{RE}$ processes are isoenergetic with respect to 25 . Finally, the agostic coordination mode in $\mathbf{2 7}$ is displaced by a DMSO molecule forming the cyclometalated product $\mathbf{2 8}$. Moreover, they showed that the reaction mechanism starting from the four-coordinate 16-electron complex $\mathbf{2 3}$ does not provide low-energy paths for OA, demonstrating the kinetic inertness of these types of compounds.

Three-coordinate species have been invoked by Nolan and co-workers to account for the reaction of cis- $\left[\mathrm{Pt}\left(\mathrm{NO}_{3}\right)_{2} \mathrm{~L}_{2}\right] 29$ with tetramethylthiourea (tmtu) (Scheme 16) [121]. The sulfur atom of tmtu displaces one nitrate ligand of $\mathbf{2 9}$ forming $\mathbf{3 0}$, which eventually evolves to the cyclometalated product $\mathbf{3 3}$ via $\mathrm{C}-\mathrm{H}$ bond activation. The increase of nitrate concentration as well as the addition of coordinating agents, such as triethylamine and triphenylphosphine, clearly retard the process. Therefore, a dissociative mechanism has been proposed to

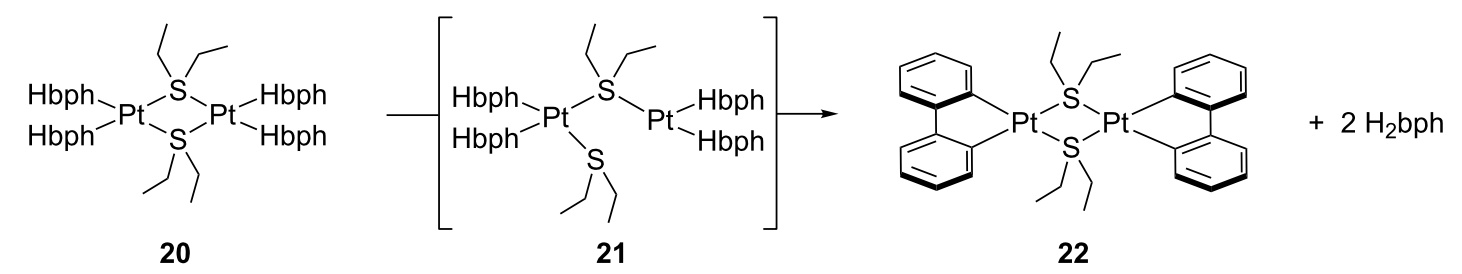



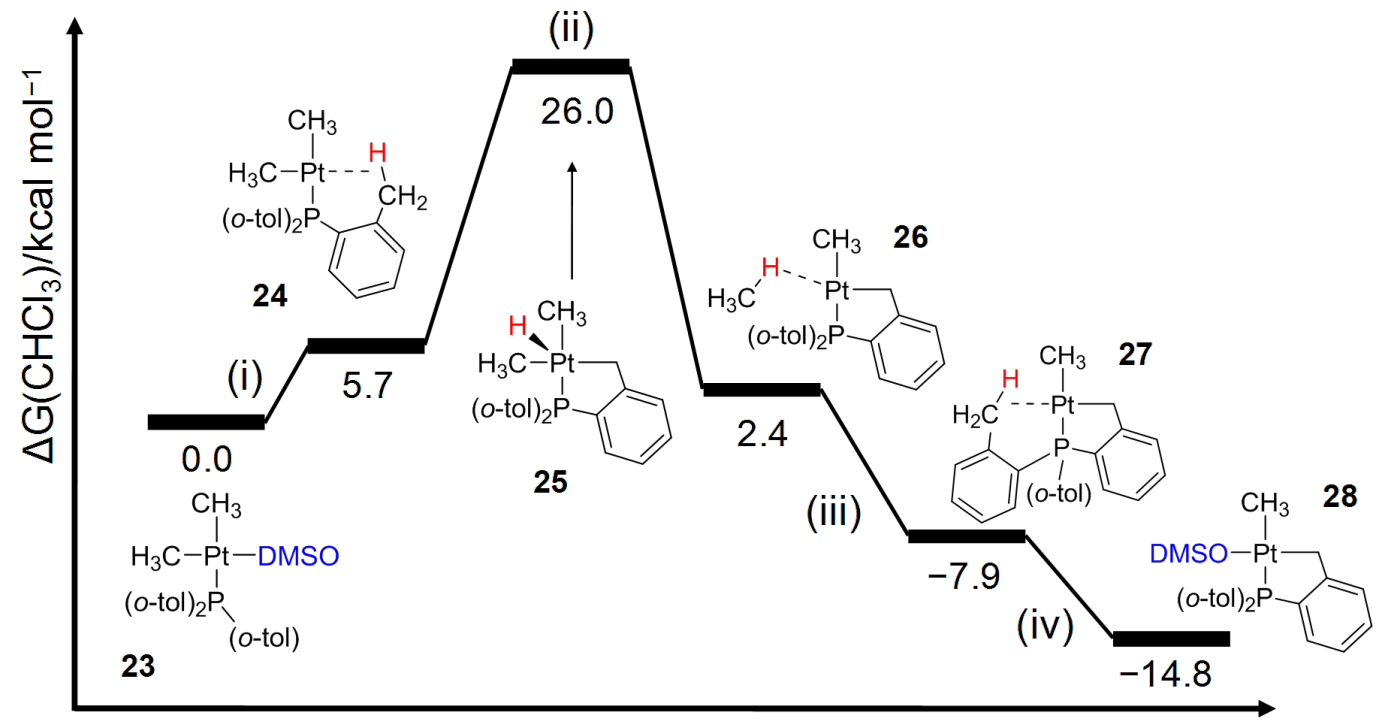

Reaction coordinate

Figure 17: Gibbs energy profile (in chloroform solvent) for the cyclometalation of 23 [120].

$$
\begin{aligned}
& \mathrm{L}^{-} \mathrm{Pt}^{-}-\mathrm{ONO}_{2} \\
& \overbrace{\mathrm{NO}_{3}^{\ominus}}^{29}
\end{aligned}
$$<smiles></smiles>

30

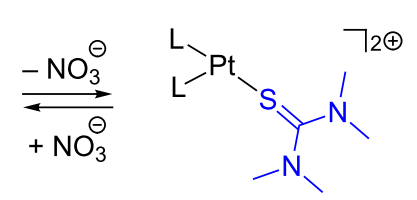

31

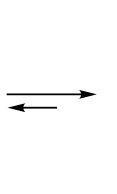<smiles>[3H][P]1([3H])CN(C)C(N(C)C)=[SH]1</smiles>

32

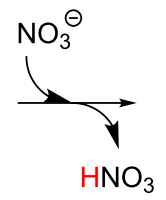<smiles>[3H][PH]1([Tl])CN(C)C(N(C)C)=[SH]1</smiles>

33

Scheme 16: Coordination of tmtu to 29 and subsequent C-H bond activation via three-coordinate species 31 and 32 [121].

generate the unsaturated species 31. Then, one methyl group of the coordinated tmtu can stabilize the open coordination site via agostic interaction, 32, inducing an intramolecular $\mathrm{C}-\mathrm{H}$ bond activation process to yield $\mathbf{3 3}$. It was also observed that less $\sigma$-donor phosphine ligands increase the reaction rate. Less-electron-donating ligands may not stabilize 31, favoring an agostic contact in 32, which, consequently, accelerates the cyclometalation reaction. Indeed, the presence of stronger $\sigma$-donors such as ICy ligand (1,3-biscyclohexylimidazol-2-ylidene) inhibits the process.

T-shaped Pt(II) complexes bearing NHC ligands can be prepared starting from the pertinent iodo-precursors by halide removal (Scheme 17) [44]. For IPr [44], IMes* and IMes

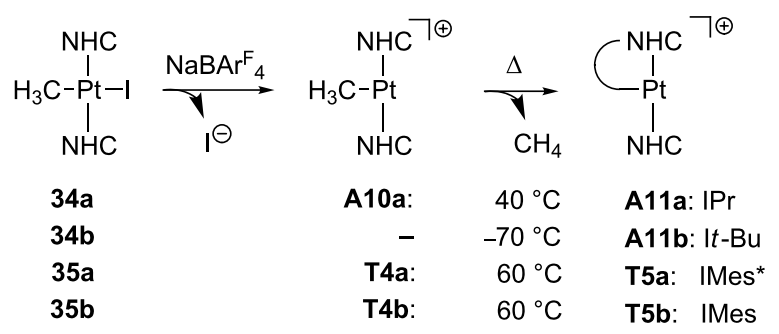

Scheme 17: Cyclometalation process of $\mathrm{NHC}$-based $\mathrm{Pt}(\mathrm{II})$ complexes $[28,44]$. 


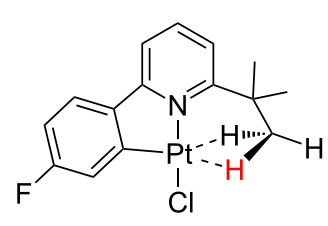

A9<smiles>CC(C)C[P+]1(Cl)CC(C)(C)c2cccc(c2)-c2ccc(F)cc21</smiles>

36

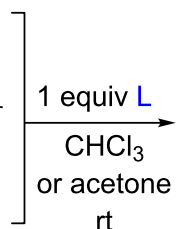<smiles></smiles>

37a: $L=$ DMSO

37b: $\quad \mathrm{PPh}_{3}$

37c: pyridine

Scheme 18: Cyclometalation process of complex A9 [43].

ligands [28], the corresponding methyl complexes A10a and $\mathbf{T} 4 \mathbf{a}, \mathbf{b}$ can be isolated. Interestingly, cyclometalation involving a methyl group of the carbene arm was observed upon heating these methyl derivatives. It is noteworthy that the process barely depends on the nature of the fourth coordination site, either agostic A10a or pure empty site T4a,b. In the case of $\mathrm{I} t-\mathrm{Bu}$ ligand [44], a similar cyclometalation reaction is observed even at low temperatures $\left(-70^{\circ} \mathrm{C}\right)$, but the putative methyl intermediate could not be detected.

The agostic complex A9 can exchange the site of cyclometalation by $\mathrm{C}\left(\mathrm{sp}^{3}\right)-\mathrm{H}$ bond activation (Scheme 18) [43]. The addition of one equivalent of $\mathrm{L}$ ( $\mathrm{L}=\mathrm{DMSO}, \mathrm{PPh}_{3}$ or pyridine) to A9 in chloroform or acetone at room temperature yields the products $\mathbf{3 7}$, in which one methyl group (previously agostic) has been cyclometalated, and $\mathrm{L}$ has entered into the coordination sphere of the platinum atom. The authors reasonably propose a $\sigma$-bond metathesis $(\sigma-\mathrm{CAM})$ mechanism via intermediate $\mathbf{3 6}$ invoking the well-known capacity of agostic interactions to facilitate the $\mathrm{C}-\mathrm{H}$ bond cleavage.

The "rollover" process is a class of cyclometalation, in which a heteroaryl ligand undergoes decoordination and bond-rotation processes prior to $\mathrm{C}-\mathrm{H}$ bond activation. A recent review on this topic collects the most important features of this reaction [122]. Early work by Young and co-workers [123] proposes the formation of coordinately unsaturated species 39 and 39' as intermediates in the "rollover" reactions of $\mathbf{3 8}$, leading to polymeric species (Scheme 19).

Zucca and co-workers reported the synthesis of several cyclometalated compounds $\mathbf{4 4}$ by means of substitution and "rollover" processes (Scheme 20) [124]. Starting from derivative 41, DMSO displacement by 6-substituted 2,2'-bipyridines<smiles></smiles>

38

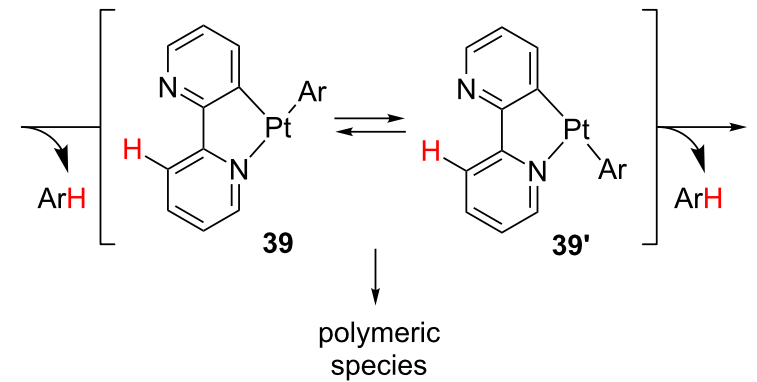

39

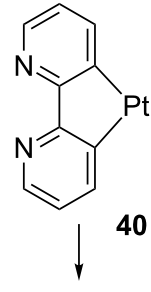

polymeric species

Scheme 19: "Rollover" reaction of $\mathbf{3 8}$ and subsequent oligomerization [123].<smiles>CC(C)CN=N</smiles>

41<smiles>[R]C1=CC=CC2=C3C=CC=CN3[P+](C)(C)N12</smiles>

42
+2 DMSO

$\mathrm{R}=$ alkyl, phenyl<smiles></smiles>

43<smiles></smiles>

44 
<smiles></smiles>

$\left[\mathrm{Pt}\left(\mathrm{CH}_{3}\right)(N, \mathrm{C}, \mathrm{N}-\mathrm{NPA})\right]_{4}$ 50

NPA $=N-(2 '-$ pyridyl) -7 -azaindole $N, C, N-N P A=$ cyclometalated NPA

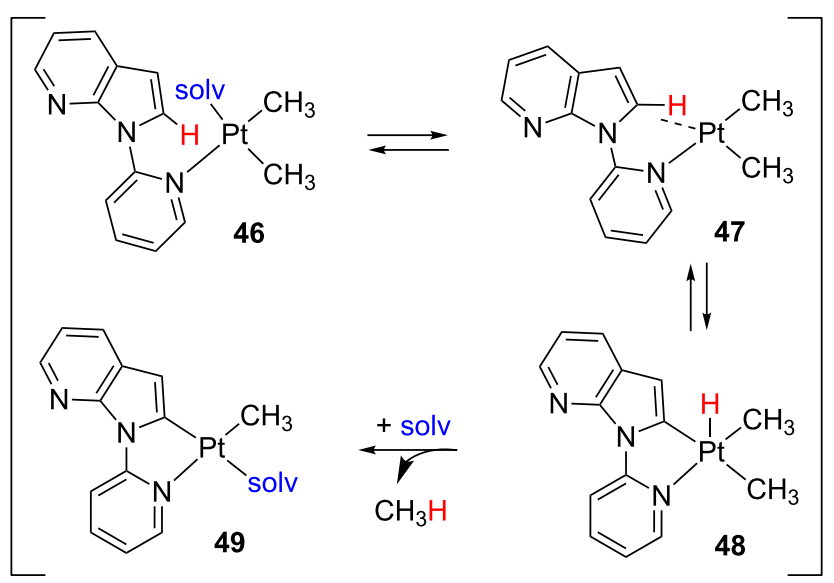

solv $=\mathrm{THF}, \mathrm{CH}_{2} \mathrm{Cl}_{2}$, benzene

Scheme 21: Self-assembling process of $\mathbf{4 5}$ by "rollover" reaction [126]

(NN ligands) yields the corresponding bidentate derivatives $\mathbf{4 2}$. Due to the steric congestion between the R group of the bipyridine and the methyl ligand $\mathbf{4 2}$ becomes unstable promoting the decoordination of the nitrogen atom. Subsequent $\mathrm{C}-\mathrm{H}$ bond activation is proposed to take place through an agostic intermediate 43 generated by rotation around the $2,2^{\prime}-\mathrm{C}-\mathrm{C}$ bond of the bipyridine ligand. After the release of methane, the vacant site is easily occupied by one DMSO ligand yielding $\mathbf{4 4}$. Interestingly, from $44(\mathrm{R}=t-\mathrm{Bu}, \mathrm{Ph})$ the corresponding hydride compounds can be prepared [125]. It is worth pointing out that, depending on the ligand present in solution, both 16-electron and 14-electron species are obtained, though the latter are not stable, and only oligomers with bridging hydrides can be detected [125].

Wang and co-workers disclosed the spontaneous self-assembling of $\left[\mathrm{Pt}(\mathrm{Me})_{2}(\mathrm{NPA})\right] \mathbf{4 5}$ by a "rollover" cyclometalation process (Scheme 21) [126]. The suggested mechanism begins with a $\mathrm{C}-\mathrm{N}$ bond rotation by chelating ligand dissociation forming species $\mathbf{4 6}$, which is stabilized by solvent coordination. Eventually, an agostic interaction in $\mathbf{4 7}$ prior to the rate-determining $\mathrm{C}-\mathrm{H}$ bond cleavage should displace the solvent molecule. An oxidative addition and reductive elimination (OA/RE) scenario via hydride Pt(IV) $\mathbf{4 8}$ and subsequent methane release yield the corresponding solvent adduct $\mathbf{4 9}$, from which selfassociation generates the cyclic tetramer 50. Indeed, when good coordinating agents such as acetonitrile are added, the reaction slows down.

A "rollover" process has been observed for the already cyclometalated compound A9 in DMSO providing two zwitterionic products, cis- and trans-51 (Scheme 22) [127]. On the other hand, by switching the DMSO solvent to the less polar chloroform the expected cyclometalated product 37 a (Scheme 18) is obtained. DFT calculations correctly explain the relative stabilities

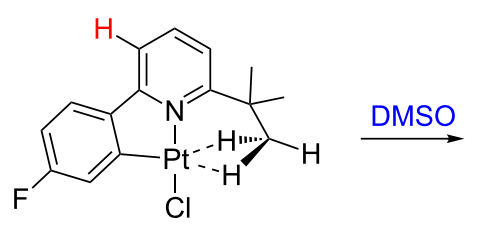

A9<smiles></smiles>

cis- 51

$E(D M S O)=-1.4$

$\mathrm{E}\left(\mathrm{CHCl}_{3}\right)=+2.6$

Scheme 22: "Rollover" reaction of $\mathbf{A} 9$. Energies (solvent) in $\mathrm{kcal} \mathrm{mol}^{-1}$ [127] 


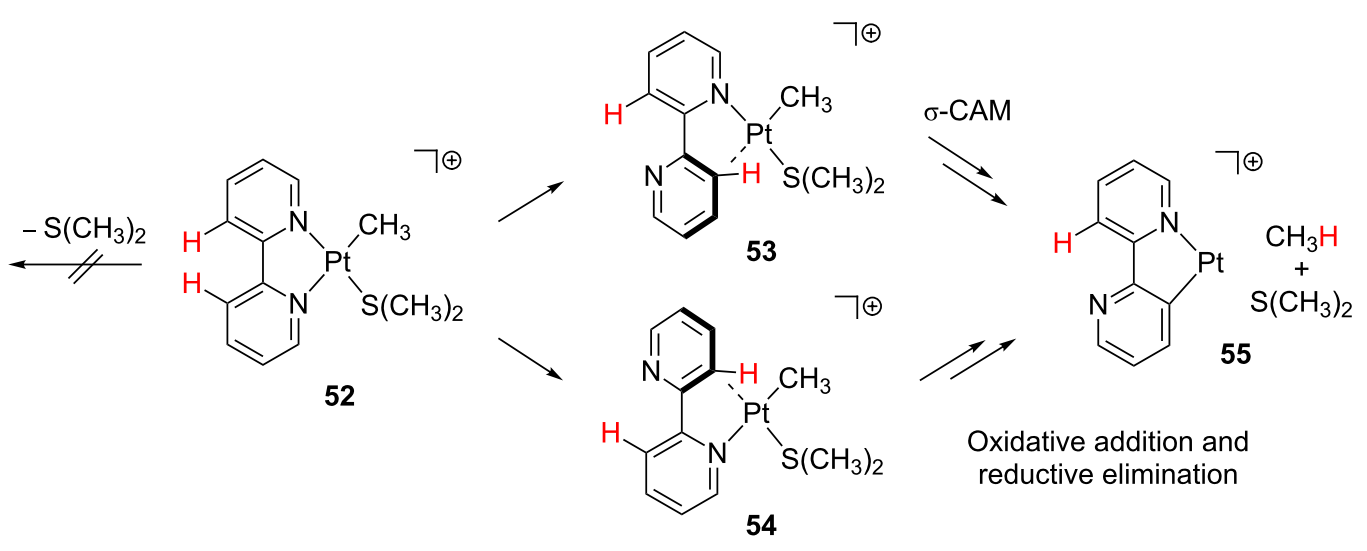

Scheme 23: Proposed mechanisms for the "rollover" cyclometalation of $\mathbf{5 2}$ in gas-phase ion-molecule reactions [128].

of 51 with respect to 37 a depending on the polarity of the solvent [127].

This kind of reactivity has also attracted attention in gas-phase conditions [122]. The gas-phase behavior of cationic species $\mathbf{5 2}$ has been analyzed by means of combined experimental and computational studies (Scheme 23) [128]. DFT calculations discourage the initial loss of dimethylsulfide. Instead, decomplexation and $\mathrm{C}-\mathrm{C}$ bond rotation processes starting from the four-coordinate complex $\mathbf{5 2}$ are favored. The resulting isomeric compounds exhibit an empty coordination site that is filled by an agostic interaction prior to the $\mathrm{C}-\mathrm{H}$ bond activation. Intermediate 53 evolves through a $\sigma$-CAM process, whereas intermediate $\mathbf{5 4}$ undergoes oxidative addition and reductive elimination processes. The release of methane and dimethylsulfide yields 55. Further studies including labeling experiments support the reversibility of these "rollover" reactions. The highly unsaturated species $\mathbf{5 5}$ is still reactive and can coordinate and decompose $\mathrm{XMe}_{2}$ molecules $(\mathrm{X}=\mathrm{S}$ [128] and $\mathrm{O}$ [129]) and dehydrogenate alkanes [130]. Finally, other cyclometalation processes including "rollover" reactions have also been observed for the complex $\left[\mathrm{Pt}(\mathrm{Me}) \mathrm{L}\left(\mathrm{SMe}_{2}\right)\right]$ bearing a diimine ligand instead of the ubiquitous bipyridyl backbone [131].

\section{$\beta-\mathrm{H}$ elimination}

As previously noted, the agostic complexes A1-4 (Figure 7) are in equilibrium with the hydrido-alkene isomers [34-38]. Experimental evidence points out that substituted alkyls and large chelate ring-size diphosphine ligands favor the $\beta$-agostic isomer. As a representative example, Scheme 24 shows the $\beta-\mathrm{H}$ elimination for A1d together with the reverse 1,2-insertion for 56. Interestingly, upon crystallization in dichloromethane solvent, A1d eliminates norbornene from 56 and generates the dinuclear complex 57 [35]. The presence of chloride as a bridging ligand suggests that solvent molecules are involved in the reaction. Therefore, the participation of T-shaped intermediates, probably stabilized as solvento adducts, might be relevant in the overall process.

Although $\beta$-elimination should be easily accomplished, Goldberg and co-workers realized that other reactions can compete. The thermolysis of five-coordinate $\mathrm{Pt}(\mathrm{IV})$ complexes 7 containing nacnac ([ $\{(o-$ $\left.\left.\left.\left.{ }_{i P_{2}} \mathrm{C}_{6} \mathrm{H}_{3}\right) \mathrm{NC}\left(\mathrm{CH}_{3}\right)\right\}_{2} \mathrm{CH}\right]^{-}, 7 \mathbf{b}\right)[99,101]$ and AnIM $\left(\left[o-\mathrm{C}_{6} \mathrm{H}_{4}-\right.\right.$ $\left.\left.\left\{\mathrm{N}\left(\mathrm{C}_{6} \mathrm{H}_{3} \mathrm{PPr}_{2}\right)\right\}\left(\mathrm{CH}=\mathrm{NC}_{6} \mathrm{H}_{3} \mathrm{iPr}_{2}\right)\right]^{-}, 7 \mathbf{c}\right)$ [101] ligands produces D-59 in benzene- $d_{6}$ (Scheme 25). The first step in this reaction seems to be the direct reductive elimination of 7 liberating ethane. The resulting intermediate $\mathbf{8}$ undergoes cyclometalation

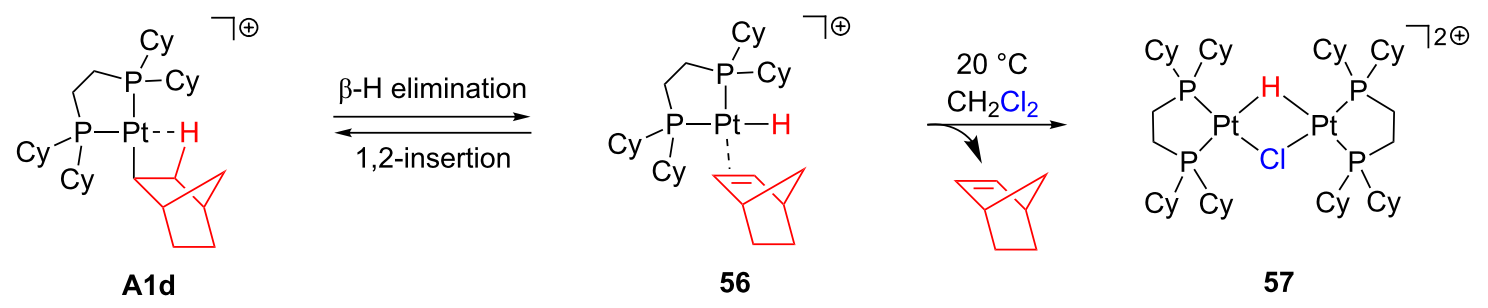

Scheme 24: $\beta$ - $\mathrm{H}$ elimination and 1,2-insertion equilibrium involving A1d and the subsequent generation of $\mathbf{5 7}$ [35]. 


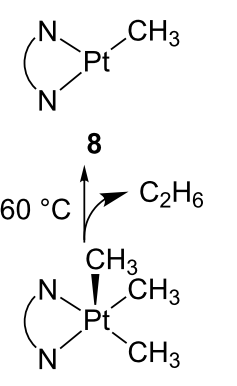

7

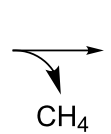

$\mathrm{CH}_{4}$<smiles>C1CN2CCP(C2)N1</smiles>

58

$-R-D \uparrow+R-D$<smiles></smiles>

60

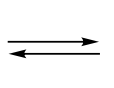

59

$\mathrm{R}=\mathrm{C}_{6} \mathrm{D}_{5}, \mathrm{C}_{6} \mathrm{D}_{11}$<smiles>C1CN2CCN(C1)P2</smiles><smiles>CC(C)c1cccc(C(C)C)c1NC(=CC(C)C(C)C)Nc1c(C(C)C)cccc1C(C)C</smiles>

nacnac

b<smiles>CC(C)c1cccc(C(C)C)c1N=Cc1cccc(C(C)C)c1Nc1c(C(C)C)cccc1C(C)C</smiles>

AnIm

Scheme 25: Proposed mechanism for thermolysis of $7 \mathbf{b}$ and $7 \mathbf{c}$ in benzene- $d_{6}$ and cyclohexane- $d_{12}$ solvents [101].

to give the complex $\mathbf{5 8}$. The subsequent $\beta$-H elimination process shall provide the expected hydride complex 59. However, solvent molecules come into play, so that the unsaturated intermediate 58 activates the C-D bond of benzene- $d_{6}$ forming $\mathbf{6 0}$. Cyclometalation and subsequent $\beta-\mathrm{H}$ elimination processes generate D-59, which has fully incorporated the corresponding deuterium atoms. This latter evidence suggests that the intermolecular C-D bond activation of benzene- $d_{6}$ is indeed faster than the $\beta$-elimination. On the other hand, when the reaction is conducted in a cyclohexane- $d_{12}$ solution, D-59 is hardly obtained and $\mathbf{5 9}$ prevails. It means that, in sharp contrast to the arene solvent, the intermolecular $\mathrm{C}-\mathrm{D}$ bond activation of alkanes becomes slower than the $\beta$-elimination.

This type of reaction has also been observed for the agostic complex A11a [28], although the $\mathrm{CH}$ group of the agostic contact is not involved. Upon heating or under UV irradiation (Scheme 26), one hydrogen of the cyclometalated isopropyl group in A11a undergoes a $\beta$-H elimination process yielding 61, in which the alkene and the hydride ligands are located mutually trans.

\section{Intermolecular $\mathrm{C}-\mathrm{H}$ bond activation}

Three-coordinate T-shaped Pt(II) complexes have been postulated in hydrocarbon $\mathrm{C}-\mathrm{H}$ bond activations, particularly in the

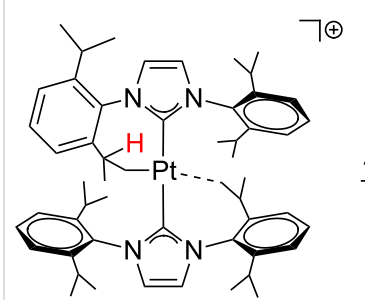

A11a

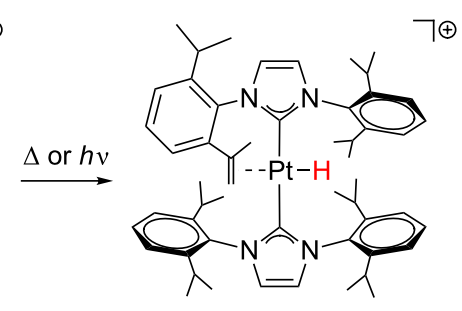

61
Scheme 26: $\beta-\mathrm{H}$ elimination process of A11a [28].

Shilov system for the functionalization of methane. A number of excellent reviews about $\mathrm{C}-\mathrm{H}$ bond activation have been published [132-137].

Labile ligands in masked T-shaped compounds allow further reactivity. Although some solvent complexes exhibit associative pathways eluding 14-electron species $[73,138]$, the participation of such coordinatively unsaturated intermediates should be taken into account for other systems [135,136]. A good example is the investigation reported by Wick and Goldberg (Scheme 27) [95]. From the anionic species [Pt(Me) $\left.{ }_{2} \mathrm{Tp}^{\prime}\right]^{-} \mathbf{6 2}$, they attempted to generate the unsaturated species $\mathbf{6 3}$ through the abstraction of one methyl ligand. Indeed, the treatment of $\mathbf{6 2}$ with $\mathrm{B}\left(\mathrm{C}_{6} \mathrm{~F}_{5}\right)_{3}$ in benzene, cyclohexane and $n$-pentane provides
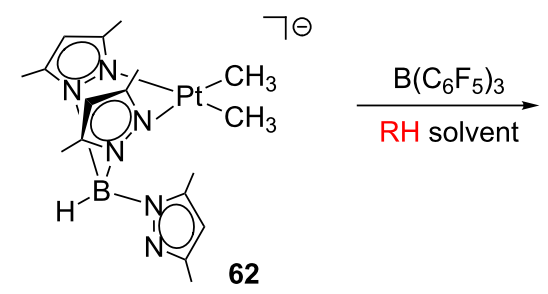

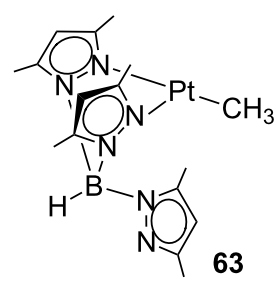

$\mathrm{R}-\mathrm{H}$

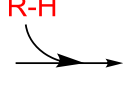

64a: $\mathrm{R}=\mathrm{C}_{6} \mathrm{H}_{5}$

64b: $\quad \mathrm{C}_{6} \mathrm{H}_{11}(\mathrm{Cy})$

64c: $\quad n-\mathrm{C}_{5} \mathrm{H}_{11}$ 
the products 64 arising from the $\mathrm{C}-\mathrm{H}$ bond activation of solvent molecules. Interestingly, the activation of pentane molecules only occurs at the primary carbon atom.

A similar situation has been observed for the reductive elimination of methane in the complex 65 (Scheme 28) [105]. Experimental evidence is consistent with a dissociative methane loss from 66 as the rate-determining step. Therefore, as shown in Scheme 27, the unsaturated intermediate $\mathbf{6 3}$ is supposed to operate again. When the reaction is carried out in $\mathrm{CD}_{3} \mathrm{CN} / \mathrm{C}_{6} \mathrm{~F}_{6}$ mixtures, acetonitrile binds the transient $\mathbf{6 3}$ forming the corresponding adduct 67 . On the other hand, when benzene- $d_{6}$ and toluene- $d_{8}$ are used as solvents, intermolecular C-D bond acti- vations occur with the formation of $\mathbf{6 8}$. In cyclohexane- $d_{12}$ solution, the observation of deuterated methane isotopomers indicates $\mathrm{C}-\mathrm{D}$ bond-activation processes, though the corresponding alkyl $\mathrm{Pt}(\mathrm{IV})$ product could not be characterized.

Nevertheless, the participation of one arm of the Tp' ligand stabilizing the open coordination site in $\mathbf{6 3}$ should be considered. As pointed out by Keinan and co-workers [139], the intermediate $[\mathrm{Pt}(\mathrm{Me}) \mathrm{Tp}]$ can adopt two different structures; the bidentate $\kappa^{2}$ coordination mode $(69)$ provides a T-shaped structure (Figure 18 left) whereas the $\kappa^{3}$-complex (69') exhibits a see-saw geometry (Figure 18 right). The former is slightly favored by only $1.8 \mathrm{kcal} \mathrm{mol}^{-1}$.

$$
\text { (n) }
$$
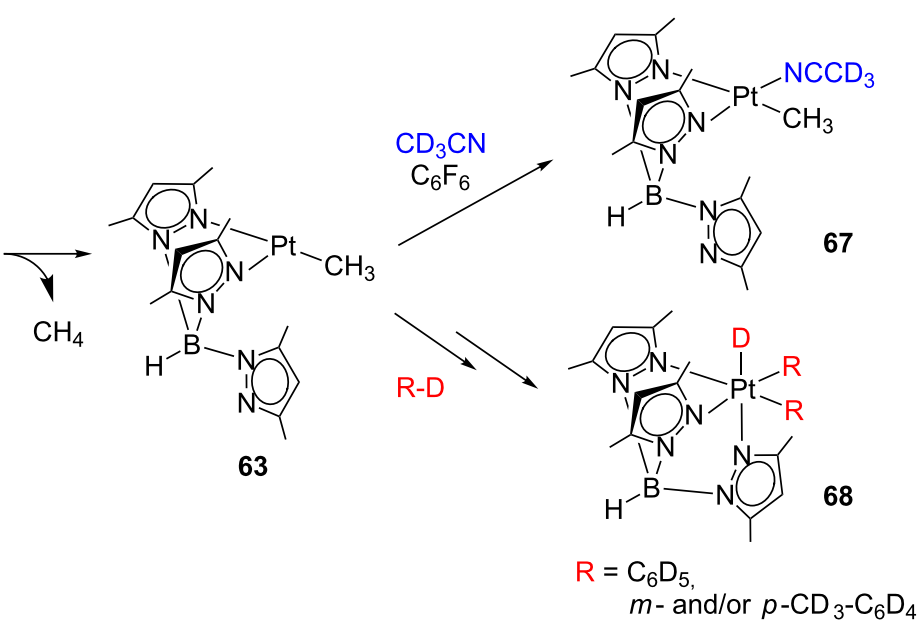

Scheme 28: Reductive elimination of methane from 65 followed by $\mathrm{CD}_{3} \mathrm{CN}$ coordination or $\mathrm{C}-\mathrm{D}$ bond-activation processes [105].

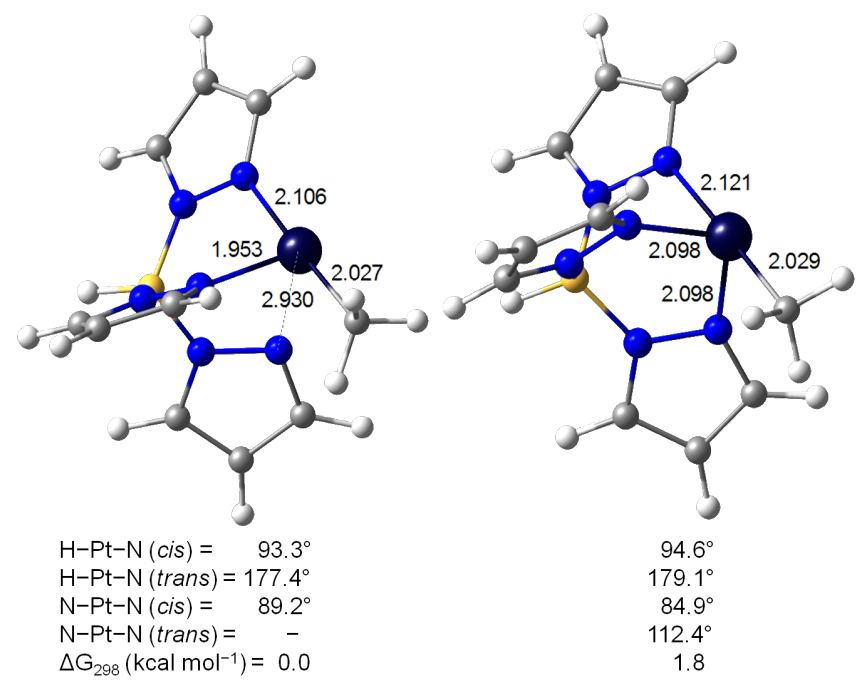

Figure 18: DFT-optimized structures describing the $\mathrm{k}^{2}$ (69, left) and $\mathrm{k}^{3}$ (69', right) coordination modes of [Pt(Me)Tp] [139]. Bond distances in angstroms, angles in degrees and Gibbs energies in $\mathrm{kcal} \mathrm{mol}^{-1}$. 
Recently, arene activation has been reported regarding true T-shaped species with NHC ligands [28]. The cyclometalated complexes A11a, A11b, T5a and T5b were tested toward C-H bond-activation processes by using benzene as a solvent (Scheme 29). No reaction was observed for A11a and A11b even under drastic conditions (high temperatures and long reaction times). On the other hand, T5a yields the phenyl product T6a, whereas $\mathbf{T 5 b}$ barely reacts.<smiles>CP1CCNC1</smiles>

A11a: A11b: T5a: T5b:
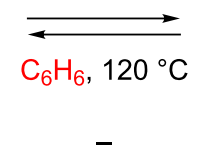

$-$

$1: 4$

$50: 1$

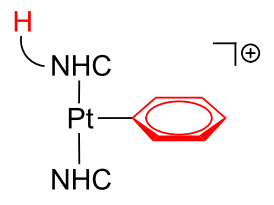

- $\operatorname{IPr}$

- $\mid t-\mathrm{Bu}$

T6a: IMes*

T7: IMes
Scheme 29: Intermolecular arene $\mathrm{C}-\mathrm{H}$ bond activation from $\mathrm{NHC}$ based complexes [28].

DFT calculations suggest an oxidative addition and reductive elimination scenario via Pt(IV) hydride intermediates 70 (Figure 19). The steric environment of the agostic complexes A11a and A11b complicates the reaction, which is reflected in the high energy barriers (more than $40 \mathrm{kcal} \mathrm{mol}^{-1}$, red line). In sharp contrast, the true T-shaped species T5a and T5b, with no agostic bonds, show lower energy profiles (ca. $30 \mathrm{kcal} \mathrm{mol}^{-1}$, blue line) and the reaction thermodynamics ( $\Delta E_{\mathrm{r}}$ values, Figure 19) accounts for the observation of T6a and the poor detection of $\mathbf{T} 7$.

Other arenes can also be activated by the use of T5a to afford T6 (Figure 6). In toluene solvent, only the two products $m$-T6b and $p$-T6b corresponding to meta- and para-site activations are observed in a 5:1 molar ratio. Neither ortho- nor benzylic $\mathrm{C}-\mathrm{H}$ bond activations are detected. Once again, DFT calculations provide reasonable $\Delta E^{\ddagger}$ for both meta and para-routes (ca. $30 \mathrm{kcal} \mathrm{mol}^{-1}$ ), and the thermodynamic effects, i.e., that only $m$-T6b and $p$-T6b are slightly more stable than T5a, explain the experimental evidence.

Some pincer complexes can indeed activate the $\mathrm{C}-\mathrm{H}$ bonds of benzene, though the mechanism is not fully understood $[50,140]$. In this line, Ozerov and co-workers have attempted to access unsaturated species by means of abstraction of triflate ligand from 71 (Scheme 30) [12]. The presumable generation of the low electron-count intermediate 72, results in the intermolecular $\mathrm{C}-\mathrm{H}$ bond activation of several arene solvents. Phenyl 73a and phenyl- $d_{5}$ 73b together with $o$-fluoro $73 \mathbf{c}$ and $o$-chlorophenyl $\mathbf{7 3 d}$ are obtained. The toluene solvent also reacts forming a mixture of $o-, m$ - and $p$-tolyl complexes $(8 \%$ $o-73 \mathbf{e}$ and $92 \% m-73 \mathbf{e}$ and $p$-73e). Additional experiments proved that the reverse processes are not kinetically accessible.

IPr = 1,3-bis(2,6-diisopropylphenyl)imidazol-2-ylidene

It $-\mathrm{Bu}=1,3$-bis(tert-butyl)imidazol-2-ylidene

IMes $^{*}=4,5$-dimethyl-1,3-bis(2,4,6-trimethylphenyl)imidazol-2-ylidene

IMes = 1,3-bis(2,4,6-trimethylphenyl)imidazol-2-ylidene

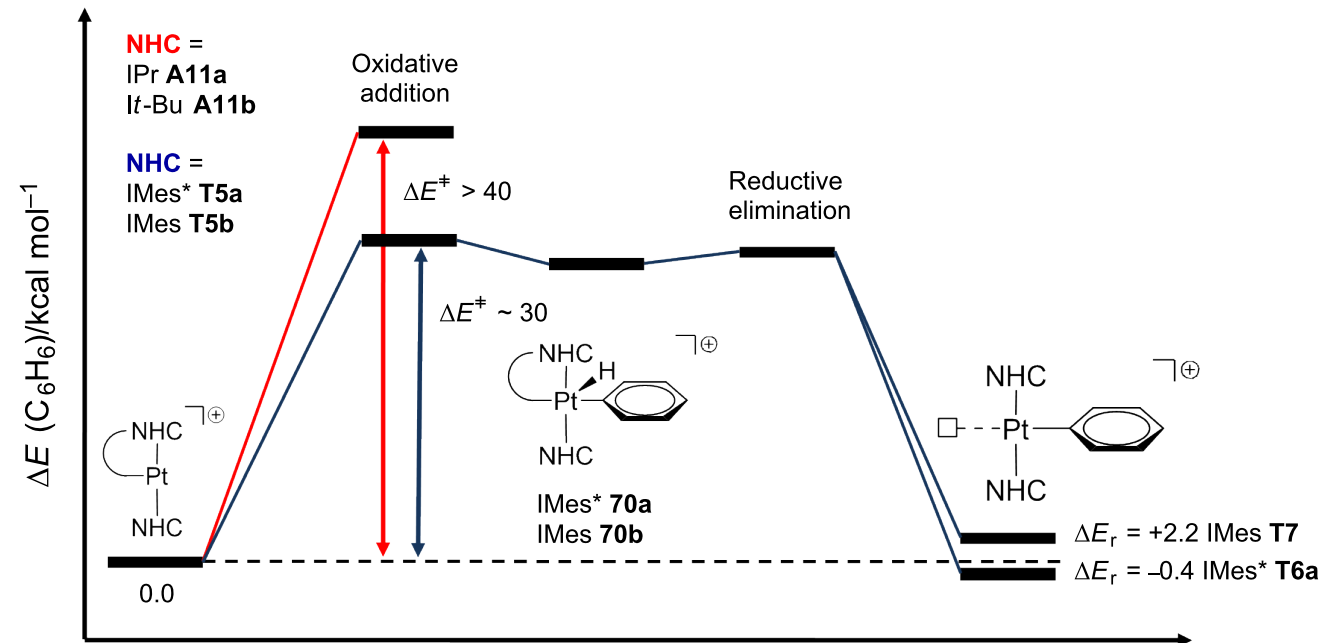

Reaction coordinate

Figure 19: Energy profiles (in benzene solvent) for the benzene $\mathrm{C}-\mathrm{H}$ bond activation from $\mathbf{A 1 1 a}, \mathbf{A} 11 \mathbf{b}, \mathbf{T 5 a}$ and T5b [28] 


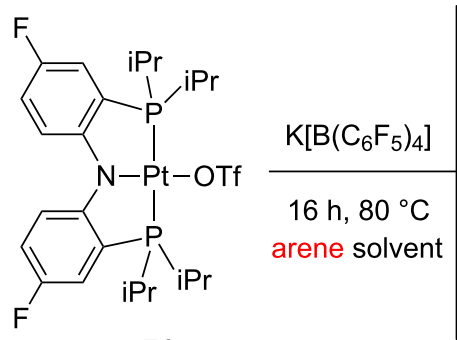

71

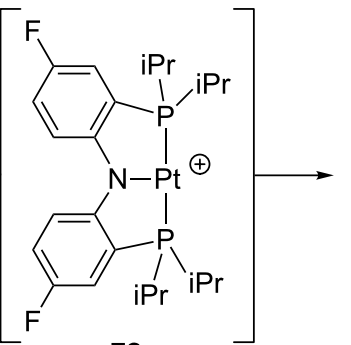

72

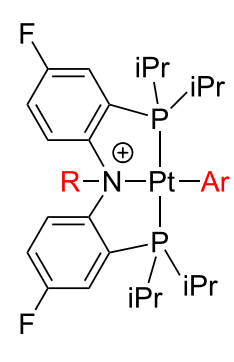

$$
\begin{aligned}
& {\left[\mathrm{B}\left(\mathrm{C}_{6} \mathrm{~F}_{5}\right)_{4}\right]^{\ominus}} \\
& \text { 73a: } \mathrm{R}=\mathrm{H} ; \mathrm{Ar}=\mathrm{C}_{6} \mathrm{H}_{5} \\
& \text { 73b: } \mathrm{R}=\mathrm{D} ; \mathrm{Ar}=\mathrm{C}_{6} \mathrm{D}_{5} \\
& 0-73 \mathrm{c}: \mathrm{R}=\mathrm{H} ; \mathrm{Ar}=0-\mathrm{F}-\mathrm{C}_{6} \mathrm{H}_{4} \\
& 0-73 \mathrm{~d}: \quad 0-\mathrm{Cl}_{2} \mathrm{C}_{6} \mathrm{H}_{4} \\
& o-, m-, p-73 \mathrm{e}: \quad 0-, m-, p-\mathrm{CH}_{3} \mathrm{C}_{6} \mathrm{H}_{4}
\end{aligned}
$$

Scheme 30: Intermolecular arene C-H bond activation from PNP-based complex 71 [12].

In some cases, $\mathrm{C}-\mathrm{X}$ bond-activation processes involving $\mathrm{PhBr}$ and $\mathrm{CH}_{2} \mathrm{Cl}_{2}$ molecules have also been registered.

Complexes of the type $[\mathrm{Pt}(\mathrm{Me})(\mathrm{NN})]^{+} \mathbf{7 4}$ (Scheme 31) have shown reactivity toward the $\mathrm{C}-\mathrm{H}$ bond activation of benzene in gas-phase ion-molecule reactions [7]. Suitable labeling experiments disclose the reversibility of the $\mathrm{C}-\mathrm{H}$ bond activation. Interestingly, the relative rate constants reveal that $\mathbf{7 4 d}$ reacts slower than $\mathbf{7 4 a}-\mathbf{c}$. In the absence of solvent, both reactants $\mathbf{7 4 a}-\mathbf{c}$ and phenyl products $\mathbf{7 6} \mathbf{a}-\mathbf{c}$ are believed to exhibit true T-shaped structures. On the other hand, the lower reactivity of 74d has been attributed to an interaction of the empty site of the platinum with one ortho-chlorine atom of the (o,o'$\left.\mathrm{Cl}_{2} \mathrm{C}_{6} \mathrm{H}_{3}\right) \mathrm{N}=\mathrm{C}\left(\mathrm{CH}_{3}\right)-\mathrm{C}\left(\mathrm{CH}_{3}\right)=\mathrm{N}\left(o, o{ }^{\prime}-\mathrm{Cl}_{2} \mathrm{C}_{6} \mathrm{H}_{3}\right)\left({ }^{\mathrm{Me}} \mathrm{DAB}{ }^{\mathrm{DCP}}\right)$ ligand [141], which blocks the approach of a benzene molecule. Oxidative addition and reductive elimination (OA/RE) as well as $\sigma$-CAM scenarios have been evaluated for $\mathbf{7 4 b}$, but unfortunately the results are functional-dependent. B3LYP cannot reproduce the experimental evidences, $\mathrm{mPW} 1 \mathrm{~K}$ and mPW1PW91 favor the $\sigma$-CAM mechanism, and M05-2X considers both of them [7]. The bipyridyl complex 74b can also activate toluene and methane molecules forming $\mathbf{7 4 b b}$ and 74bc, respectively [142]. Concerning the toluene activation, meta-, para- and benzylic positions can be activated forming $m-76 \mathbf{b b}, p-76 \mathbf{b b}$ and Bn-76bb, respectively. BP86 calculations suggest that $\mathrm{OA} / \mathrm{RE}$ and $\sigma-\mathrm{CAM}$ are competitive pathways.

\section{$\mathrm{H}_{2}$ activation}

Some agostic complexes previously reported can activate small molecules such as $\mathrm{H}_{2}$ (Scheme 32). For instance, the complexes A5a and A5b react with dihydrogen ( 1 atm $\left.\mathrm{H}_{2}, 20^{\circ} \mathrm{C}\right)$ in dichloromethane solution to yield the corresponding agostic hydride products A6a and A6b [39]. Both species were found in equilibrium, exhibiting A5/A6 ratios of 4:1 and 1:2 for species $\mathbf{a}$ and $\mathbf{b}$, respectively. A similar behavior is observed for the<smiles>[R]P1([R])(C)Cc2cccc(C)c2P1([R])(C)c1c(C)cccc1C</smiles><smiles>[R][R]([R])([H])P([R])([R])(c1c(C)cccc1C)c1c(C)cccc1C</smiles>

A5a: $\mathrm{R}=\mathrm{Ph}$

$4: 1$

A6a: $\mathrm{R}=\mathrm{Ph}$

A5b: $\quad$ Cy $1: 2$

A6b: Cy

A5c: $\quad \mathrm{iPr}$

$1: 3$

A6c: $\quad \mathrm{iPr}$ 
analogous reaction of $\mathbf{A 5 c}$ ( 1 bar $\mathrm{H}_{2},-30{ }^{\circ} \mathrm{C}$ to room temperature), in which A6c is obtained in a 1:3 ratio [40]. These results suggest that hydride species seem to be favored according to the basicity of the phosphine ligand. In previous works, the dichloromethane molecule in the solvento complex S1a was labile enough to allow $\mathrm{H}_{2}$ activation but, unlike A6, the corresponding dihydrogen adduct 77 was observed (Scheme 32) [54]. The latter undergoes a fluxional process which can be slowed down by cooling at $-60{ }^{\circ} \mathrm{C}$.

Weller and co-workers reported an alternative procedure to obtain $\mathbf{7 7}$ from $\mathbf{A} 7$ by addition of dihydrogen in $\mathrm{CD}_{2} \mathrm{Cl}_{2}$ solution (Scheme 33) [41]. The agostic interaction in $\mathbf{A} 7$ is supposed to be displaced by one dihydrogen molecule forming the putative intermediate 78. The concomitant release of methane may be the driving force of the reaction, thus the entropic factors together with the nature of the phosphine ligands should be taken into account. Additionally, the related compound 16 (Scheme 13) can also activate dihydrogen mole-<smiles>CC(C)CCCCC(C)C</smiles>

A7

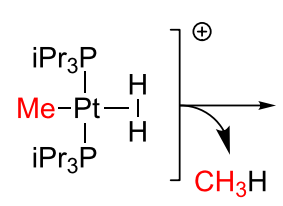

78

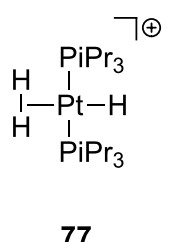

77 a<smiles>CC1CP(OC2CCCC2)(C(C)C)([PH](C(C)C)(C(C)C)C(C)C)C1C</smiles>

16<smiles>CC(C)[PH](C(C)(C)C)(C(C)(C)C)P(C(C)(C)C)(C(C)(C)C)(C(C)(C)C)C(C)(C)C</smiles>

S1c
Scheme 33: Dihydrogen activation through complexes A7 and 16 [41]. For a: see Scheme 13. cules; the cyclometalated ring is opened and the corresponding hydride complex S1c is obtained [54].

\section{$\mathrm{X}_{2}$ activation}

The cyclometalated compounds A11a and T5a can activate $X_{2}$ molecules $(\mathrm{X}=\mathrm{Br}, \mathrm{I})$ in dichloromethane solution affording 79 and $\mathbf{8 0}$ in which one $\mathrm{C}\left(\mathrm{sp}^{3}\right)-\mathrm{X}$ bond is constructed (Scheme 34) [143]. It is noteworthy that the reaction occurs in the presence (A11a) or the absence (T5a) of agostic interactions in the starting materials.

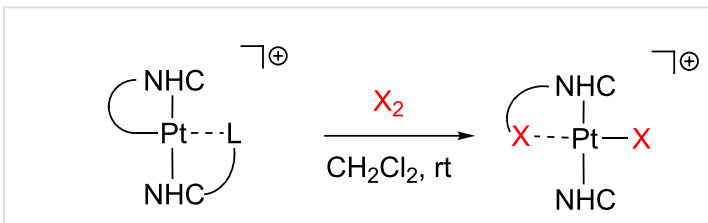

$$
\begin{aligned}
& \text { 79a: } \mathrm{X}=\mathrm{Br} ; \mathrm{NHC}=\mathrm{IPr} \\
& \text { 80a: IMes* } \\
& \text { 79b: } X=\mathrm{I} ; \quad \mathrm{NHC}=\mathrm{IPr} \\
& \text { 80b: }
\end{aligned}
$$

Interestingly, during the reaction of $\mathbf{A 1 1 a}$ with $\mathrm{Br}_{2}$ at low temperature $\left(-78^{\circ} \mathrm{C}\right)$ a paramagnetic, see-saw $\mathrm{Pt}(\mathrm{III})$ alkyl intermediate 81 a could be isolated and characterized (Scheme 35), although the iodo-analogue $\mathbf{8 1 b}$ could not. DFT calculations correctly predicted the feasibility of $\mathbf{8 1 a}$ $\left(-9.5 \mathrm{kcal} \mathrm{mol}^{-1}\right.$ below reactants) and explained the nondetection of $\mathbf{8 1 b}\left(+4.5 \mathrm{kcal} \mathrm{mol}^{-1}\right.$ above reactants) in terms of higher relative energies.

A related $\mathrm{Cl}_{2}$ activation process involving unsaturated species has been recently reported by Rourke and co-workers (Scheme 36) [144]. Under certain conditions, the reaction of 82 with $\mathrm{PhI} \cdot \mathrm{Cl}_{2}$ yields $\mathbf{8 3}$. Although suitable crystals of $\mathbf{8 3}$ could not be obtained, the structure was elucidated by NMR studies showing the formation of one $\mathrm{C}\left(\mathrm{sp}^{3}\right)-\mathrm{Cl}$ bond. Similarly to the

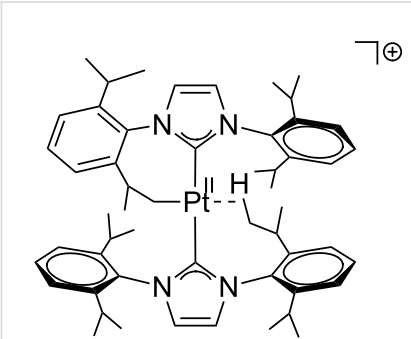

A11a

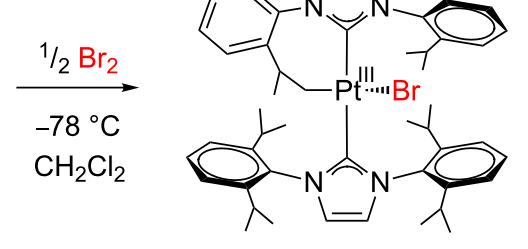

$81 \mathrm{a}$

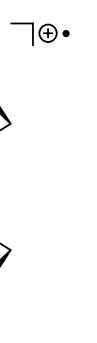

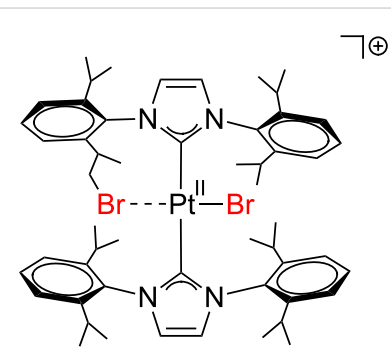

$79 a$

Scheme 35: Detection and isolation of the $\mathrm{Pt}(\mathrm{III})$ complex 81a [143]. 


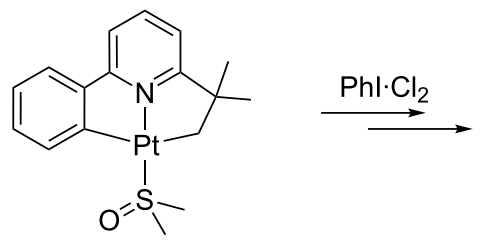

82<smiles></smiles>

83<smiles></smiles>

84

Scheme 36: $\mathrm{Cl}_{2}$ bond activation through complexes 82 and 83 [144]

agostic species A9, the resulting $\mathrm{CH}_{2} \mathrm{Cl}$ group is interacting with the open coordination site. Further reaction of $\mathbf{8 3}$ with $\mathrm{PhI} \cdot \mathrm{Cl}_{2}$ forms the oxidation product $\mathbf{8 4}$.

\section{cis-trans Isomerization}

The cis-trans isomerization of several solvento species $\mathbf{S 5}$ has been studied and the formation of low electron-count Pt(II) complexes $\mathbf{8 5}$ through dissociative pathways accounts for the experimental observations [2,61]. The general mechanism is depicted as follows: (i) rate-determining dissociation step of a solvent molecule, (ii) isomerization process, and (iii) fast association of a solvent molecule (Scheme 37).

As shown in Scheme 37, the 14-electron structures $\mathbf{8 5}$ are involved in the process. Due to their high tendency to fulfill the empty coordination site, these species strongly favor intramolecular contacts. Indeed, it has been experimentally observed that the complexes $\mathbf{S 5}$ bearing $\mathrm{R}=\mathrm{Et}, n$-Pr and $n$-Bu groups react much faster than other derivatives with $\mathrm{R}$ groups without

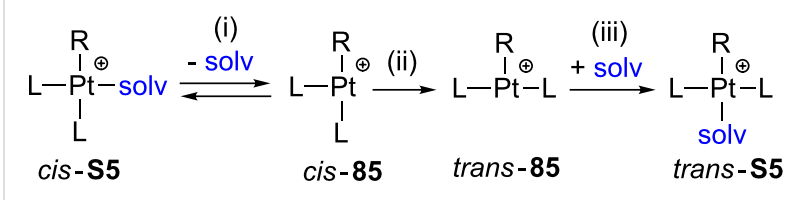

Scheme 37: cis-trans Isomerization mechanism of the solvento $\mathrm{Pt}(\mathrm{II})$ complexes S5 [2,61].

$\beta$-hydrogen atoms [61]. This phenomenon has been called the $\beta$-hydrogen kinetic effect [2]. It is defined by an incipient $\beta$-agostic interaction that can stabilize transient T-shaped intermediates and transition states, and therefore, an increase of the reaction rate would be expected. Further computational studies were performed on complexes $\left[\mathrm{Pt}(\mathrm{R})\left(\mathrm{PMe}_{3}\right)_{2}(\mathrm{solv})\right]^{+} \mathbf{8 5}$ describing the isomerization process in different solvents [2]. The $\beta$-hydrogen kinetic effect can be detected during the first steps of the isomerization energy profiles (Figure 20) for both the methyl (85a, red line) and the ethyl $(\mathbf{8 5} \mathbf{b}$, blue line)

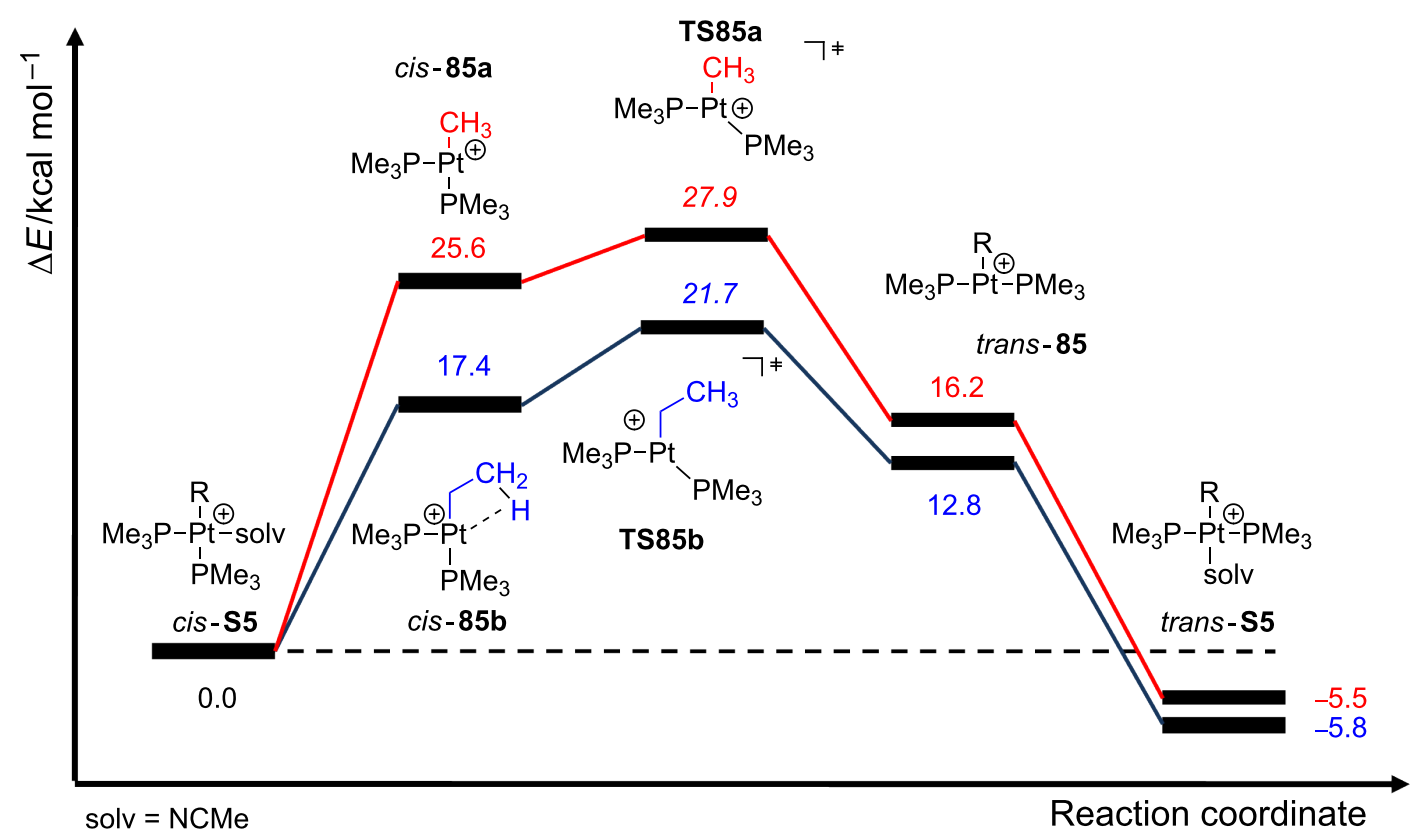

Figure 20: Energy profiles for the isomerization of complexes $\left[\mathrm{Pt}(\mathrm{R})\left(\mathrm{PMe}_{3}\right)_{2}(\mathrm{NCMe})\right]^{+}$where $\mathrm{R}$ means $\mathrm{Me}(\mathbf{8 5 a}$, red line) and Et (85b, blue line) $[2]$. 
complexes in acetonitrile. Note that the agostic contact in cis$\mathbf{8 5 b}$ decreases the overall energy requirement with respect to cis-85a, but at the same time, it increases the relative energy barrier to reach the $\mathrm{Y}$-shaped transition state $\mathbf{T S 8 5}$, i.e., $4.3 \mathrm{kcal}$ $\mathrm{mol}^{-1}$ for the ethyl (TS85b) and $2.3 \mathrm{kcal} \mathrm{mol}^{-1}$ for the methyl (TS85a) derivatives. By removal of the agostic interaction in cis-85b (through a rotation of the $\mathrm{C}-\mathrm{C}$ bond of the ethyl ligand), this energy stabilization was estimated to be $5.9 \mathrm{kcal} \mathrm{mol}^{-1}$. Other solvents such as methanol, dimethylsulfoxide and benzene were also considered. The donor ability strongly affects the dissociation step, although it has a little impact on the strength of the agostic interaction.

In the presence of benzyl ligands, a similar cis-trans isomerization via the unsaturated species $\left[\mathrm{Pt}(\mathrm{R})\left(\mathrm{PEt}_{3}\right)_{2}\right]^{+}$(Scheme 37) has been claimed [62]. DFT calculations on the model derivative $\left[\mathrm{Pt}(\mathrm{Bn})\left(\mathrm{PMe}_{3}\right)_{2}\right]^{+}$predict a $\mathrm{Pt} \cdots \eta^{2}$-benzyl coordination mode in $\mathbf{8 6}$ involving the ipso-carbon of the benzyl ligand (Figure 21). This stabilization accounts for $7.6 \mathrm{kcal} \mathrm{mol}^{-1}$, i.e., $1.7 \mathrm{kcal} \mathrm{mol}^{-1}$ stronger than the above-mentioned agostic contact for the same family of compounds $\left(5.9 \mathrm{kcal} \mathrm{mol}^{-1}\right.$, [2]). The interaction is favored by electron-donating groups on the phenyl ring and, as a consequence, the reaction rate is enhanced.

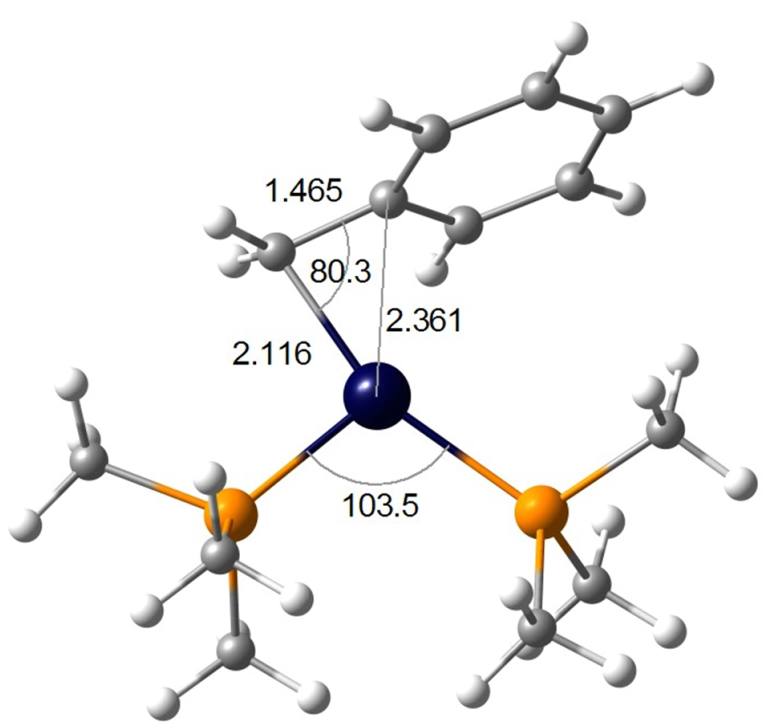

Figure 21: DFT-optimized structure of intermediate 86 [62]. Bond distances in angstrom and angles in degrees.

\section{Dissociative ligand substitution}

Experimental evidences obtained in poorly coordinating solvents strongly support that neutral complexes of the type cis$\left[\mathrm{Pt}(\mathrm{R})_{2} \mathrm{~S}_{2}\right](\mathbf{8 7})$ undergo ligand substitutions through dissociative pathways as depicted in Scheme 38: (i) sulfur ligand dissociation/reassociation via transient 14-electron structures $(\mathbf{8 8})$, (ii) subsequent ligand addition (89), and (iii) displacement of the sulfur ligand (90) [117,119]. The electron-rich metal, the $\mathrm{Pt}-\mathrm{S}$ bond weakening due to the trans-influence of the $\mathrm{R}$ groups, and the stabilization of $\mathrm{T}$-shaped intermediates favor this dissociative pathway. Interestingly, for the complex cis$\left[\mathrm{Pt}(\mathrm{Ph})_{2}(\mathrm{CO})\left(\mathrm{SMe}_{2}\right)\right]$, in which one thioether ligand has been replaced by $\mathrm{CO}$, the operating mechanism becomes associative [145]. Steric and $\beta$-hydrogen kinetic effects [2] have been invoked to explain the fast reaction of $\left[\mathrm{Pt}(\mathrm{Hbph})_{2}(\mathrm{DMSO})_{2}\right]$ (Hbph $=\eta^{1}$-biphenyl monoanion) compared to species containing other R groups [117].

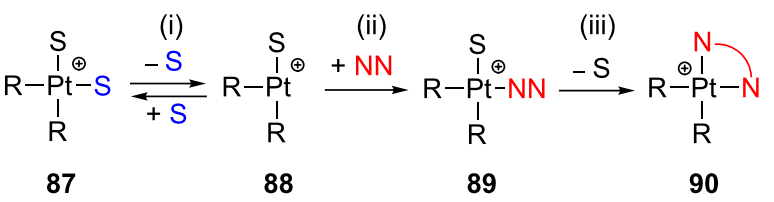

$$
\begin{aligned}
& \mathrm{R}=\text { alkyl, aryl } \\
& S=\text { sulfur ligand }
\end{aligned}
$$

Scheme 38: Proposed dissociative ligand-substitution mechanism of cis- $\left[\mathrm{Pt}(\mathrm{R})_{2} \mathrm{~S}_{2}\right]$ complexes (87) [117].

Puddephatt and co-workers have demonstrated that, depending on the nature of the R group, dissociative mechanisms can also facilitate the substitution of dimethylsulfide by phthalazine in the dinuclear species 91 (Scheme 39) [146]. When alkyl derivatives are employed, kinetic evidence mainly points to an associative mechanism via $\mathbf{9 2}$, although a minor part of the reaction has been related to a dissociative pathway. The inclusion of phenyl and $p$-tolyl ligands in 91 completely changes the mechanism. A first-order reaction is observed and large negative entropies of activation are collected. The proposed mechanism involves the dissociation of dimethylsulfide generating the puta-

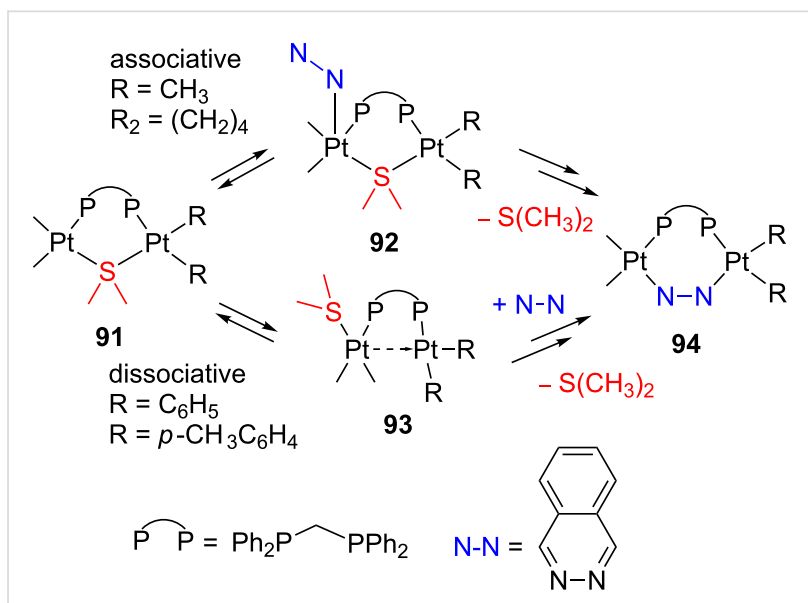

Scheme 39: Proposed mechanisms for the ligand substitution of the dinuclear species 91 [146]. 
tive unsaturated intermediate $\mathbf{9 3}$. This species is supposed to be stabilized by a donor-aceptor Pt-Pt bond, i.e., the electron-rich four-coordinate platinum atom interacts with the electron-deficient three-coordinate counterpart. Consequently, the electron density of the former platinum atom decreases, thereby favoring the subsequent attack of the $\mathrm{N}-\mathrm{N}$ ligand to yield $\mathbf{9 4}$.

\section{Conclusion}

There are only a very few authenticated three-coordinate $\mathrm{Pt}(\mathrm{II})$ complexes. Yet, T-shaped intermediates play an important role in a number of organometallic transformations. Given the electronic and coordinative unsaturated nature of such compounds, they can only be isolated when the vacant coordination site is blocked to avoid intra- and intermolecular interactions. Steric effects are important in preventing the coordination of a fourth external ligand. The use of bulky species, which hamper the entry of ligands into the platinum coordination sphere, is a good strategy toward this goal. The presence of shorter or less flexible alkyl chains in bulky ligands could avoid agostic interactions. Electronic effects, as well as the involvement of strong electron-donating ligands, also have a stabilizing impact. Overall, the number of true T-shaped complexes that are wellcharacterized is still very low. Nevertheless, a much larger number of $\mathrm{Pt}(\mathrm{II})$ complexes can be described as operationally three-coordinate in a kinetic sense. This happens when the fourth position in a square-planar complex is occupied by a very weak ligand, which can be easily displaced. We have named these compounds masked T-shaped complexes. An intramolecular agostic interaction, a weakly coordinated solvent molecule or a counteranion can play such a role. Whether or not the interaction of the platinum atom with the fourth ligand is very weak, the three-coordinate complex should be very close in energy to the square-planar ground state. Consequently, in practice the masked T-shaped complexes can be devised as a resting state of the three-coordinate species.

The accessibility of three-coordinate complexes makes them suitable intermediates in Pt(II) chemistry. In spite of the difficulty in detecting these intermediates, this review gathers a number of recent experimental and theoretical reports, which claim the involvement of T-shaped Pt(II) intermediates in reaction mechanisms. In the near future, the acquired knowledge on the synthetic routes and structural features, as well as the advances in the detection techniques and computational methods, should lead to an improved design of such compounds and to a wider recognition of the role they play in chemical transformations.

\section{Acknowledgements}

Financial support from the Spanish Ministerio de Economia y Competitividad (DGICYT, Projects CTQ2010-17476,
CTQ2011-23336 and ORFEO Consolider-Ingenio 2010 CSD2007-00006) and the Junta de Andalucía (project No. FQM-3151) is acknowledged. M. A. O thanks the Spanish MECD for a research grant.

\section{References}

1. Hartwig, J. F. Organotransition metal chemistry: from bonding to catalysis; University Science: Sausalito, CA, USA, 2010.

2. Romeo, R.; D’Amico, G.; Sicilia, E.; Russo, N.; Rizzato, S. J. Am. Chem. Soc. 2007, 129, 5744-5755. doi:10.1021/ja0702162

3. Yamashita, M.; Hartwig, J. F. J. Am. Chem. Soc. 2004, 126, 5344-5345. doi:10.1021/ja0315107

4. Walter, M. D.; White, P. S.; Brookhart, M. New J. Chem. 2013, 37, 1128-1133. doi:10.1039/c3nj41145a

5. Moncho, S.; Ujaque, G.; Lledós, A.; Espinet, P. Chem.-Eur. J. 2008, 14, 8986-8994. doi:10.1002/chem.200800423

6. Gerdes, G.; Chen, P. Organometallics 2003, 22, 2217-2225. doi:10.1021/om0209982

7. Butschke, B.; Schröder, D.; Schwarz, H. Organometallics 2009, 28, 4340-43496. doi:10.1021/om900388k

8. Ozerov, O. V.; Watson, L. A.; Pink, M.; Caulton, K. G. J. Am. Chem. Soc. 2007, 129, 6003-6016. doi:10.1021/ja062327r

9. Alvarez, S. Coord. Chem. Rev. 1999, 193-195, 13-41. doi:10.1016/S0010-8545(99)00085-5

10. Albright, T. A.; Burdett, J. K.; Whango, M. H. Orbital interactions in chemistry; Wiley: New York, 1985.

11. Jean, Y. Molecular orbitals of transition metal complexes; Oxford University Press: New York, 2005.

12. DeMott, J. C.; Bhuvanesh, N.; Ozerov, O. V. Chem. Sci. 2013, 4, 642-649. doi:10.1039/c2sc21385k

13. Su, M.-D.; Chu, S.-Y. J. Phys. Chem. A 1998, 102, 10159-10166. doi:10.1021/jp982861o

14. Komiya, S.; Albright, T. A.; Hoffmann, R.; Kochi, J. K. J. Am. Chem. Soc. 1976, 98, 7255-7265. doi:10.1021/ja00439a024

15. Berthon-Gelloz, G.; de Bruin, B.; Tinant, B.; Markó, I. E. Angew. Chem. 2009, 121, 3207-3210. doi:10.1002/ange.200900435 Angew. Chem. Int. Ed. 2009, 48, 3161-3164. doi:10.1002/anie.200900435

16. Takagi, N.; Sakaki, S. J. Am. Chem. Soc. 2012, 134, 11749-11759. doi:10.1021/ja304110h

17. Su, M.-D. Mol. Phys. 1993, 80, 1223-1251. doi:10.1080/00268979300102991

18. Sturmayr, D.; Schubert, U. Monatsh. Chem. 2003, 134, 791-795. doi:10.1007/s00706-002-0568-6

19. Goel, R. G.; Srivastava, R. C. Can. J. Chem. 1983, 61, 1352-1359. doi:10.1139/v83-238

20. Braunschweig, H.; Radacki, K.; Rais, D.; Scheschkewitz, D. Angew. Chem. 2005, 117, 5796-5799. doi:10.1002/ange.200501588 Angew. Chem. Int. Ed. 2005, 44, 5651-5654. doi:10.1002/anie.200501588

21. Braunschweig, H.; Radacki, K.; Uttinger, K. Chem.-Eur. J. 2008, 14, 7858-7866. doi:10.1002/chem.200800879

22. Braunschweig, H.; Brenner, P.; Dewhurst, R. D.; Jimenez-Halla, J. O. C.; Kupfer, T.; Rais, D.; Uttinger, K. Angew. Chem., Int. Ed. 2013, 125, 3055-3058. doi:10.1002/anie.201209717

23. Lam, W. H.; Lam, K. C.; Lin, Z.; Shimada, S.; Perutz, R. N.; Marder, T. B. Dalton Trans. 2004, 1556-1562. doi:10.1039/b402632b 
24. Toner, A.; Matthes, J.; Gründemann, S.; Limbach, H.-H.; Chaudret, B.; Clot, E.; Sabo-Etienne, S. Proc. Natl. Acad. Sci. U. S. A. 2007, 104, 6945-6950. doi:10.1073/pnas.0608979104

25. Dorta, R.; Stevens, E. D.; Hoff, C. D.; Nolan, S. P. J. Am. Chem. Soc. 2003, 125, 10490-10491. doi:10.1021/ja0362151

26. Lavallo, V.; Canac, Y.; De Hope, A.; Donnadieu, B.; Bertrand, G. Angew. Chem. 2005, 117, 7402-7405. doi:10.1002/ange.200502566 Angew. Chem., Int. Ed. 2005, 44, 7236-7239 doi:10.1002/anie.200502566

27. Clavier, H.; Nolan, S. P. Chem. Commun. 2010, 46, 841-861. doi:10.1039/b922984a

28. Rivada-Wheelaghan, O.; Ortuño, M. A.; Díez, J.; Lledós, A.; Conejero, S. Angew. Chem. 2012, 124, 4002-4005. doi:10.1002/ange.201200070 Angew. Chem., Int. Ed. 2012, 51, 3936-3939. doi:10.1002/anie.201200070

29. Brookhart, M.; Green, M. L. H. J. Organomet. Chem. 1983, 250 , 395-408. doi:10.1016/0022-328X(83)85065-7

30. Brookhart, M.; Green, M. L. H.; Wong, L. L. Carbon-Hydrogen-Transition Metal Bonds. In Progress in Inorganic Chemistry; Lippard, S. J., Ed.; John Wiley \& Sons, Inc.: Hoboken, NJ, USA, 1988; Vol. 36, pp 1-124. doi:10.1002/9780470166376.ch1

31. Brookhart, M.; Green, M. L. H.; Parkin, G. Proc. Natl. Acad. Sci. U. S. A. 2007, 104, 6908-6914. doi:10.1073/pnas.0610747104

32. Clot, E.; Eisenstein, O. Struct. Bond. 2004, 113, 1-36. doi:10.1007/b97940

33. Lein, M. Coord. Chem. Rev. 2009, 253, 625-634 doi:10.1016/j.ccr.2008.07.007

34. Carr, N.; Dunne, B. J.; Orpen, A. G.; Spencer, J. L. J. Chem. Soc., Chem. Commun. 1988, 926-928. doi:10.1039/C39880000926

35. Carr, N.; Dunne, B. J.; Mole, L.; Orpen, A. G.; Spencer, J. L. J. Chem. Soc., Dalton Trans. 1991, 863-871. doi:10.1039/DT9910000863

36. Mole, L.; Spencer, J. L.; Carr, N.; Orpen, A. G. Organometallics 1991, 10, 49-52. doi:10.1021/om00047a026

37. Carr, N.; Mole, L.; Orpen, A. G.; Spencer, J. L. J. Chem. Soc., Dalton Trans. 1992, 2653-2662. doi:10.1039/DT9920002653

38. Spencer, J. L.; Mhinzi, G. S. J. Chem. Soc., Dalton Trans. 1995, 3819-3824. doi:10.1039/DT9950003819

39. Baratta, W.; Stoccoro, S.; Doppiu, A.; Herdtweck, E.; Zucca, A.; Rigo, P. Angew. Chem. 2003, 115, 109-113. doi:10.1002/ange.200390003 Angew. Chem. Int. Ed. 2003, 42, 105-108. doi:10.1002/anie.200390035

40. Campos, J.; Peloso, R.; Carmona, E. Angew. Chem. 2012, 124, 8380-8383. doi:10.1002/ange.201202655 Angew. Chem. Int. Ed. 2012, 51, 8255-8258. doi:10.1002/anie.201202655

41. Ingleson, M.; Mahon, M. F.; Weller, A. S. Chem. Commun. 2004, 2398-2399. doi:10.1039/b410846a

42. Thakur, T. S.; Desiraju, G. R. J. Mol. Struct.: THEOCHEM 2007, 810, 143-154. doi:10.1016/j.theochem.2007.02.012

43. Crosby, S. H.; Clarkson, G. J.; Rourke, J. P. J. Am. Chem. Soc. 2009, 131, 14142-14143. doi:10.1021/ja905046n

44. Rivada-Wheelaghan, O.; Donnadieu, B.; Maya, C.; Conejero, S. Chem.-Eur. J. 2010, 16, 10323-10326. doi:10.1002/chem.201000955
45. Zhu, J.; Lin, Z. Inorg. Chem. 2005, 44, 9384-9390. doi:10.1021/ic0513641

46. Braunschweig, H.; Brenner, P.; Müller, A.; Radacki, K.; Rais, D.; Uttinger, K. Chem.-Eur. J. 2007, 13, 7171-7176. doi:10.1002/chem.200700539

47. Brainard, R. L.; Nutt, W. R.; Lee, T. R.; Whitesides, G. M. Organometallics 1988, 7, 2379-2386. doi:10.1021/om00101a019

48. Peters, R. G.; White, S.; Roddick, D. M. Organometallics 1998, 17, 4493-4499. doi:10.1021/om980334I

49. Hill, G. S.; Rendina, L. M.; Puddephatt, R. J. J. Chem. Soc., Dalton Trans. 1996, 1809-1813. doi:10.1039/DT9960001809

50. Harkins, S. B.; Peters, J. C. Organometallics 2002, 21, 1753-1755. doi:10.1021/om011044z

51. Poverenov, E.; Gandelman, M.; Shimon, L. J. W.; Rozenberg, H.; Ben-David, Y.; Milstein, D. Organometallics 2005, 24, 1082-1090. doi:10.1021/om049182m

52. Poverenov, E.; Leitus, G.; Shimon, L. J. W.; Milstein, D. Organometallics 2005, 24, 5937-5944. doi:10.1021/om050637x

53. Schwartsburd, L.; Poverenov, E.; Shimon, L. J. W.; Milstein, D. Organometallics 2007, 26, 2931-2936. doi:10.1021/om0700720

54. Butts, M. D.; Scott, B. L.; Kubas, G. K. J. Am. Chem. Soc. 1996, 118, 11831-11843. doi:10.1021/ja961836y

55. Stahl, S. S.; Labinger, J. A.; Bercaw, J. E. Inorg. Chem. 1998, 37, 2422-2431. doi:10.1021/ic970944y

56. Holtcamp, M. W.; Labinger, J. A.; Bercaw, J. E. Inorg. Chim. Acta 1997, 265, 117-125. doi:10.1016/S0020-1693(97)05675-2

57. Konze, W. V.; Scott, B. L.; Kubas, G. J. Chem. Commun. 1999, 1807-1808. doi:10.1039/a902274k

58. Konze, W. V.; Scott, B. L.; Kubas, G. J. J. Am. Chem. Soc. 2002, 124, 12550-12556. doi:10.1021/ja020798h

59. Thomas, J. C.; Peters, J. C. J. Am. Chem. Soc. 2001, 123, 5100-5101. doi:10.1021/ja0058987

60. Thomas, J. C.; Peters, J. C. J. Am. Chem. Soc. 2003, 125, 8870-8888. doi:10.1021/ja0296071

61. Romeo, R.; Alibrandi, G. Inorg. Chem. 1997, 36, 4822-4830. doi:10.1021/ic970210।

62. Guido, E.; D’Amico, G.; Russo, N.; Sicilia, E.; Rizzato, S.; Albinati, A.; Romeo, A.; Plutino, M. R.; Romeo, R. Inorg. Chem. 2011, 50, 2224-2239. doi:10.1021/ic101879s

63. Holtcamp, M. W.; Labinger, J. A.; Bercaw, J. E. J. Am. Chem. Soc. 1997, 119, 848-849. doi:10.1021/ja9620595

64. Holtcamp, M. W.; Henling, L. M.; Day, M. W.; Labinger, J. A.; Bercaw, J. E. Inorg. Chim. Acta 1998, 270, 467-478. doi:10.1016/S0020-1693(97)06102-1

65. Johansson, L.; Ryan, O. B.; Rømming, C.; Tilset, M. Organometallics 1998, 17, 3957-3966. doi:10.1021/om9801498

66. Johansson, L.; Ryan, O. B.; Tilset, M. J. Am. Chem. Soc. 1999, 121, 1974-1975. doi:10.1021/ja984028a

67. Johansson, L.; Tilset, M.; Labinger, J. A.; Bercaw, J. E. J. Am. Chem. Soc. 2000, 122, 10846-10855. doi:10.1021/ja0017460

68. Procelewska, J.; Zahl, A.; van Eldik, R.; Zhong, H. A.; Labinger, J. A.; Bercaw, J. E. Inorg. Chem. 2002, 41, 2808-2810. doi:10.1021/ic0201710

69. Zhong, H. A.; Labinger, J. A.; Bercaw, J. E. J. Am. Chem. Soc. 2002, 124, 1378-1399. doi:10.1021/ja011189x

70. Heyduk, A. F.; Labinger, J. A.; Bercaw, J. E. J. Am. Chem. Soc. 2003, 125, 6366-6367. doi:10.1021/ja029099v

71. Owen, J. S.; Labinger, J. A.; Bercaw, J. E. J. Am. Chem. Soc. 2006, 128, 2005-2016. doi:10.1021/ja056387t 
72. Chen, G. S.; Labinger, J. A.; Bercaw, J. E. Proc. Natl. Acad. Sci. U. S. A. 2007, 104, 6915-6920. doi:10.1073/pnas.0610981104

73. Johansson, L.; Ryan, O. B.; Rømming, C.; Tilset, M. J. Am. Chem. Soc. 2001, 123, 6579-6590. doi:10.1021/ja010277e

74. Heyduk, A. F.; Driver, T. G.; Labinger, J. A.; Bercaw, J. E. J. Am. Chem. Soc. 2004, 126, 15034-15035. doi:10.1021/ja045078k

75. McKeown, B. A.; Foley, N. A.; Lee, J. P.; Gunnoe, T. B. Organometallics 2008, 27, 4031-4033. doi:10.1021/om8006008

76. McKeown, B. A.; Gonzalez, H. E.; Friedfeld, M. R.; Gunnoe, T. B.; Cundari, T. R.; Sabat, M. J. Am. Chem. Soc. 2011, 133, 19131-19152. doi:10.1021/ja206064v

77. Thomas, C. M.; Peters, J. C. Organometallics 2005, 24, 5858-5867. doi:10.1021/om050538j

78. Zhang, F.; Prokopchuk, E. M.; Broczkowski, M. E.; Jennings, M. C.; Puddepthatt, R. J. Organometallics 2006, 25, 1583-1591. doi:10.1021/om050982m

79. Karshtedt, D.; McBee, J. L.; Bell, A. T.; Tilley, T. D. Organometallics 2006, 25, 1801-1811. doi:10.1021/om0600902

80. Britovsek, G. J. P.; Taylor, R. A.; Sunley, G. J.; Law, D. J.; White, A. J. P. Organometallics 2006, 25, 2074-2079. doi:10.1021/om060036

81. Zhao, S.-B.; Wu, G.; Wang, S. Organometallics 2006, 25, 5979-5989. doi:10.1021/om0608861

82. Albrecht, M.; van Koten, G. Angew. Chem. 2001, 113, 3866-3898. doi:10.1002/1521-3773(20011015)113:20<3866::AID-ANGE3866>3.0. $\mathrm{CO} ; 2-\mathrm{Y}$

Angew. Chem., Int. Ed. 2001, 40, 3750-3781 doi:10.1002/1521-3773(20011015)40:20<3750::AID-ANIE3750>3.3.C $\mathrm{O} ; 2-\mathrm{Y}$

83. van der Boom, M. E.; Milstein, D. Chem. Rev. 2003, 103, 1759-1792. doi:10.1021/cr960118r

84. Hofmann, A.; Jaganyi, D.; Munro, O. Q.; Liehr, G.; van Eldik, R. Inorg. Chem. 2003, 42, 1688-1700. doi:10.1021/ic020605r

85. Grove, D. M.; van Koten, G.; Louwen, J. N.; Noltes, J. G.; Spek, A. L.; Ubbels, H. J. C. J. Am. Chem. Soc. 1982, 104, 6609-6616. doi:10.1021/ja00388a022

86. Terheijden, J.; van Koten, G.; Vinke, I. C.; Spek, A. L. J. Am. Chem. Soc. 1985, 107, 2891-2898. doi:10.1021/ja00296a010

87. Poverenov, E.; Efremenko, I.; Frenkel, A. I.; Ben-David, Y.; Shimon, L. J. W.; Leitus, G.; Konstantinovski, L.; Martin, J. M. L.; Milstein, D. Nature 2008, 455, 1093-1096. doi:10.1038/nature07356

88. Kimmich, B. F. M.; Bullock, R. M. Organometallics 2002, 21, 1504-1507. doi:10.1021/om0108651

89. Vuzman, D.; Poverenov, E.; Diskin-Posner, Y.; Leitus, G.; Shimon, L. J. W.; Milstein, D. Dalton Trans. 2007, 5692-5700. doi:10.1039/B711444C

90. Mitton, S. J.; McDonald, R.; Turculet, L. Organometallics 2009, 28 , 5122-5136. doi:10.1021/om9003863

91. Serra, D.; Cao, P.; Cabrera, J.; Padilla, R.; Rominger, F.; Limbach, M. Organometallics 2011, 30, 1885-1895. doi:10.1021/om101128f

92. Calderone, V.; Casini, A.; Mangani, S.; Messori, L.; Orioli, P. L. Angew. Chem. 2006, 118, 1289-1291. doi:10.1002/ange.200502599 Angew. Chem., Int. Ed. 2006, 45, 1267-1269 doi:10.1002/anie.200502599

93. Casini, A.; Mastrobuoni, G.; Temperini, C.; Gabbiani, C.; Francese, S.; Moneti, G.; Supuran, C. T.; Scozzafava, A.; Messori, L. Chem. Commun. 2007, 156-158. doi:10.1039/b611122j
94. Ortega-Carrasco, E.; Cossío, F. P.; Lledós, A.; Maréchal, J.-D. J. Inorg. Biochem. 2012, 117, 230-236. doi:10.1016/j.jinorgbio.2012.09.020

95. Wick, D. D.; Goldberg, K. I. J. Am. Chem. Soc. 1997, 119, 10235-10236. doi:10.1021/ja971952g

96. Reinartz, S.; White, P. S.; Brookhart, M.; Templeton, J. L. Organometallics 2000, 19, 3854-3866. doi:10.1021/om000440z

97. Reinartz, S.; White, P. S.; Brookhart, M.; Templeton, J. L. J. Am. Chem. Soc. 2001, 123, 6425-6426. doi:10.1021/ja0104047

98. Reinartz, S.; Baik, M.-H.; White, P. S.; Brookhart, M.; Templeton, J. L. Inorg. Chem. 2001, 40, 4726-4732. doi:10.1021/ic010099q

99. Fekl, U.; Goldberg, K. I. J. Am. Chem. Soc. 2002, 124, 6804-6805. doi:10.1021/ja0258677

100. Fekl, U.; Kaminsky, W.; Goldberg, K. I. J. Am. Chem. Soc. 2003, 125, 15286-15287. doi:10.1021/ja037781z

101. Kloek, S. M.; Goldberg, K. I. J. Am. Chem. Soc. 2007, 129, 3460-3461. doi:10.1021/ja0669629

102.Luedtke, A. T.; Goldberg, K. I. Inorg. Chem. 2007, 46, 8496-8498. doi:10.1021/ic701504z

103. Vedernikov, A. N.; Caulton, K. G. Angew. Chem. 2002, 114, 4276-4278. doi:10.1002/1521-3757(20021104)114:21<4276::AID-ANGE4276>3.0 $\mathrm{CO} ; 2-8$

Angew. Chem. Int. Ed. 2002, 41, 4102-4104. doi:10.1002/1521-3773(20021104)41:21<4102::AID-ANIE4102>3.0.C O;2-\#

104.Vedernikov, A. N.; Huffman, J. C.; Caulton, K. G. New J. Chem. 2003, 27, 665-667. doi:10.1039/b302055j

105.Jensen, M. P.; Wick, D. D.; Reinartz, S.; White, P. S.; Templeton, J. L.; Goldberg, K. I. J. Am. Chem. Soc. 2003, 125, 8614-8624. doi:10.1021/ja028477t

106. Lledós, A.; Ortuño, M. A.; Vidossich, P.; Ujaque, G.; Conejero, S. Dalton Trans. 2013. doi:10.1039/c3dt50761k

107.Romeo, R.; Fenech, L.; Scolaro, L. M.; Albinati, A.; Macchioni, A.; Zuccaccia, C. Inorg. Chem. 2001, 40, 3293-3302. doi:10.1021/ic0014080

108. Romeo, R.; Fenech, L.; Carnabuci, S.; Plutino, M. R.; Romeo, A. Inorg. Chem. 2002, 41, 2839-2847. doi:10.1021/ic011206j

109. Romeo, R.; Carnabuci, S.; Plutino, M. R.; Romeo, A.; Rizzato, S.; Albinati, A. Inorg. Chem. 2005, 44, 1248-1262. doi:10.1021/ic0485920

110. Romeo, R.; Carnabuci, S.; Fenech, L.; Plutino, M. R.; Albinati, A. Angew. Chem. 2006, 118, 4606-4610. doi:10.1002/ange.200600827 Angew. Chem., Int. Ed. 2006, 45, 4494-4498. doi:10.1002/anie.200600827

111.Romeo, R.; D’Amico, G.; Guido, E.; Albinati, A.; Rizzato, S. Inorg. Chem. 2007, 46, 10681-10692. doi:10.1021/ic701396j

112.Foley, P.; DiCosimo, R.; Whitesides, G. M. J. Am. Chem. Soc. 1980, 102, 6713-6725. doi:10.1021/ja00542a009

113. Romeo, R. Comments Inorg. Chem. 1990, 11, 21-57. doi:10.1080/02603599008035817

114. Omae, I. J. Organomet. Chem. 2011, 696, 1128-1145. doi:10.1016/j.jorganchem.2010.11.023

115. Albrecht, M. Chem. Rev. 2010, 110, 576-623. doi:10.1021/cr900279a 116. Thorn, D. L. Organometallics 1998, 17, 348-352. doi:10.1021/om970759s

117.Plutino, M. R.; Scolaro, L. M.; Albinati, A.; Romeo, R. J. Am. Chem. Soc. 2004, 126, 6470-6484. doi:10.1021/ja030486u

118. Romeo, R.; Plutino, M. R.; Romeo, A. Helv. Chim. Acta 2005, 88, 507-522. doi:10.1002/hlca.200590035 
119.Scott, J. D.; Puddephatt, R. J. Organometallics 1983, 2, 1643-1648. doi:10.1021/om50005a028

120. Marrone, A.; Re, N.; Romeo, R. Organometallics 2008, 27 , 2215-2222. doi:10.1021/om701070f

121.Fantasia, S.; Pasini, A.; Nolan, S. P. Dalton Trans. 2009, 8107-8110. doi:10.1039/b911164f

122.Butschke, B.; Schwarz, H. Chem. Sci. 2012, 3, 308-326. doi:10.1039/c1sc00651g

123.Skapski, A. C.; Sutcliffe, V. F.; Young, G. B. J. Chem. Soc., Chem. Commun. 1985, 609-611. doi:10.1039/C39850000609

124.Minghetti, G.; Stoccoro, S.; Cinellu, M. A.; Soro, B.; Zucca, A. Organometallics 2003, 22, 4770-4777. doi:10.1021/om0301583

125. Minghetti, G.; Stoccoro, S.; Cinellu, M. A.; Petretto, G. L.; Zucca, A. Organometallics 2008, 27, 3415-3421. doi:10.1021/om800027g

126.Zhao, S.-B.; Wang, R.-Y.; Wang, S. J. Am. Chem. Soc. 2007, 129, 3092-3093. doi:10.1021/ja0702770

127.Crosby, S. H.; Clarkson, G. J.; Rourke, J. P. Organometallics 2011, 30, 3603-3609. doi:10.1021/om200293e

128. Butschke, B.; Schlangen, M.; Schröder, D.; Schwarz, H. Chem.-Eur. J. 2008, 14, 11050-11060. doi:10.1002/chem.200801658

129. Butschke, B.; Tabrizi, S. G.; Schwarz, H. Chem.-Eur. J. 2010, 16, 3962-3969. doi:10.1002/chem.200902742

130.Butschke, B.; Schwarz, H. Chem.-Eur. J. 2012, 18, 14055-14062. doi:10.1002/chem.201201652

131.Butschke, B.; Schlangen, M.; Schröder, D.; Schwarz, H. Helv. Chim. Acta 2008, 91, 1902-1915. doi:10.1002/hlca.200890204

132.Shilov, A. E.; Shul'pin, G. B. Chem. Rev. 1997, 97, 2879-2932. doi:10.1021/cr9411886

133.Periana, R. A.; Taube, D. J.; Gamble, S.; Taube, H.; Satoh, T.; Fujii, H. Science 1998, 280, 560-564. doi:10.1126/science.280.5363.560

134.Labinger, J. A.; Bercaw, J. E. Nature 2002, 417, 507-514. doi:10.1038/417507a

135. Fekl, U.; Goldberg, K. I. Adv. Inorg. Chem. 2003, 54, 259-320. doi:10.1016/S0898-8838(03)54005-3

136. Lersch, M.; Tilset, M. Chem. Rev. 2005, 105, 2471-2526. doi:10.1021/cr030710y

137.Balcells, D.; Clot, E.; Eisenstein, O. Chem. Rev. 2010, 110, 749-823. doi:10.1021/cr900315k

138. Johansson, L.; Tilset, M. J. Am. Chem. Soc. 2001, 123, 739-740. doi:10.1021/ja002505v

139.Iron, M. A.; Lo, H. C.; Martin, J. M. L.; Keinan, E. J. Am. Chem. Soc. 2002, 124, 7041-7054. doi:10.1021/ja025667v

140.Liang, L.-C.; Lin, J.-M.; Lee, W.-Y. Chem. Commun. 2005, 2462-2464. doi:10.1039/b501520k

141. Moret, M.-E.; Chen, P. Organometallics 2007, 26, 1523-1530. doi:10.1021/om0610039

142.Butschke, B.; Schwarz, H. Organometallics 2011, 30, 1588-1598. doi:10.1021/om101138d

143. Rivada-Wheelaghan, O.; Ortuño, M. A.; Díez, J.; García-Garrido, S. E.; Maya, C.; Lledós, A.; Conejero, S. J. Am. Chem. Soc. 2012, 134, 15261-15264. doi:10.1021/ja307139p

144.Crosby, S. H.; Thomas, H. R.; Clarkson, G. J.; Rourke, J. P. Chem. Commun. 2012, 48, 5775-5777. doi:10.1039/c2cc31572f

145.Romeo, R.; Grassi, A.; Scolaro, L. M. Inorg. Chem. 1992, 31 , 4383-4390. doi:10.1021/ic00047a028

146.Rashidi, M.; Nabavizadeh, S. M.; Zare, A.; Jamali, S.; Puddephatt, R. J. Inorg. Chem. 2010, 49, 8435-8443. doi:10.1021/ic1010067

\section{License and Terms}

This is an Open Access article under the terms of the Creative Commons Attribution License

(http://creativecommons.org/licenses/by/2.0), which permits unrestricted use, distribution, and reproduction in any medium, provided the original work is properly cited.

The license is subject to the Beilstein Journal of Organic Chemistry terms and conditions:

(http://www.beilstein-journals.org/bjoc)

The definitive version of this article is the electronic one which can be found at:

doi:10.3762/bjoc. 9.153 